\title{
Synthesis of a Non-Heme Template for Attaching Four Peptides: an Approach to Artificial Iron(II)-containing Peroxidases
}

\author{
Marco van den Heuvel, Tieme A. van den Berg, Richard M. Kellogg, \\ Christin T. Choma, ${ }^{*}+$ and Ben L. Feringa*
}

Department of Organic and Molecular Inorganic Chemistry, University of Groningen, Nijenborgh 4, 9747 AG Groningen, The Netherlands

* Corresponding authors: B. L. Feringa; phone: +31-50-3634235; fax: +31-50-3634296;

B.L.Feringa@chem.rug.nl. C. T. Choma; phone: +1-518-276-2804; fax:+1-518-276-4887; chomac@rpi.edu.

† Current address: Department of Chemistry, Rensselaer Polytechnic Institute, Troy, NY, 12180-3590, USA.

\section{SUPPORTING INFORMATION}

Experimental Procedures .................................................................... S2

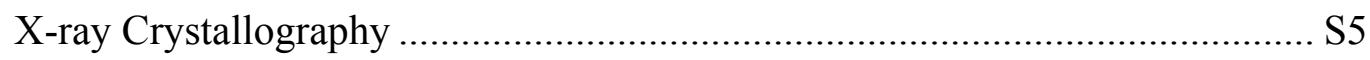

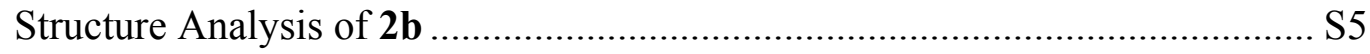

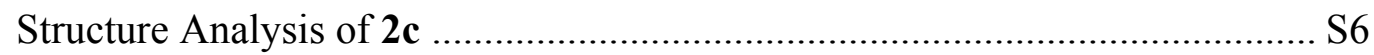

Crystallographic Data (Table) …................................................................. S7



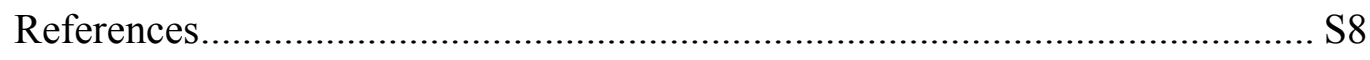

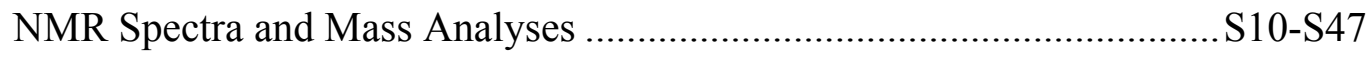


The experimental procedures and analytic data of compounds $5,6,10,12,14,16,18,20,22$, and 24 , as well as the crystallographic data for complexes $\mathbf{2 b}$ and $\mathbf{2 c}$, and the cyclic voltammetry measurements of 2b are presented. ${ }^{1} \mathrm{H}$ and ${ }^{13} \mathrm{C}$ NMR spectra for all prepared compounds are provided, with exception of 1d (only ${ }^{1} \mathrm{H}$ NMR and mass analysis) and $\mathbf{1 e}$ (only mass analysis). The COSY spectrum for $\mathbf{3 8}$ is also included.

\section{Experimental Procedures}

THF and diethyl ether were freshly distilled from sodium/benzophenone under a nitrogen atmosphere. $\mathrm{CH}_{2} \mathrm{Cl}_{2}$, diethyl ether, and hexane were distilled from $\mathrm{P}_{2} \mathrm{O}_{5}$ and stored over molecular sieves (4A). DMF


distilled from $\mathrm{KOH}$ pellets and stored over molecular sieves $(4 \AA)$ under nitrogen. Sodium hydride $(60 \%$ in mineral oil) was washed three times with dry hexane prior to use. Butyl lithium ( $n$-BuLi) was used as 1.6 M solution in hexane. Column chromatography was performed on aluminum oxide 90 (neutral, act. III) or silica gel 60 (230-400 mesh). ${ }^{1} \mathrm{H}(200$ or $300 \mathrm{MHz})$ and ${ }^{13} \mathrm{C}(50.3$ or $75.5 \mathrm{MHz}) \mathrm{NMR}$ spectra were referenced to the residual proton resonance. Chemical shifts $(\delta)$ are denoted in ppm and coupling constants $(J)$ are given in hertz. Melting points are uncorrected. The mass analysis was performed by chemical ionization (MS CI), electrospray ionization mass analysis (ESI-MS), or exact mass determination (HRMS). Matrix-assisted laser desorption ionization time-of-flight mass spectrometry (MALDI) analyses were carried out using a $\mathrm{N}_{2}$ UV-laser $\left(\lambda=337 \mathrm{~nm}, 4 \mathrm{~ns}\right.$ pulse, $\left.\mathrm{E}_{\text {pulse }}=180 \mathrm{~mJ}\right)$. Samples were prepared in an $\alpha$-cyano matrix (1:1, dissolved in MeCN and 0.1\% TFA (7:3), $20 \mathrm{mg} / \mathrm{mL})$. Reversed-phase high-pressure liquid chromatography (RP-HPLC) was conducted using a photodiode array detector (set at TIC and $450 \mathrm{~nm}$ ) and a quadrupole mass spectrometer. The C18 analytical column $(150 \times 2.1 \mathrm{~mm}, 5 \mu)$ was run at a flow of $0.3 \mathrm{~mL} / \mathrm{min}$, and the preperative column $(250 \times 4.5 \mathrm{~mm}, 5 \mu)$ at a flow of $1.5 \mathrm{~mL} / \mathrm{min}$. The samples were purified by gradient elution of mixtures of solvent A $(10 \%$ acetonitrile in water with $0.1 \%$ TFA) and solvent B (95\% acetonitrile in water with $0.1 \%$ TFA). The crude products were dissolved in mixtures of solvents A and B. The homogeneous fractions were collected, lyophilized, and analysed by ESI-MS or MALDI.

2-Bromo-5-pyridinecarbaldehyde (5). $n$-BuLi (62 mL, $99 \mathrm{mmol}, 1.05$ equiv) was added to a suspension of $4(22.7 \mathrm{~g}, 94.1 \mathrm{mmol})$ in dry diethyl ether $(1 \mathrm{~L})$ at $-80^{\circ} \mathrm{C}$ under a nitrogen atmosphere. Dry DMF $(8.0$ $\mathrm{mL}, 103 \mathrm{mmol}, 1.1$ equiv) was added after stirring the suspension at $-80^{\circ} \mathrm{C}$ for $1 \mathrm{~h}$. After an additional hour at $-80^{\circ} \mathrm{C}$ the reaction mixture was allowed to warm to room temperature. Dilute $\mathrm{HCl}(1 \mathrm{M}, 200$ $\mathrm{mL}$ ) was added and the mixture was stirred for $15 \mathrm{~min}$. After separation the aqueous layer was extracted 
with diethyl ether. The organic layer was washed with water, brine, and dried over $\mathrm{Na}_{2} \mathrm{SO}_{4}$. Concentration by rotary evaporation yielded 5 as a light brown solid $(16.8 \mathrm{~g}, 96 \%) . R_{f}=0.49\left(\mathrm{SiO}_{2}\right.$, hexane/ethyl acetate $=3: 1) . \mathrm{mp} 100.7-102.2^{\circ} \mathrm{C}\left(\right.$ lit. $\left.^{1} 100^{\circ} \mathrm{C}\right) .{ }^{1} \mathrm{H}$ NMR $\left(\mathrm{CDCl}_{3}, 300 \mathrm{MHz}\right) \delta 7.67(\mathrm{~d}, J=$ $8.4 \mathrm{~Hz}, 1 \mathrm{H}), 8.01(\mathrm{dd}, J=8.4,2.2 \mathrm{~Hz}, 1 \mathrm{H}), 8.82(\mathrm{~d}, J=2.2 \mathrm{~Hz}, 1 \mathrm{H}), 10.08(\mathrm{~s}, 1 \mathrm{H}) .{ }^{13} \mathrm{C} \mathrm{NMR}\left(\mathrm{CDCl}_{3}\right.$, 75.5 MHz) $\delta 129.0,130.5,137.5,148.2,152.4$, 189.4. HRMS calcd for $\mathrm{C}_{6} \mathrm{H}_{4} \mathrm{NOBr} 184.948$, found 184.949 .

(6-Bromo-3-pyridinyl)methanol (6). $\mathrm{NaBH}_{4}(2.28 \mathrm{~g}, 60.3 \mathrm{mmol}, 0.5$ equiv) was added to a solution of $5(22.4 \mathrm{~g}, 120 \mathrm{mmol})$ in methanol $(400 \mathrm{~mL})$ at $0^{\circ} \mathrm{C}$. After 15 min concentrated $\mathrm{HCl}$ was added until $\mathrm{pH}$ 2 was reached. Then saturated aqueous $\mathrm{Na}_{2} \mathrm{CO}_{3}$ solution was added until $\mathrm{pH} 10$ was reached. The solution was concentrated and extracted with ethyl acetate. The organic layer was washed with brine and dried over $\mathrm{Na}_{2} \mathrm{SO}_{4}$. When the solvent was evaporated, the product was obtained as a yellow/brown oil that solidified upon standing $(21.8 \mathrm{~g}, 96 \%) . R_{f}=0.12\left(\mathrm{SiO}_{2}\right.$, hexane/ethyl acetate=3:1). mp 42.5$45.0^{\circ} \mathrm{C}$ (lit. $\left.{ }^{2} 49-51^{\circ} \mathrm{C}\right) .{ }^{1} \mathrm{H}$ NMR $\left(\mathrm{CDCl}_{3}, 300 \mathrm{MHz}\right) \delta 2.82$ (br.s, $\left.1 \mathrm{H}\right), 4.68(\mathrm{~s}, 2 \mathrm{H}), 7.45(\mathrm{~d}, J=8.1 \mathrm{~Hz}$, $1 \mathrm{H}), 7.57(\mathrm{dd}, J=8.1,2.2 \mathrm{~Hz}, 1 \mathrm{H}), 8.29(\mathrm{~s}, 1 \mathrm{H}) .{ }^{13} \mathrm{C} \mathrm{NMR}\left(\mathrm{CDCl}_{3}, 75.5 \mathrm{MHz}\right) \delta 61.6,128.0,135.8$, 137.5, 140.8, 148.5. HRMS calcd for $\mathrm{C}_{6} \mathrm{H}_{6} \mathrm{BrNO}$ 186.963, found 186.964.

2-Bromo-5-(3-\{[tert-butyl(dimethyl)silyl]oxy\}propyl)pyridine (10) was prepared as described for 7. Starting from 9 (12.7 g, $58.7 \mathrm{mmol})$ the product was obtained as a brown oil (18.6 g, 96\%). Purification by flash column chromatography over silica using a gradient of hexane/diethyl ether (19:1 to 9:1) yielded 10 as a light brown oil $(15.7 \mathrm{~g}, 81 \%) . R_{f}=0.43\left(\mathrm{Al}_{2} \mathrm{O}_{3}\right.$, hexane/diethyl ether=19:1). ${ }^{1} \mathrm{H}$ NMR $\left(\mathrm{CDCl}_{3}, 300 \mathrm{MHz}\right) \delta 0.03(\mathrm{~s}, 6 \mathrm{H}), 0.89(\mathrm{~s}, 9 \mathrm{H}), 1.79(\mathrm{~m}, 2 \mathrm{H}), 2.64(\mathrm{t}, J=7.9 \mathrm{~Hz}, 2 \mathrm{H}), 3.60(\mathrm{t}, J=6.0$ $\mathrm{Hz}, 2 \mathrm{H}), 7.36(\mathrm{~s}, 1 \mathrm{H}), 7.37(\mathrm{~s}, 1 \mathrm{H}), 8.20(\mathrm{~s}, 1 \mathrm{H}) .{ }^{13} \mathrm{C} \mathrm{NMR}\left(\mathrm{CDCl}_{3}, 75.5 \mathrm{MHz}\right) \delta-5.4,18.2,25.8,28.3$, 33.6, 61.4, 127.5, 136.7, 138.6, 139.2, 150.2. MS CI $[\mathrm{M}+\mathrm{H}]^{+}$calcd for $\mathrm{C}_{14} \mathrm{H}_{25} \mathrm{BrNOSi} m / z 330.1$, found 330.2 .

5-(3-\{[tert-Butyl(dimethyl)silyl]oxy\}propyl)-2-pyridinecarbaldehyde (12) was prepared as described for 11 (Method A), starting from 10 (9.90 g, $30.0 \mathrm{mmol})$, as a light brown oil (6.03 g, 72\%) after purification by flash column chromatography over silica using a gradient of hexane/diethyl ether (9:1 to 3:1). $R_{f}=0.25\left(\mathrm{SiO}_{2}\right.$, hexane/diethyl ether=9:1). ${ }^{1} \mathrm{H} \mathrm{NMR}\left(\mathrm{CDCl}_{3}, 300 \mathrm{MHz}\right) \delta 0.04(\mathrm{~s}, 6 \mathrm{H}), 0.89(\mathrm{~s}$, 9H), $1.85(\mathrm{~m}, 2 \mathrm{H}), 2.79$ (t, $J=7.9 \mathrm{~Hz}, 2 \mathrm{H}), 3.62(\mathrm{t}, J=6.0 \mathrm{~Hz}, 2 \mathrm{H}), 7.68(\mathrm{dd}, J=7.7,1.5 \mathrm{~Hz}, 1 \mathrm{H}), 7.88$ $(\mathrm{d}, J=7.7 \mathrm{~Hz}, 1 \mathrm{H}), 8.61(\mathrm{~d}, J=1.5 \mathrm{~Hz}, 1 \mathrm{H}), 10.04(\mathrm{~s}, 1 \mathrm{H}) .{ }^{13} \mathrm{C} \mathrm{NMR}\left(\mathrm{CDCl}_{3}, 75.5 \mathrm{MHz}\right) \delta-5.5,18.2$, 25.8, 29.4, 33.5, 61.5, 121.4, 136.7, 142.8, 150.5, 150.9, 193.0. MS CI $[\mathrm{M}+\mathrm{H}]^{+}$calcd for $\mathrm{C}_{15} \mathrm{H}_{26} \mathrm{NO}_{2} \mathrm{Si}$ $m / z 280.2$, found 280.3 .

[5-(3-\{[tert-Butyl(dimethyl)silyl]oxy\}propyl)-2-pyridinyl]methanol (14) was prepared as described for 13. Starting from $12(3.91 \mathrm{~g}, 14.0 \mathrm{mmol})$ the product was obtained as a light brown oil (3.91 $\mathrm{g}$, 
99\%). $R_{f}=0.20\left(\mathrm{SiO}_{2}\right.$, hexane/ethyl acetate=3:1). ${ }^{1} \mathrm{H} \mathrm{NMR}\left(\mathrm{CDCl}_{3}, 300 \mathrm{MHz}\right) \delta 0.04(\mathrm{~s}, 6 \mathrm{H}), 0.89(\mathrm{~s}$, 9H), 1.80 (m, 2H), 2.68 (t, $J=7.9 \mathrm{~Hz}, 2 \mathrm{H}), 3.47$ (br.s, 1H), 3.61 (t, $J=6.0 \mathrm{~Hz}, 2 \mathrm{H}), 4.71$ (s, 2H), 7.15 $(\mathrm{d}, J=8.1 \mathrm{~Hz}, 1 \mathrm{H}), 7.50(\mathrm{dd}, J=8.1,1.8 \mathrm{~Hz}, 1 \mathrm{H}), 8.37(\mathrm{~s}, 1 \mathrm{H}) .{ }^{13} \mathrm{C} \mathrm{NMR}\left(\mathrm{CDCl}_{3}, 75.5 \mathrm{MHz}\right) \delta-5.4$, $18.2,25.9,28.8,34.0,61.8,64.1,120.3,136.1,136.8,148.5,156.8$. MS CI $[\mathrm{M}+\mathrm{H}]^{+}$calcd for $\mathrm{C}_{15} \mathrm{H}_{28} \mathrm{NO}_{2} \mathrm{Si} m / z$ 282.2, found 282.3.

5-(3-\{[tert-Butyl(dimethyl)silyl]oxy\}propyl)-2-(chloromethyl)pyridine (16) was prepared as described for 15. Starting from $14(3.91 \mathrm{~g}, 14.0 \mathrm{mmol})$ flash column chromatography over alumina using a gradient of hexane/diethyl ether (9:1 to 5:1) afforded 16 as a light brown oil $(3.14 \mathrm{~g}, 75 \%)$. $R_{f}=$ $0.31\left(\mathrm{SiO}_{2}\right.$, hexane/diethyl ether=9:1). ${ }^{1} \mathrm{H} \mathrm{NMR}\left(\mathrm{CDCl}_{3}, 300 \mathrm{MHz}\right) \delta 0.04(\mathrm{~s}, 6 \mathrm{H}), 0.89(\mathrm{~s}, 9 \mathrm{H}), 1.81$ (m, 2H), 2.69 (t, $J=7.9 \mathrm{~Hz}, 2 \mathrm{H}), 3.62$ (t, $J=6.0 \mathrm{~Hz}, 2 \mathrm{H}), 4.64(\mathrm{~s}, 2 \mathrm{H}), 7.36$ (d, $J=7.9 \mathrm{~Hz}, 1 \mathrm{H}), 7.53$ $(\mathrm{dd}, J=7.9,2.0 \mathrm{~Hz}, 1 \mathrm{H}), 8.41(\mathrm{~d}, J=2.0 \mathrm{~Hz}, 1 \mathrm{H}) .{ }^{13} \mathrm{C} \mathrm{NMR}\left(\mathrm{CDCl}_{3}, 75.5 \mathrm{MHz}\right) \delta-5.4,18.2,25.8$, 28.8, 33.8, 46.6, 61.7, 122.3, 136.8, 136.9, 149.6, 153.9. MS CI $[\mathrm{M}+\mathrm{H}]^{+}$calcd for $\mathrm{C}_{15} \mathrm{H}_{27} \mathrm{ClNOSi} \mathrm{m} / z$ 300.2 , found 300.5 .

Bis[5-(3-\{[tert-butyl(dimethyl)silyl]oxy\}propyl)-2-pyridinyl]methanone (18) was prepared as described for 17. Starting from $10(5.11 \mathrm{~g}, 15.4 \mathrm{mmol})$ and $\mathbf{1 2}(4.47 \mathrm{~g}, 16.0 \mathrm{mmol})$ ketone 18 was obtained as a light brown solid (6.49 g, 80\%) after flash column chromatography over silica using hexane/ethyl acetate (6:1) as the eluent. $R_{f}=0.42\left(\mathrm{SiO}_{2}\right.$, hexane/ethyl acetate=3:1). ${ }^{1} \mathrm{H} \mathrm{NMR}\left(\mathrm{CDCl}_{3}\right.$, $300 \mathrm{MHz}) \delta 0.05(\mathrm{~s}, 12 \mathrm{H}), 0.90(\mathrm{~s}, 18 \mathrm{H}), 1.85(\mathrm{~m}, 4 \mathrm{H}), 2.78(\mathrm{t}, J=7.9 \mathrm{~Hz}, 4 \mathrm{H}), 3.65(\mathrm{t}, J=6.0 \mathrm{~Hz}, 4 \mathrm{H})$, $7.68(\mathrm{dd}, J=8.1,1.5 \mathrm{~Hz}, 2 \mathrm{H}), 8.02(\mathrm{~d}, J=8.1 \mathrm{~Hz}, 2 \mathrm{H}), 8.58(\mathrm{~d}, J=1.5 \mathrm{~Hz}, 2 \mathrm{H}) .{ }^{13} \mathrm{C} \mathrm{NMR}\left(\mathrm{CDCl}_{3}, 50.3\right.$ MHz) $\delta-5.4,18.2,25.8,29.2,33.6,61.7,125.1,136.4,140.9,149.4,152.2$, 192.5. HRMS calcd for $\mathrm{C}_{29} \mathrm{H}_{48} \mathrm{~N}_{2} \mathrm{O}_{3} \mathrm{Si}_{2}$ 528.320, found 528.321.

Bis[5-(3-\{[tert-butyl(dimethyl)silyl]oxy\}propyl)-2-pyridinyl]methanone oxime (20) was prepared as described for 19. Starting from $21(1.12 \mathrm{~g}, 2.06 \mathrm{mmol})$ the product was obtained as a brown oil that solidified on standing (1.06 g, 93\%). The crude product was recrystallized from ethanol/water to yield analytically pure 20 as white plates. mp $110.1-110.4^{\circ} \mathrm{C} .{ }^{1} \mathrm{H} \mathrm{NMR}\left(\mathrm{CDCl}_{3}, 300 \mathrm{MHz}\right) \delta 0.05(\mathrm{~s}, 12 \mathrm{H})$, $0.90(\mathrm{~s}, 18 \mathrm{H}), 1.85(\mathrm{~m}, 4 \mathrm{H}), 2.76(\mathrm{~m}, 4 \mathrm{H}), 3.64(\mathrm{~m}, 4 \mathrm{H}), 7.57(\mathrm{~d}, J=8.1 \mathrm{~Hz}, 1 \mathrm{H}), 7.62(\mathrm{dd}, J=8.1,2.0$ $\mathrm{Hz}, 1 \mathrm{H}), 7.67(\mathrm{dd}, J=8.1,2.0 \mathrm{~Hz}, 1 \mathrm{H}), 7.74(\mathrm{~d}, J=8.1 \mathrm{~Hz}, 1 \mathrm{H}), 8.44$ (d, $J=2.0 \mathrm{~Hz}, 1 \mathrm{H}), 8.47(\mathrm{~d}, J=$ $2.0 \mathrm{~Hz}, 1 \mathrm{H}) .{ }^{13} \mathrm{C} \mathrm{NMR}\left(\mathrm{CDCl}_{3}, 50.3 \mathrm{MHz}\right) \delta-5.3,18.2,25.9,29.0,29.2,33.7,33.9,61.5,61.8,123.9$, 124.8, 137.1, 137.5, 137.6, 139.4, 145.7, 148.6, 150.1, 152.2. HRMS calcd for $\mathrm{C}_{29} \mathrm{H}_{49} \mathrm{~N}_{3} \mathrm{O}_{3} \mathrm{Si}_{2} 543.331$, found 543.333. Anal. calcd for $\mathrm{C}_{29} \mathrm{H}_{49} \mathrm{~N}_{3} \mathrm{O}_{3} \mathrm{Si}_{2}$ : C 64.04; $\mathrm{H}$ 9.08; N 7.73. Found: C 63.97; H 9.03; N 7.70 .

Bis[5-(3-\{[tert-butyl(dimethyl)silyl]oxy\}propyl)-2-pyridinyl]methylamine (22) was prepared as described for 21. Starting from 20 (1.42 g, $2.61 \mathrm{mmol})$ amine 22 was obtained as a green/brown viscous 
oil (1.34 g, 97\%). ${ }^{1} \mathrm{H}$ NMR $\left(\mathrm{CDCl}_{3}, 300 \mathrm{MHz}\right) \delta 0.02(\mathrm{~s}, 12 \mathrm{H}), 0.87$ (s, 18H), 1.77 (m, 4H), 2.73 (br.s, 2H), $2.63(\mathrm{t}, J=7.7 \mathrm{~Hz}, 4 \mathrm{H}), 3.60(\mathrm{t}, J=6.2 \mathrm{~Hz}, 4 \mathrm{H}), 5.26(\mathrm{~s}, 1 \mathrm{H}), 7.26(\mathrm{~d}, J=7.9 \mathrm{~Hz}, 2 \mathrm{H}), 7.43(\mathrm{dd}, J$ $=7.9,2.0 \mathrm{~Hz}, 2 \mathrm{H}), 8.38(\mathrm{~d}, J=2.0 \mathrm{~Hz}, 2 \mathrm{H}) .{ }^{13} \mathrm{C} \mathrm{NMR}\left(\mathrm{CDCl}_{3}, 50.3 \mathrm{MHz}\right) \delta-5.5,18.0,25.7,28.6$, 33.8, 61.4, 61.6, 121.1, 135.5, 136.5, 149.0, 160.0. HRMS calcd for $\mathrm{C}_{29} \mathrm{H}_{51} \mathrm{~N}_{3} \mathrm{O}_{2} \mathrm{Si}_{2}$ 529.352, found 529.350 .

\section{$N$-\{Bis[5-(3-\{[tert-butyl(dimethyl)silyl]oxy\}propyl)-2-pyridinyl]methyl $\}-N, N$-bis $\{[5-(3-\{[$ tert-}

butyl(dimethyl)silyl]oxy\}propyl)-2-pyridinyl]methyl\}amine (24) was prepared as described for 23. Starting from $22(0.58 \mathrm{~g}, 1.1 \mathrm{mmol})$ and $16(0.98 \mathrm{~g}, 3.3 \mathrm{mmol}, 3$ equiv) the product was obtained as a brown viscous oil $(0.55 \mathrm{~g}, 48 \%)$. ${ }^{1} \mathrm{H} \mathrm{NMR}\left(\mathrm{CDCl}_{3}, 300 \mathrm{MHz}\right) \delta 0.02(\mathrm{~s}, 24 \mathrm{H}), 0.87(\mathrm{~s}, 36 \mathrm{H}), 1.77$ (m, $8 \mathrm{H}), 2.61(\mathrm{~m}, 8 \mathrm{H}), 3.60(\mathrm{~m}, 8 \mathrm{H}), 3.87(\mathrm{~s}, 4 \mathrm{H}), 5.24(\mathrm{~s}, 1 \mathrm{H}), 7.41(\mathrm{dd}, J=7.9,2.0 \mathrm{~Hz}, 2 \mathrm{H}), 7.46(\mathrm{dd}, J=$ $7.9,2.0 \mathrm{~Hz}, 2 \mathrm{H}), 7.51(\mathrm{~d}, J=7.9 \mathrm{~Hz}, 2 \mathrm{H}), 7.59$ (d, $J=7.9 \mathrm{~Hz}, 2 \mathrm{H}), 8.30$ (d, $J=2.0 \mathrm{~Hz}, 2 \mathrm{H}), 8.37$ (d, $J=$ $2.0 \mathrm{~Hz}, 2 \mathrm{H}) .{ }^{13} \mathrm{C} \mathrm{NMR}\left(\mathrm{CDCl}_{3}, 75.5 \mathrm{MHz}\right) \delta-5.5,18.0,25.7,28.6,28.7,33.7,33.9,56.7,61.7,61.8$, $71.2,122.3,123.3,135.0,135.2,135.9,136.0,148.8,149.1,157.2,157.5$. ESI-MS $[\mathrm{M}+\mathrm{H}]^{+}$calcd for $\mathrm{C}_{59} \mathrm{H}_{102} \mathrm{~N}_{5} \mathrm{O}_{4} \mathrm{Si}_{4} \mathrm{~m} / z$ 1056.7, found 1056.9 .

\section{X-RAy Crystallography ${ }^{3}$}

The selected crystal was mounted on a glass fibre and aligned on a Bruker ${ }^{4}$ SMART APEX CCD diffractometer (Platform with full three-circle goniometer) equipped with a $4 \mathrm{~K} C C D$ detector and a Bruker KRYOFLEX low-temperature device. Intensity measurements were performed using graphite monochromatic Mo- $\mathrm{K}_{\bar{\alpha}}^{-}$radiation from a sealed ceramic diffraction tube $(50 \mathrm{kV} / 40 \mathrm{~mA})$. All calculations for refinement and graphics were performed on a Pentium III (Debian-Linux) computer at the University of Groningen with the program packages $S H E L X L^{5}$ (least-square refinements), a locally modified version of the program PLUTO $^{6}$ (preparation of illustrations) and the PLATON ${ }^{7}$ package (checking the final results for missed symmetry with the MISSYM option, solvent accessible voids with the $S O L V$ option, and calculation of geometric data).

\section{Structure Analysis of 2B.}

Crystallization from acetonitrile/ethyl acetate initially afforded $\mathbf{2 b}$ as red square platelets, with a monoclinic unit cell with a $\mathrm{P} 21 / \mathrm{n}$ space group, as well as a disordered and fractional occupation with the solvent molecules. Recrystallization furnished red octahedral-shaped crystals. Dimensions of the crystal used for analysis: $0.40 \times 0.32 \times 0.22 \mathrm{~mm}$.

The final unit cell was elucidated from the $x y z$ centroids of 7444 reflections after refinement and integration using the programs SMART and SAINT. In total 1800 frames were collected with an 
exposure time of $10 \mathrm{~s}$ per frame. Intensity data was corrected for Lorentz and polarization effects, as well as for decay and absorption: a semi-empirical absorption correction was applied, based on the intensities of symmetry-related reflections measured at different angular settings (SADABS), ${ }^{9}$ and reduced to $F_{o}{ }^{2}$. The program suite SHELXTL was used for space group determination $(X P R E P){ }^{5}$ The structure was solved by automated Patterson methods using the program $D I R D I F .{ }^{10}$ The positional and (an)isotropic displacement parameters for the non-hydrogen atoms were refined on $F^{2}$ using full-matrix least-squares procedures.

The asymmetric unit cell contains eleven moieties: two iron complexes (cations) and four perchlorate anions, one ethyl acetate and four acetonitrile solvent molecules with no atom setting at a special position. The triclinic unit cell contains twenty-two discrete units separated by normal van der Waals distances.

\section{Structure Analysis of 2C.}

Red coloured triangular/block-shaped crystals were obtained after a troublesome crystallization from acetonitrile by slow diffusion of ethyl acetate. Although many of the crystals were joined together, which hampered the X-ray structure determination, one crystal was suitable for analysis $(0.10 \times 0.10 \mathrm{x}$ $0.10 \mathrm{~mm})$.

The final unit cell was obtained from the $x y z$ centroids of 6038 reflections after refinement and integration using the programs SMART and SAINT. A total of 1800 frames were collected with an exposure time of $30 \mathrm{~s}$ per frame. Intensity data was corrected for Lorentz and polarization effects, scale variation, and for decay and absorption. A multi-scan absorption correction was applied, based on the intensities of symmetry-related reflections measured at different angular settings $(S A D A B S){ }^{9}$ and reduced to $F_{o}{ }^{2}$. The program suite SHELXTL was used for space group determination $(X P R E P) .^{5}$ The $E$-statistics of the triclinic unit cell were indicative of a centrosymmetric space group. The structure was solved by direct methods using SIR-97. ${ }^{11}$ The positional and anisotropic displacement parameters for the non-hydrogen atoms were refined. Refinement was complicated by a disorder problem: from the solution it was clear that one of the two perchlorate anions was highly disordered. The electron density of the atoms appeared to be diffuse, indicating transformational disorder. A disorder model with bond restraints and two different orientations were also introduced into the subsequent refinement. The siteoccupation factor of the major fraction of the disordered perchlorate anions was refined to a value of $0.519(5)$. 


\begin{tabular}{|c|c|c|c|}
\hline & $\mathbf{2 \mathbf { a } ^ { 8 }}$ & $2 b$ & $2 c$ \\
\hline Emp. formula & $\mathrm{C}_{26} \mathrm{H}_{28} \mathrm{Cl}_{2} \mathrm{FeN}_{6} \mathrm{O}_{9}$ & $\mathrm{C}_{62} \mathrm{H}_{60} \mathrm{Br}_{8} \mathrm{Cl}_{4} \mathrm{FeN}_{16} \mathrm{O}_{18}$ & $\mathrm{C}_{35} \mathrm{H}_{43} \mathrm{Cl}_{2} \mathrm{FeN}_{7} \mathrm{O}_{12}$ \\
\hline $\mathrm{MW}\left(\mathrm{g} \mathrm{mol}^{-1}\right)$ & 695.30 & 2209.96 & 880.52 \\
\hline Crystal system & monoclinic & triclinic & triclinic \\
\hline Space group & $P 2_{1} / n$ & $P \overline{1}$ & $P \overline{1}$ \\
\hline $\mathrm{T}(\mathrm{K})$ & 130 & $90(2)$ & $100(1)$ \\
\hline$a(\AA)$ & $12.191(1)$ & $16.8760(8)$ & $10.2381(6)$ \\
\hline$b(\AA)$ & $18.500(1)$ & $16.9697(8)$ & $13.1842(7)$ \\
\hline$c(\AA)$ & $13.015(1)$ & $17.1403(8)$ & $16.4591(9)$ \\
\hline$\alpha(\mathrm{deg})$ & & $64.758(1)$ & $67.046(1)$ \\
\hline$\beta(\operatorname{deg})$ & $95.928(8)$ & $63.885(1)$ & $77.949(1)$ \\
\hline$\gamma(\mathrm{deg})$ & & $77.286(1)$ & $75.701(1)$ \\
\hline$V\left(\AA^{3}\right)$ & 2919.6(4) & $3983.5(3)$ & $1966.57(19)$ \\
\hline$Z$ & 4 & 2 & 2 \\
\hline$\rho_{\text {calc }}\left(\mathrm{g} \mathrm{cm}^{-3}\right)$ & 1.582 & 1.842 & 1.487 \\
\hline$\mu\left(\mathrm{cm}^{-1}\right)$ & 7.6 & 45.86 & 5.9 \\
\hline$\lambda(\AA)$ & 0.71073 & 0.71073 & 0.71073 \\
\hline$G o o F^{a}$ & & 1.030 & 1.028 \\
\hline$R(F)^{b}$ & 0.046 & 0.0423 & 0.0584 \\
\hline$w R\left(F^{2}\right)^{c}$ & 0.049 & 0.1105 & 0.1485 \\
\hline
\end{tabular}

${ }^{a} \mathrm{GooF}=\left[\sum\left[w\left(F_{\mathrm{o}}^{2}-F_{c}^{2}\right)^{2}\right] /(n-p)\right]^{1 / 2}$ (where $n=$ number of reflections and $p=$ number of parameters refined). ${ }^{b} R(F)=\sum\left(|| F_{o}|-| F_{c} \mid\right) / \sum\left|F_{o}\right| \cdot{ }^{c} w R\left(F^{2}\right)=\left[\sum\left[\mathrm{w}\left(F_{o}{ }^{2}-F_{c}{ }^{2}\right)^{2}\right] / \sum\left[w\left(\mathrm{~F}_{o}{ }^{2}\right)^{2}\right]\right]^{1 / 2}$.

The asymmetric unit consists of four moieties: a cationic iron complex, two perchlorate anions, one of which is highly disordered, and one acetonitrile solvent molecule. Reduced cell calculations did not indicate any higher metric lattice symmetry and examination of the final atomic co-ordinates of the structure did not yield any additional metric symmetry elements.

\section{CyClic VOLTAMMETRY OF 2B}

The cyclic voltammetry measurements were performed by Dr. Scott Killeen at Unilever Research, Vlaardingen, The Netherlands, on a three-electrode electrochemical cell interfaced to a potentiostat. The electrodes used (Working: $5 \mathrm{~mm}$ diameter glassy carbon, Counter: Pt wire, Reference: Ag/AgCl (3 M $\mathrm{KCl})$ ) were freshly cleaned by standard techniques prior to each measurement. The supporting 
electrolyte was $0.1 \mathrm{M}$ tetrabutylammonium perchlorate (puriss) in acetonitrile (analytical grade). The sample for analysis was prepared by dissolving $\mathbf{2 b}(3 \mathrm{mg})$ in the electrolyte $(10 \mathrm{~mL})$. All measurements were carried out at $22^{\circ} \mathrm{C}$ and degassed with argon prior to measurement. For CV experiments the scan rate was $100 \mathrm{mV} \mathrm{s}^{-1}$ with an increment of $5 \mathrm{mV}$. The differential pulse voltammetry experiments were conducted at a scan rate of $10 \mathrm{mVs}^{-1}$ with an increment of $2 \mathrm{mV}$.

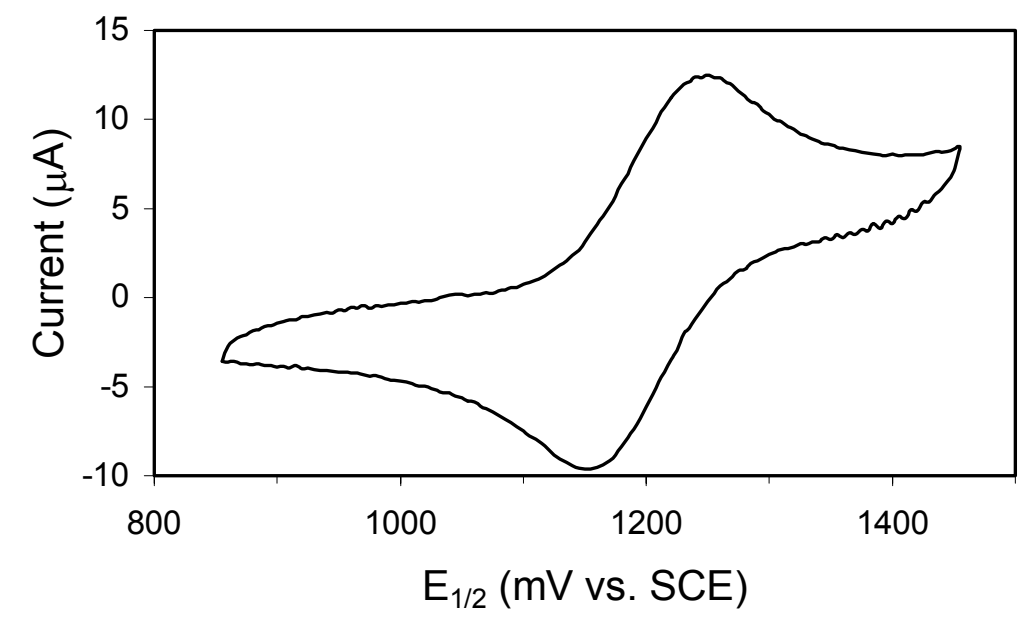

FIGURE S1. Cyclic voltammogram of $\mathbf{2} \mathbf{b}$ in acetonitrile at $22^{\circ} \mathrm{C}\left(\right.$ scan rate $\left.100 \mathrm{mVs}^{-1}\right)$.

\section{REFERENCES}

1. Windscheif, P.-M.; Vögtle, F. Synthesis 1994, 87-92.

2. Ellingboe, J. W.; Antane, M.; Nguyen, T. T.; Collini, M. D.; Antane, S.; Bender, R.; Hartupee, D.; White, V.; McCallum, J.; Park, C. H.; Russo, A.; Osler, M. B.; Wojdan, A.; Dinish, J.; Ho, D. M.; Bagli, J. F. J. Med. Chem. 1994, 37, 542-550.

3. Data collection, structure analysis and refinement was carried out by A. Meetsma, Crystal Structure Center, Chemical Physics, Materials Science Center, University of Groningen: The Netherlands.

4. SMART, SAINT, SADABS, XPREP and SHELXTL/NT, Smart Apex Software Reference Manuals, Bruker AXS, Inc.: Madison, Wisconsin, USA, 2000.

5. Sheldrick, G. M., SHELXL-97, Program for the Refinement of Crystal Structures, University of Göttingen: Germany, 1997.

6. Meetsma, A., PLUTO. Molecular Graphics Program, University of Groningen: The Netherlands, 2001. 
7. Spek, A. L., PLATON. Program for the Automated Analysis of Molecular Geometry (A Multipurpose Crystallographic Tool), University of Utrecht: The Netherlands, February 2002.

8. Lubben, M.; Meetsma, A.; Wilkinson, E. C.; Que, L., Jr.; Feringa, B. L. Angew. Chem. Int. Ed. Engl. 1995, 34, 1512-1514.

9. Sheldrick, G. M., SADABS (Version 2), Empirical Absorption Correction Program, University of Göttingen: Germany, 2000.

10. Beurskens, P. T.; Beurskens, G.; De Gelder, R.; García-Granda, S.; Gould, R. O.; Israël, R.; Smits, J. M. M., The DIRDIF-99 program system, Crystallography Laboratory, University of Nijmegen: The Netherlands, 1999.

11. Altomare, A.; Burla, M. C.; Camalli, M.; Cascarano, G. L.; Giacovazzo, C.; Guagliardi, A.; Moliterni, A. G. G.; Polidori, G.; Spagna, R. J. Appl. Cryst. 1999, 32, 115-119. 
NMR SPECTRA AND MASS ANALYSES

${ }^{1} \mathrm{H}$ NMR

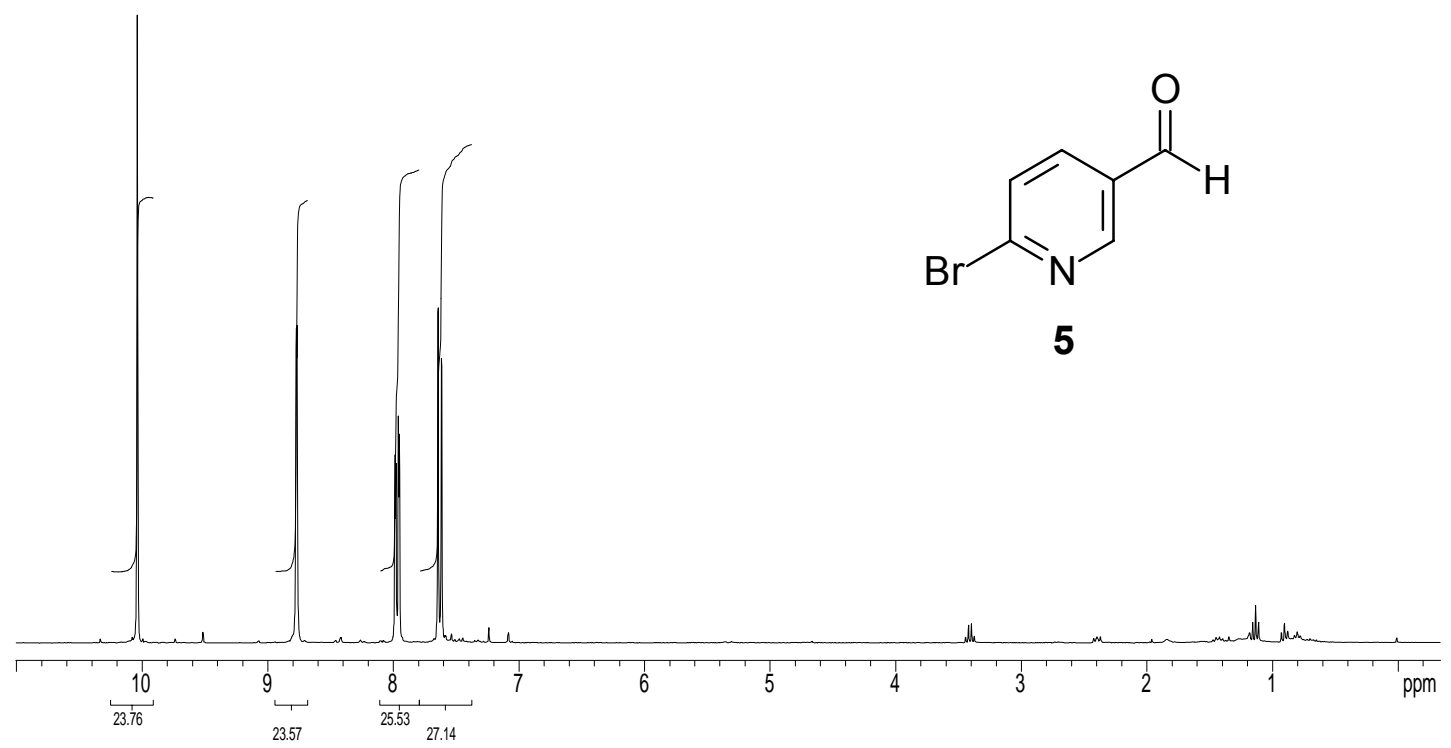

${ }^{13} \mathrm{C}$ NMR

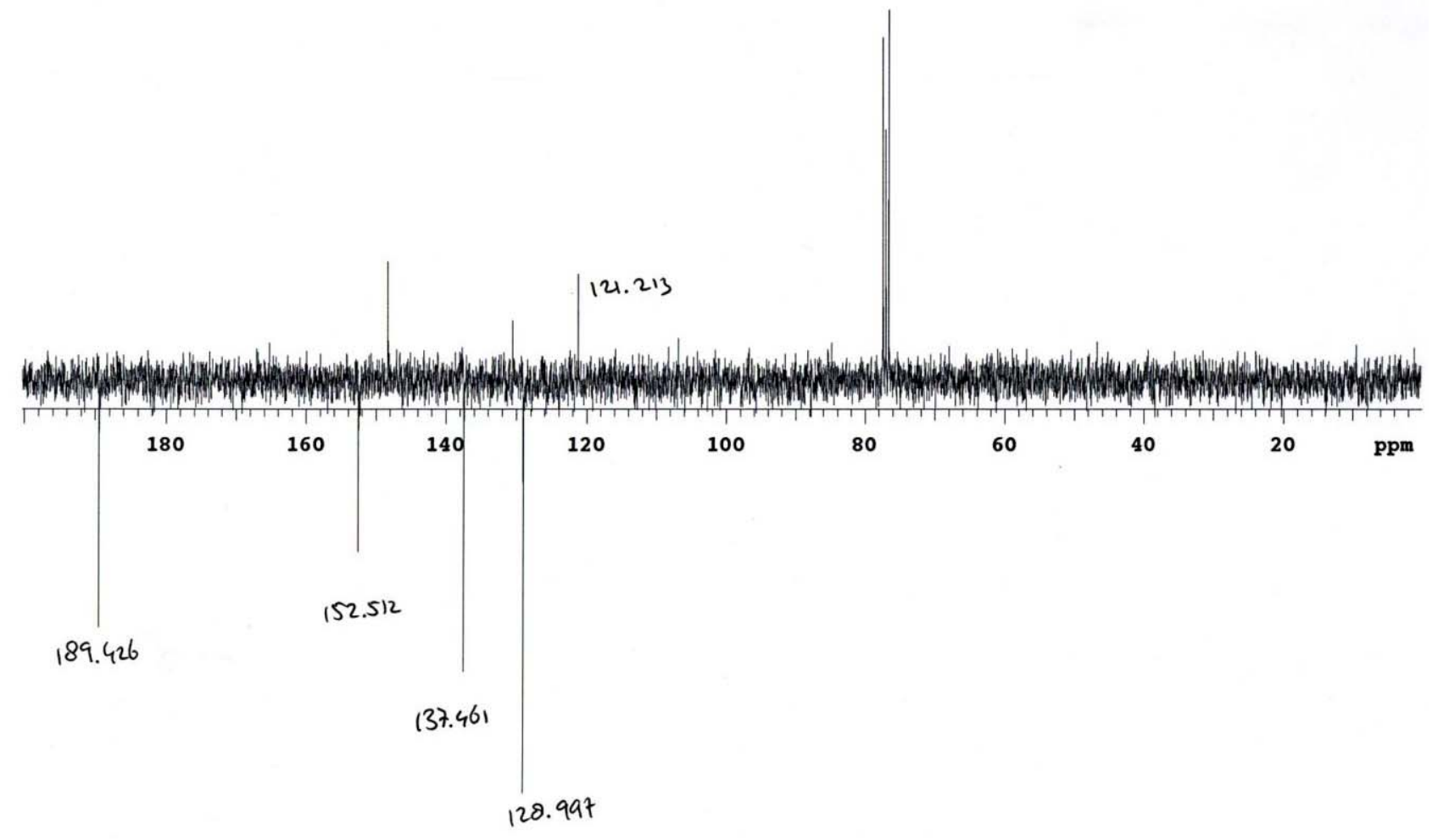


${ }^{1} \mathrm{H}$ NMR

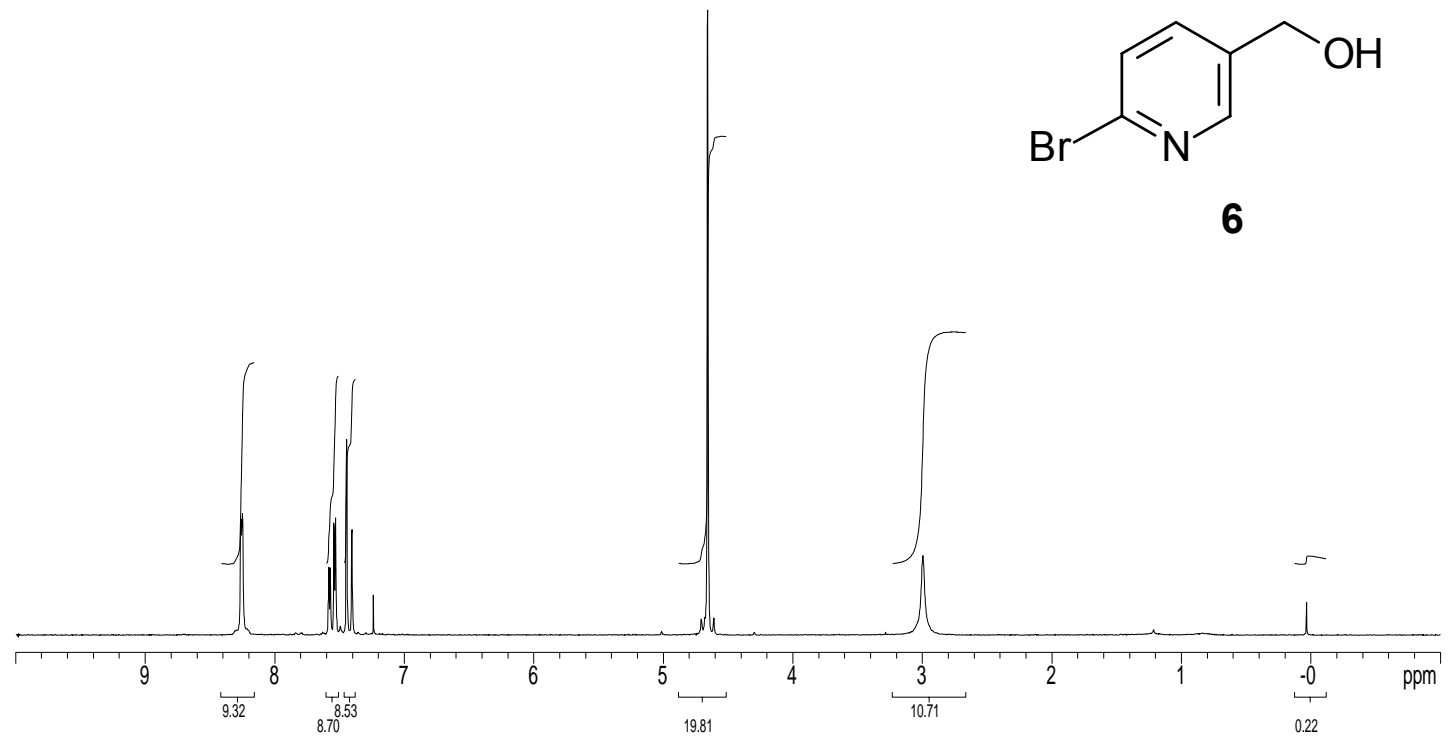

${ }^{13} \mathrm{C}$ NMR

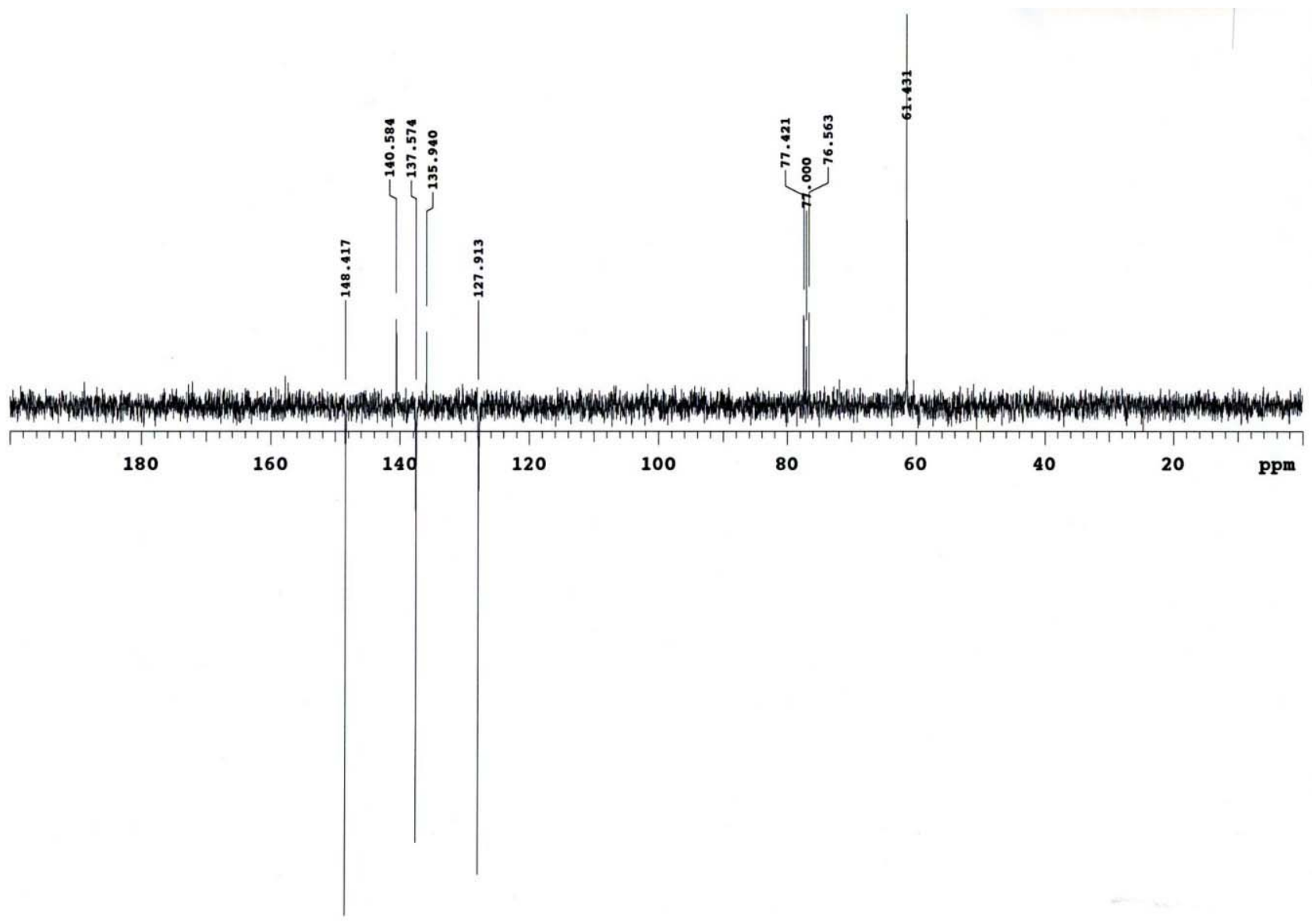


${ }^{1} \mathrm{H}$ NMR



${ }^{13} \mathrm{C}$ NMR

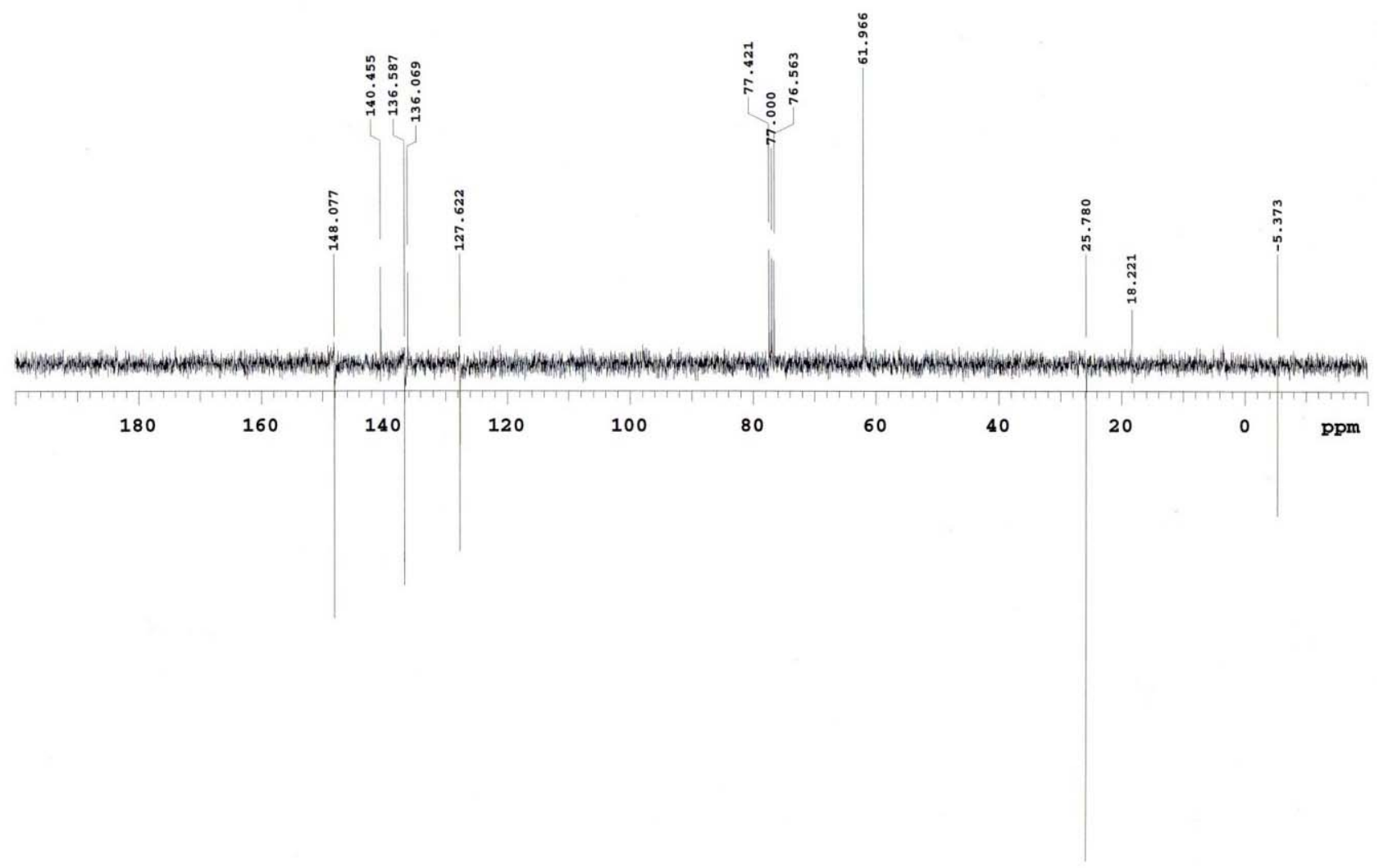


${ }^{1} \mathrm{H}$ NMR

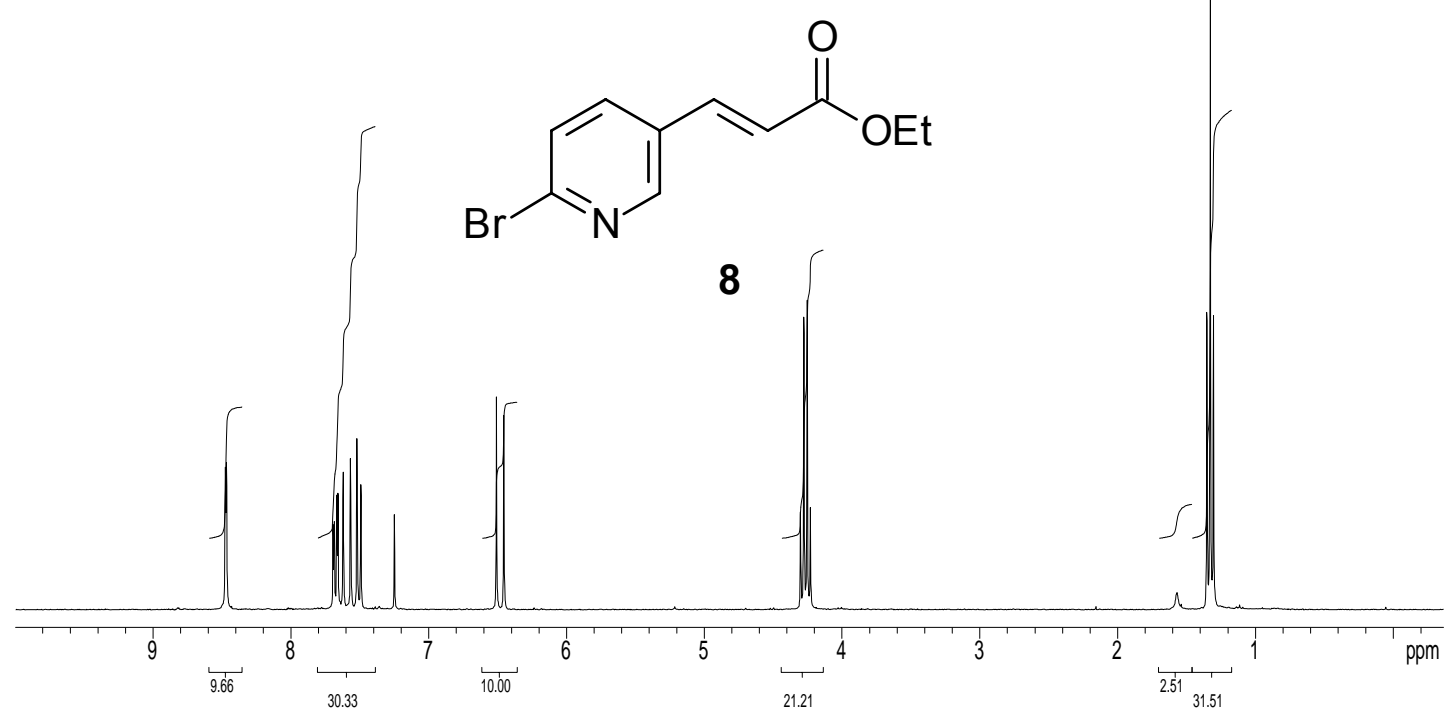

${ }^{13} \mathrm{C}$ NMR

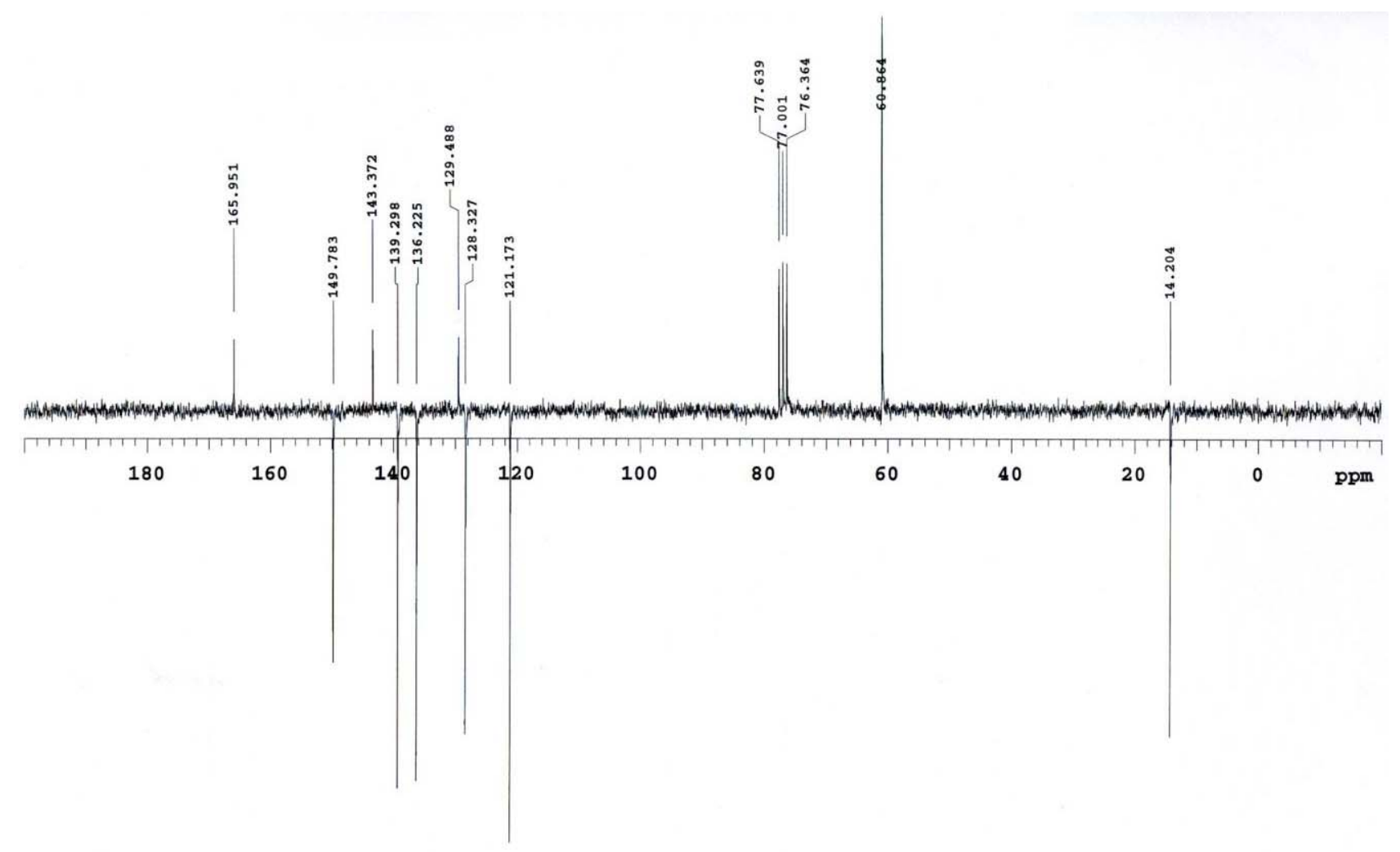


${ }^{1} \mathrm{H}$ NMR

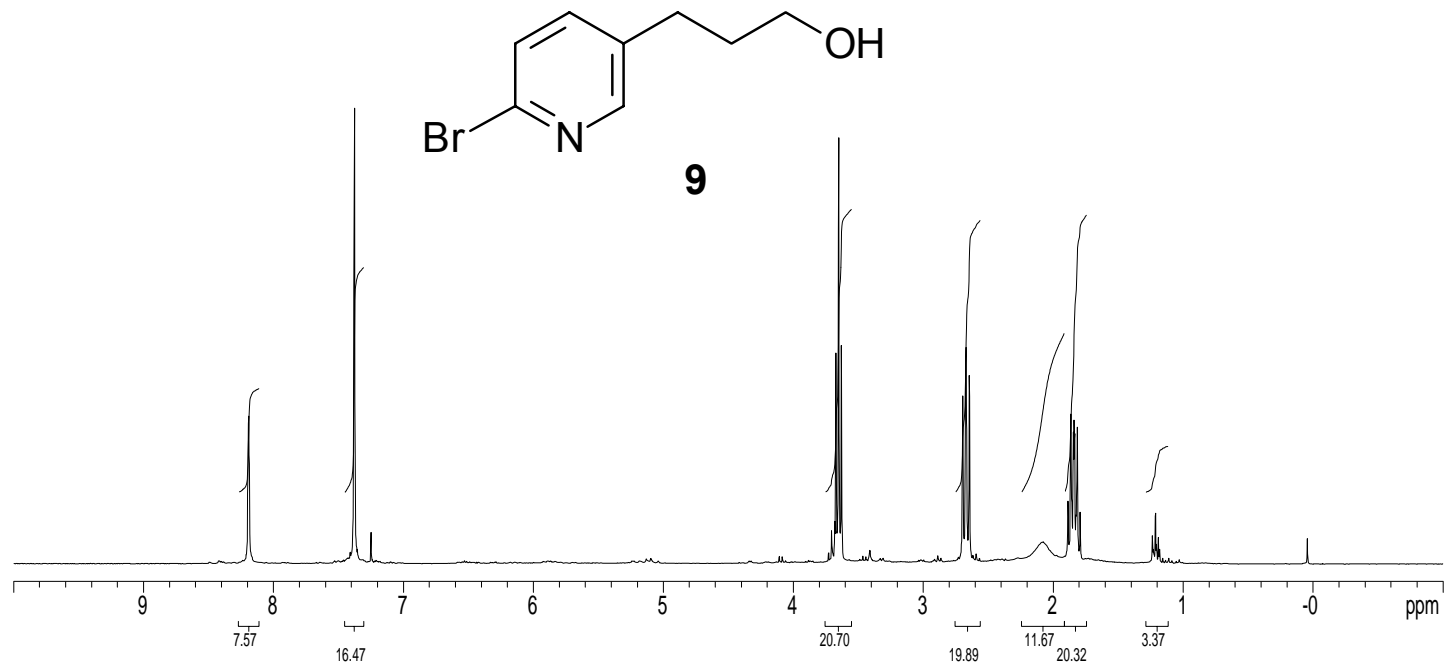

${ }^{13} \mathrm{C}$ NMR

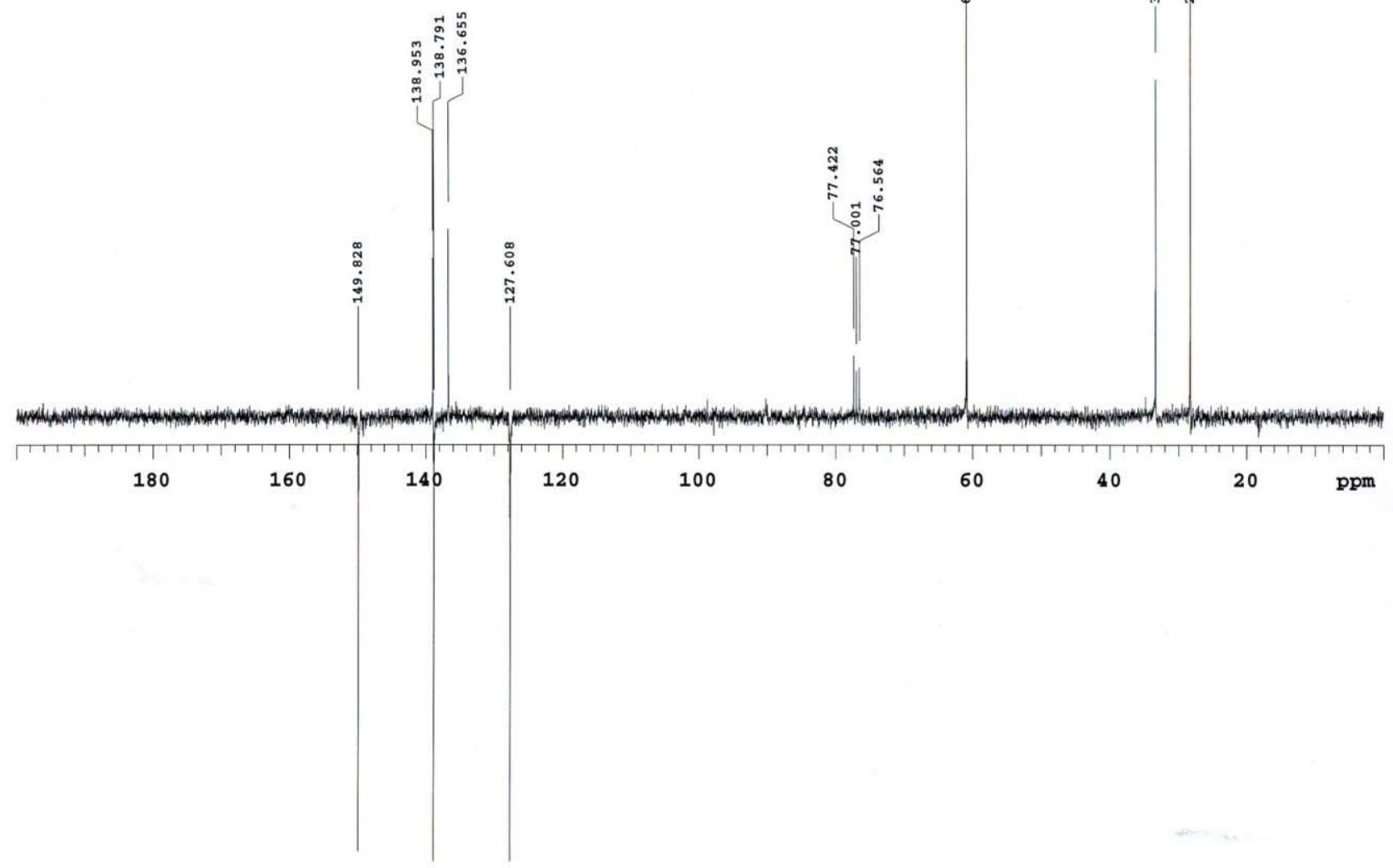


${ }^{1} \mathrm{H}$ NMR<smiles>CS(=O)(=O)OCCCc1ccc(Br)nc1</smiles>

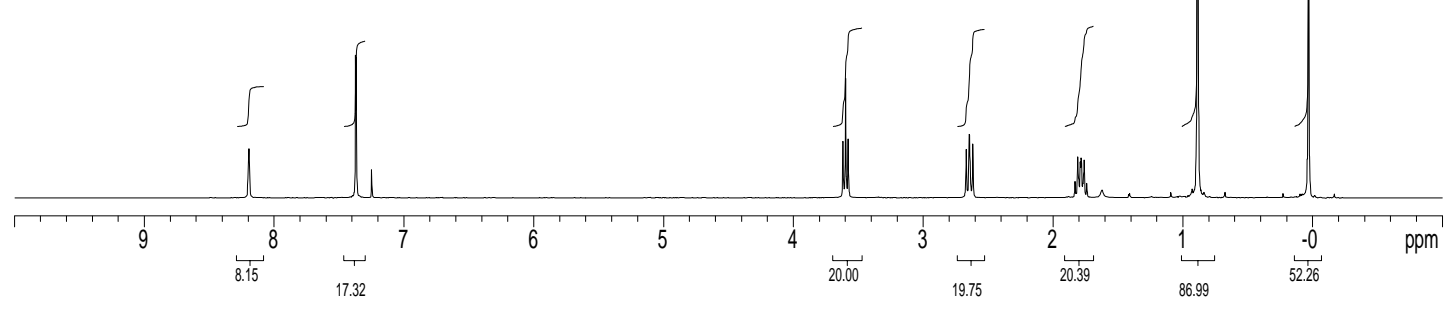

${ }^{13} \mathrm{C}$ NMR

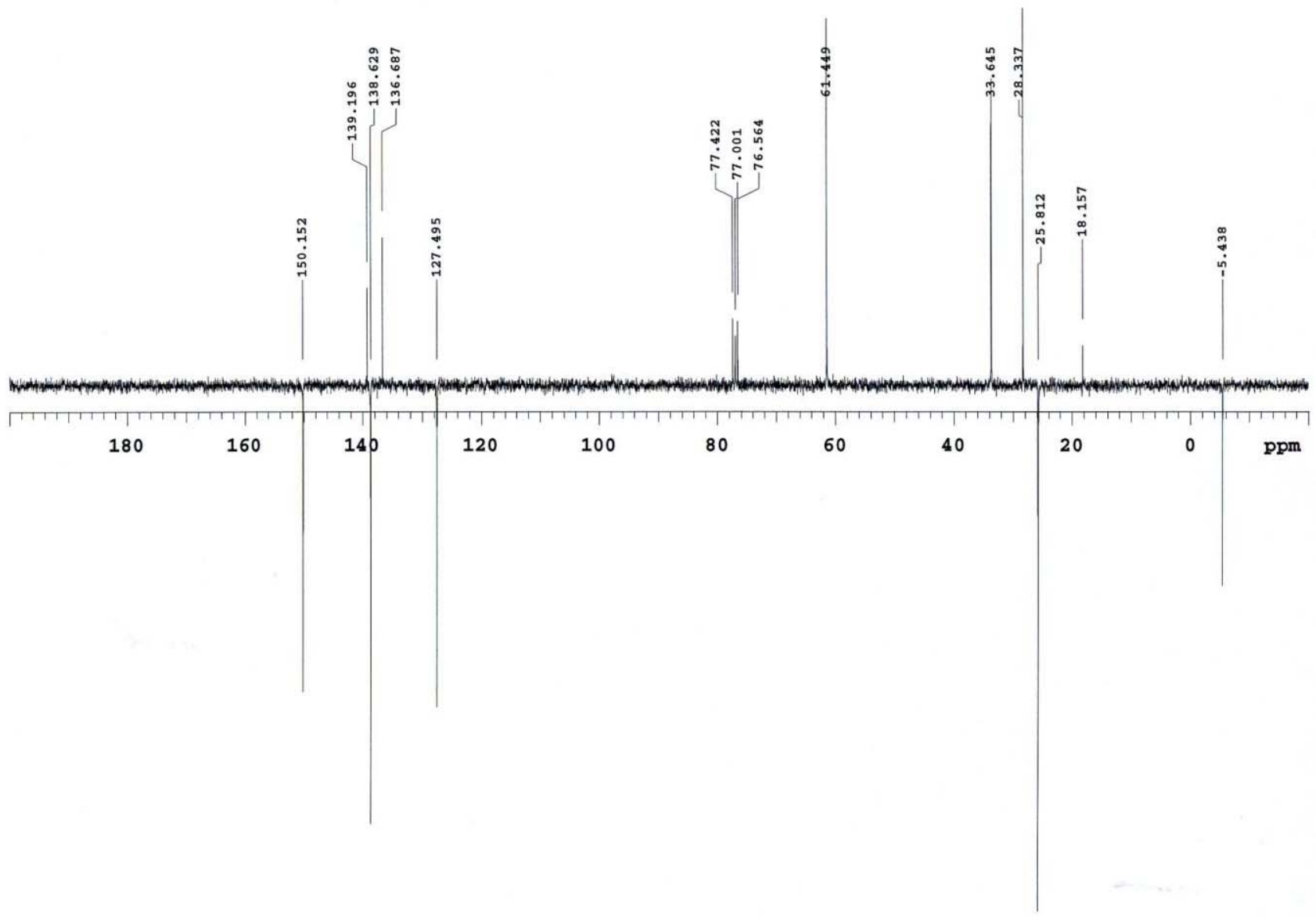


${ }^{1} \mathrm{H}$ NMR<smiles>C[R5](C)(C)OCc1ccc(C=O)nc1</smiles>

11

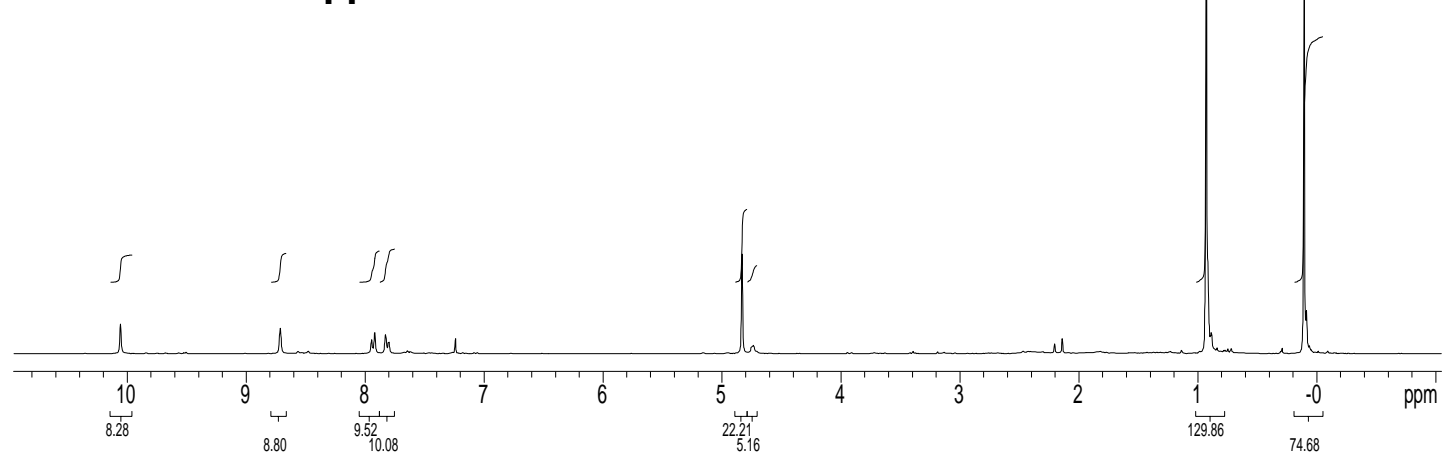

${ }^{13} \mathrm{C}$ NMR

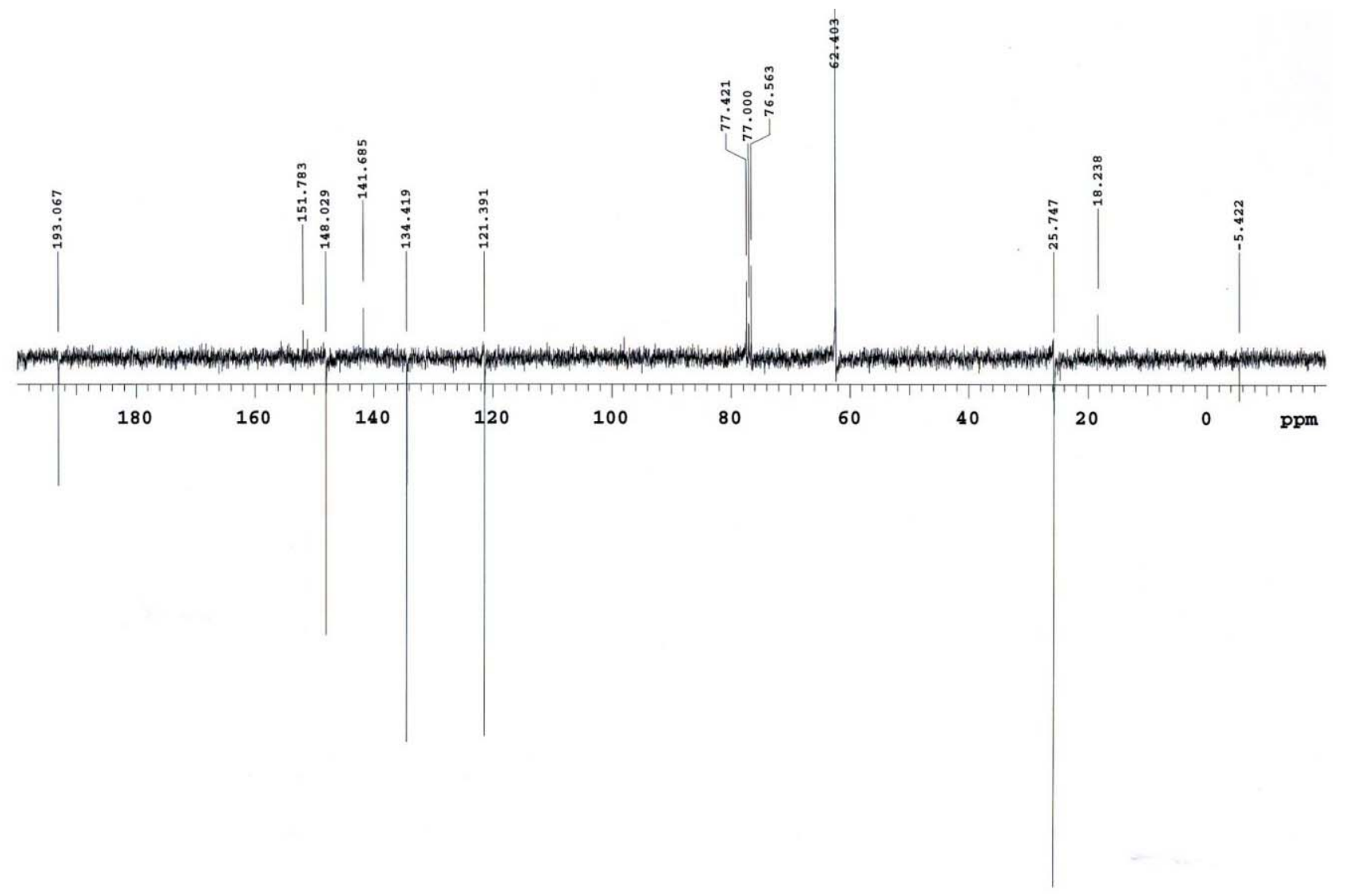


${ }^{1} \mathrm{H}$ NMR

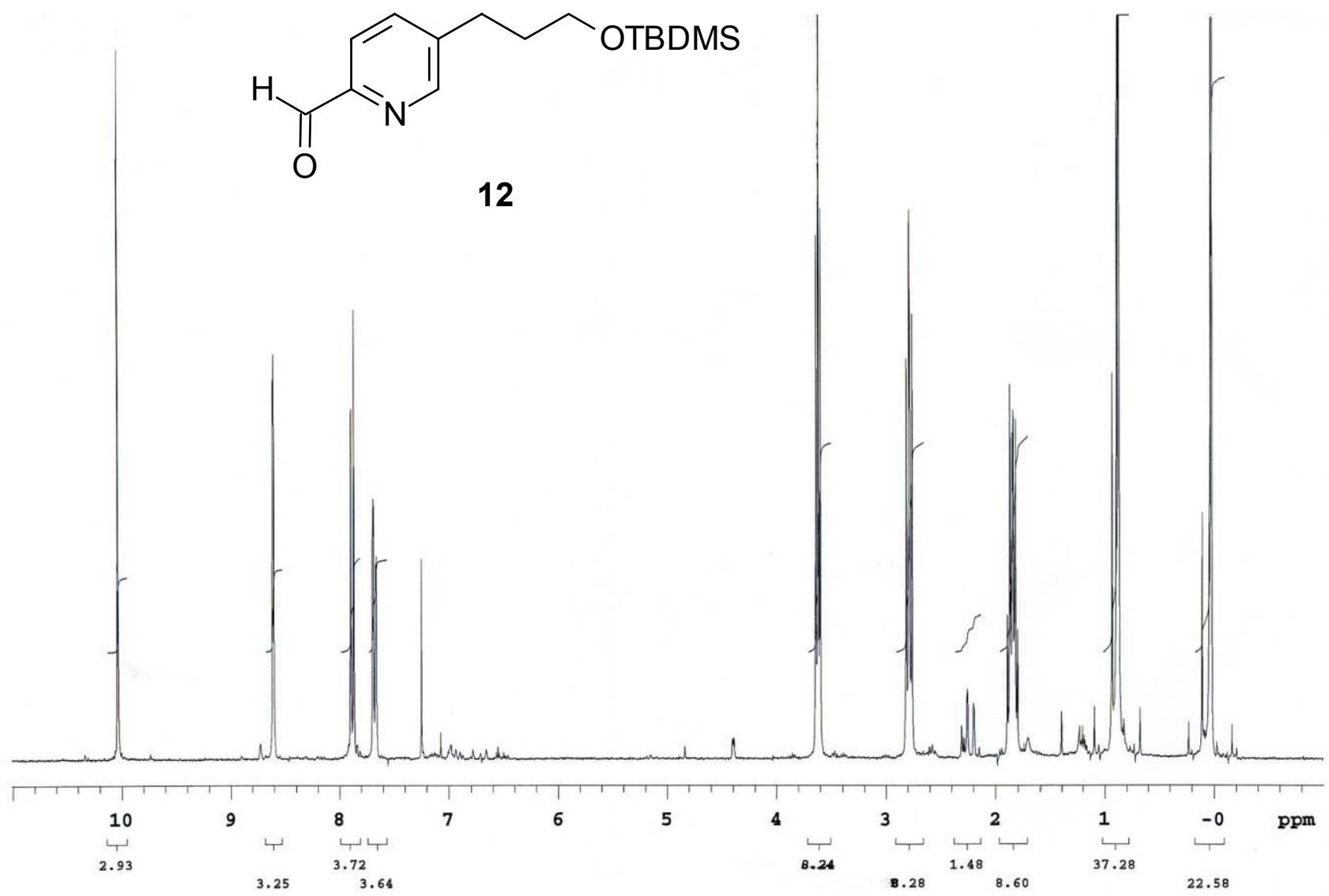

${ }^{13} \mathrm{C}$ NMR

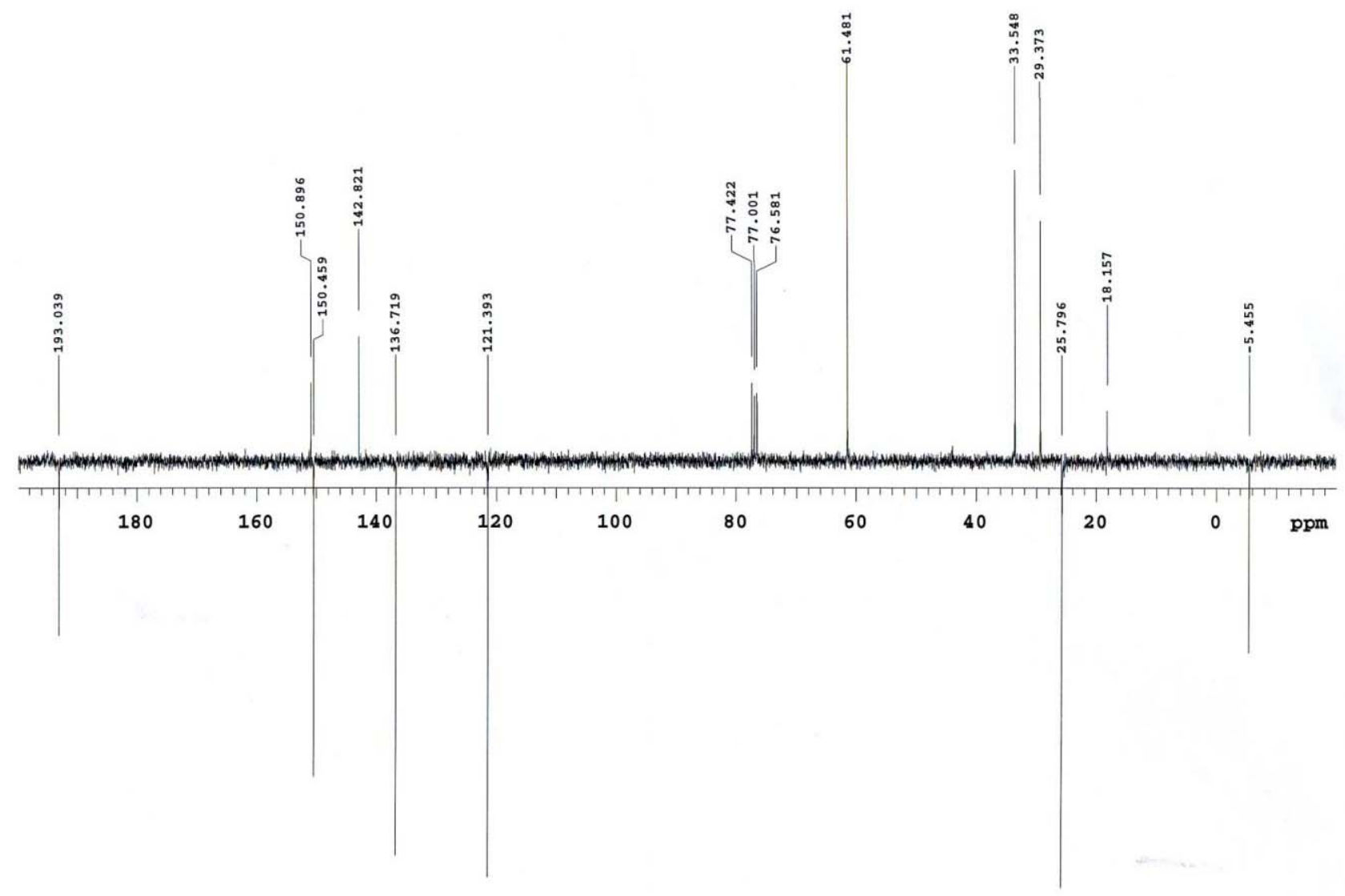


${ }^{1} \mathrm{H}$ NMR

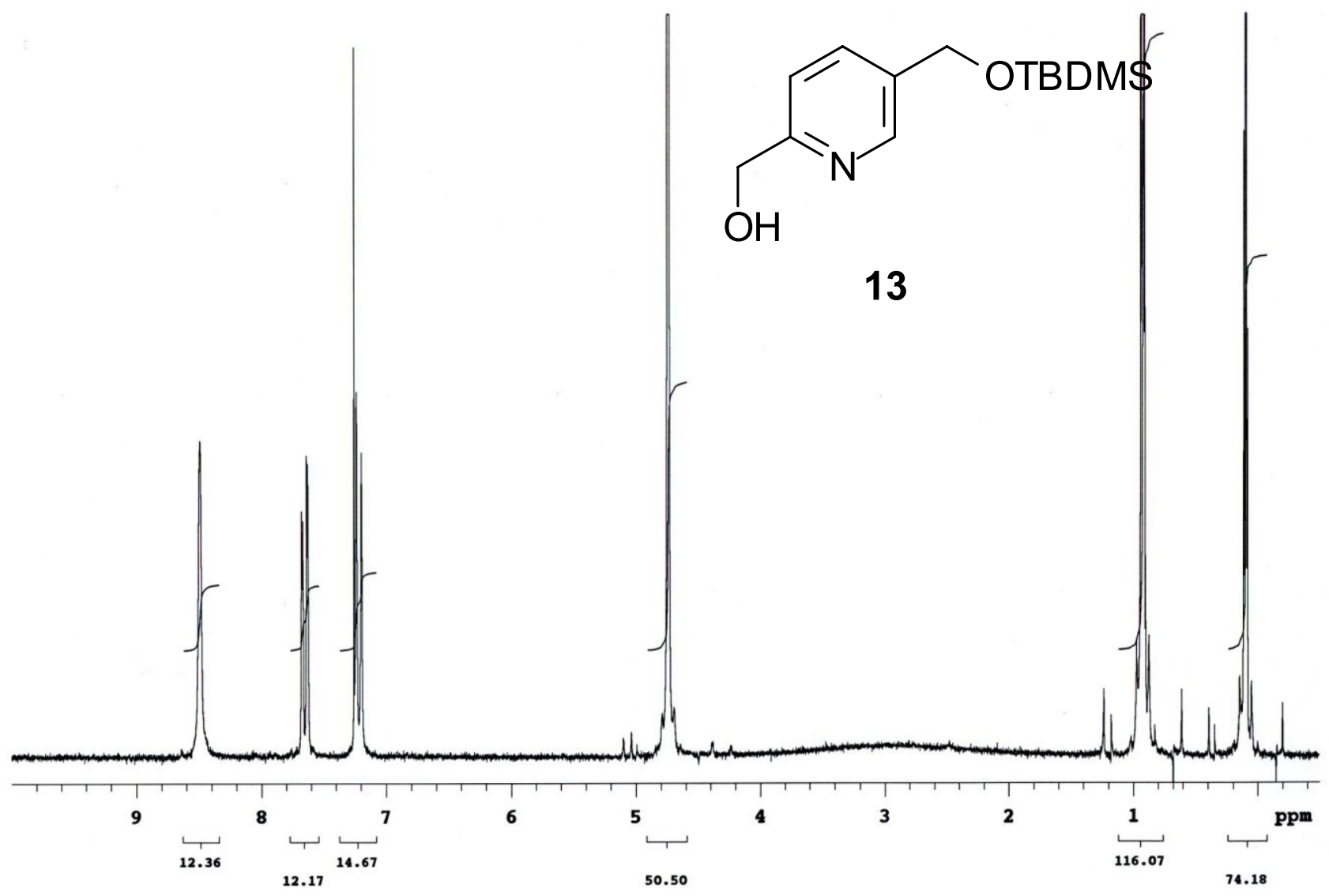

${ }^{13} \mathrm{C}$ NMR

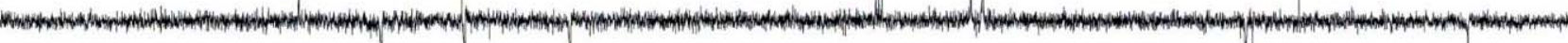

180

160

140

120

100

80

60

40

20

0

ppm 
${ }^{1} \mathrm{H}$ NMR

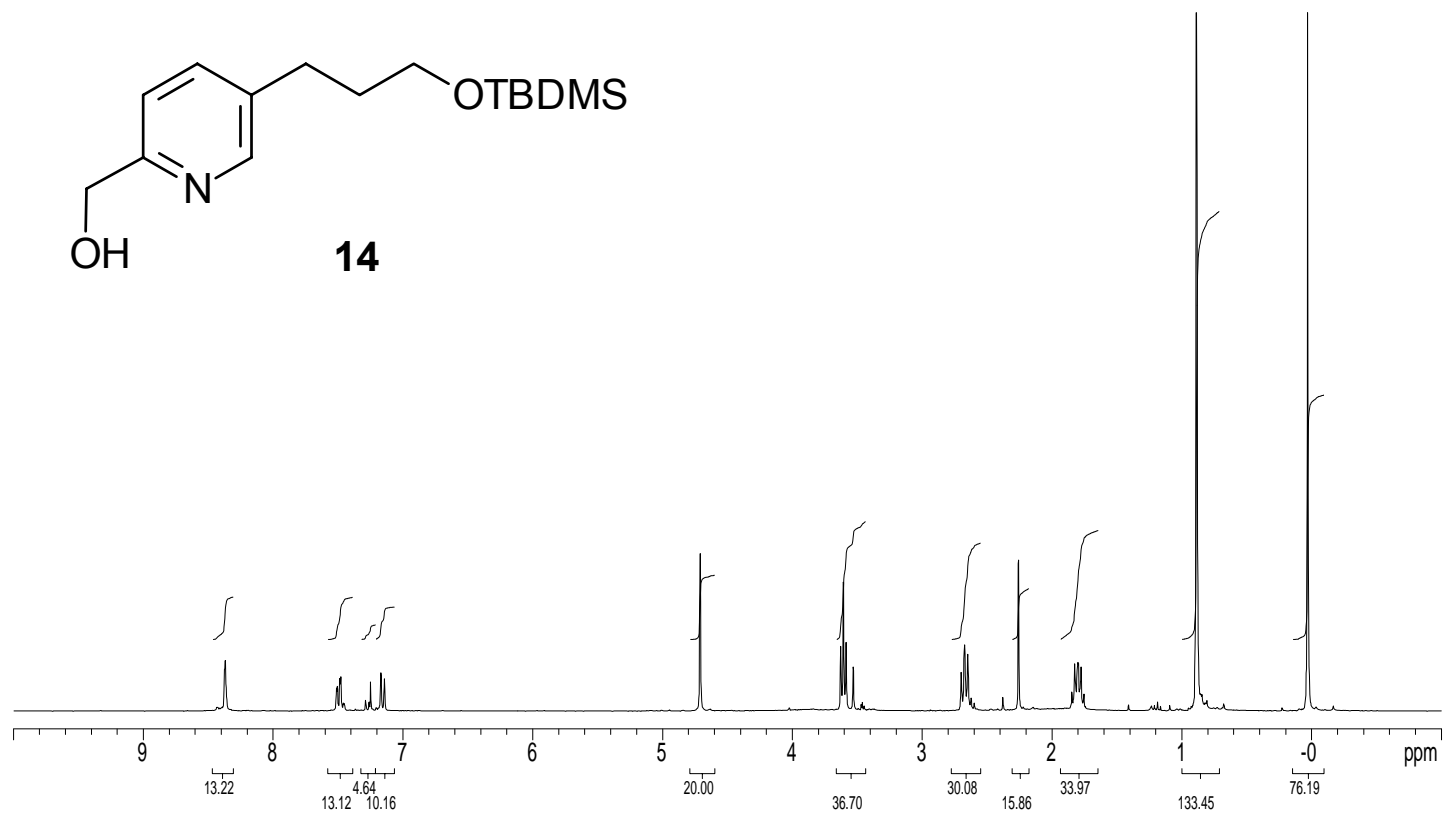

${ }^{13} \mathrm{C}$ NMR

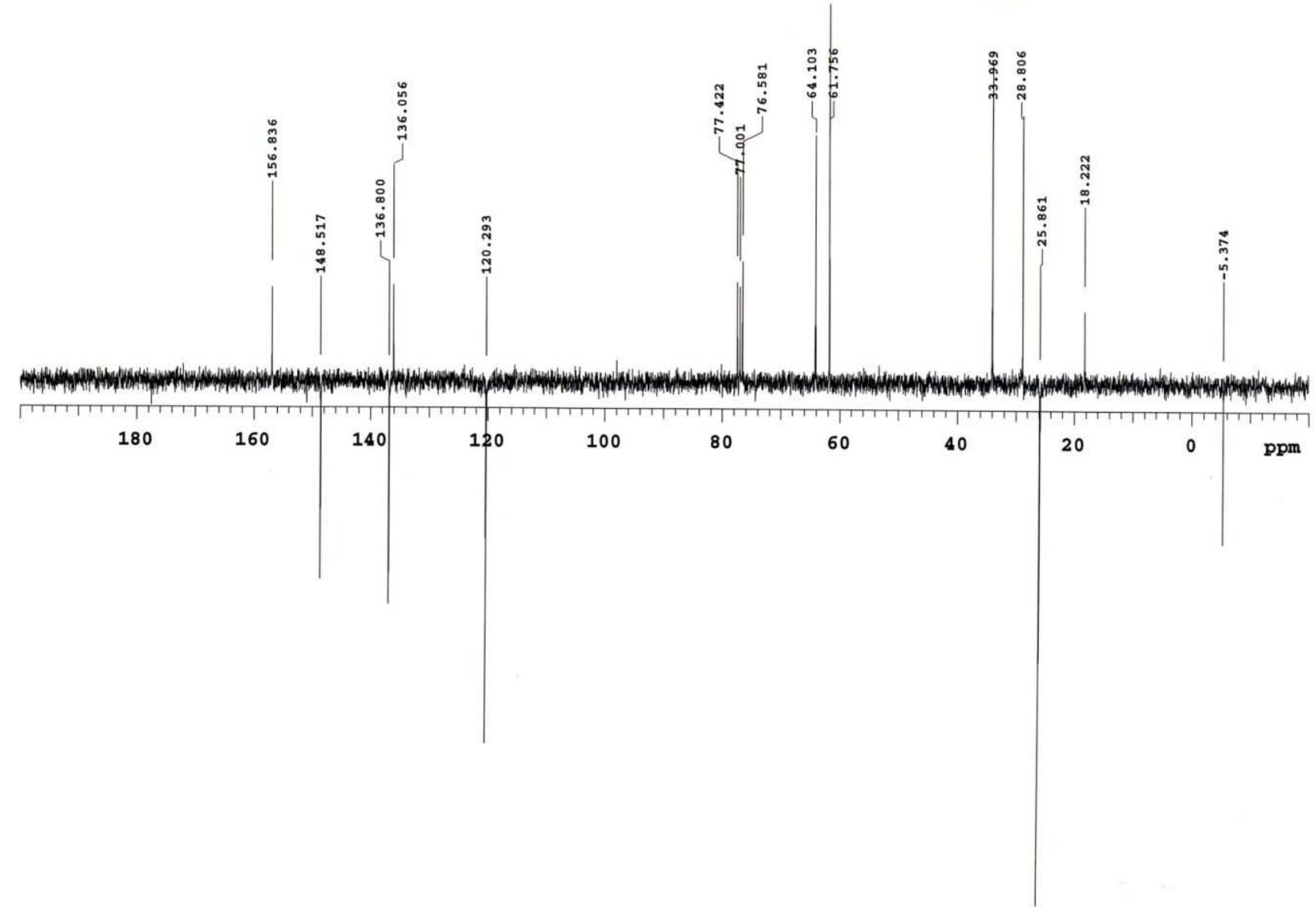


${ }^{1} \mathrm{H}$ NMR<smiles>C[R15](C)(C)[O+]Cc1ccc(CCl)nc1</smiles>

15

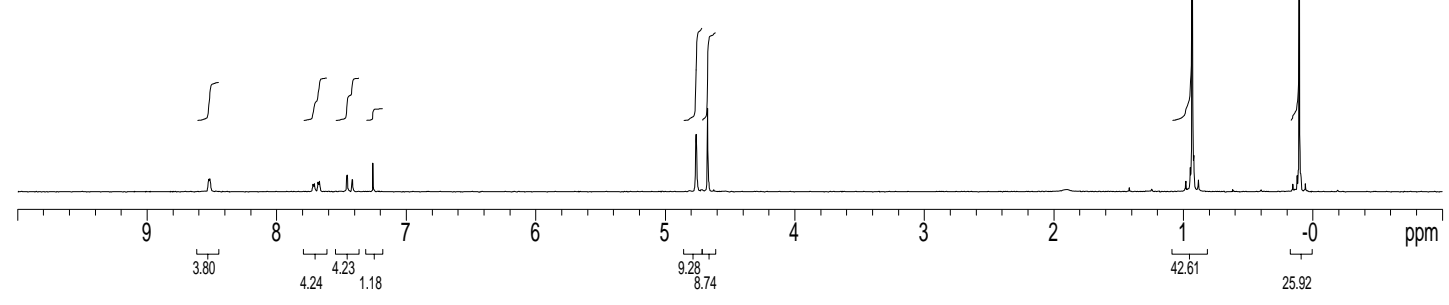

${ }^{13} \mathrm{C}$ NMR

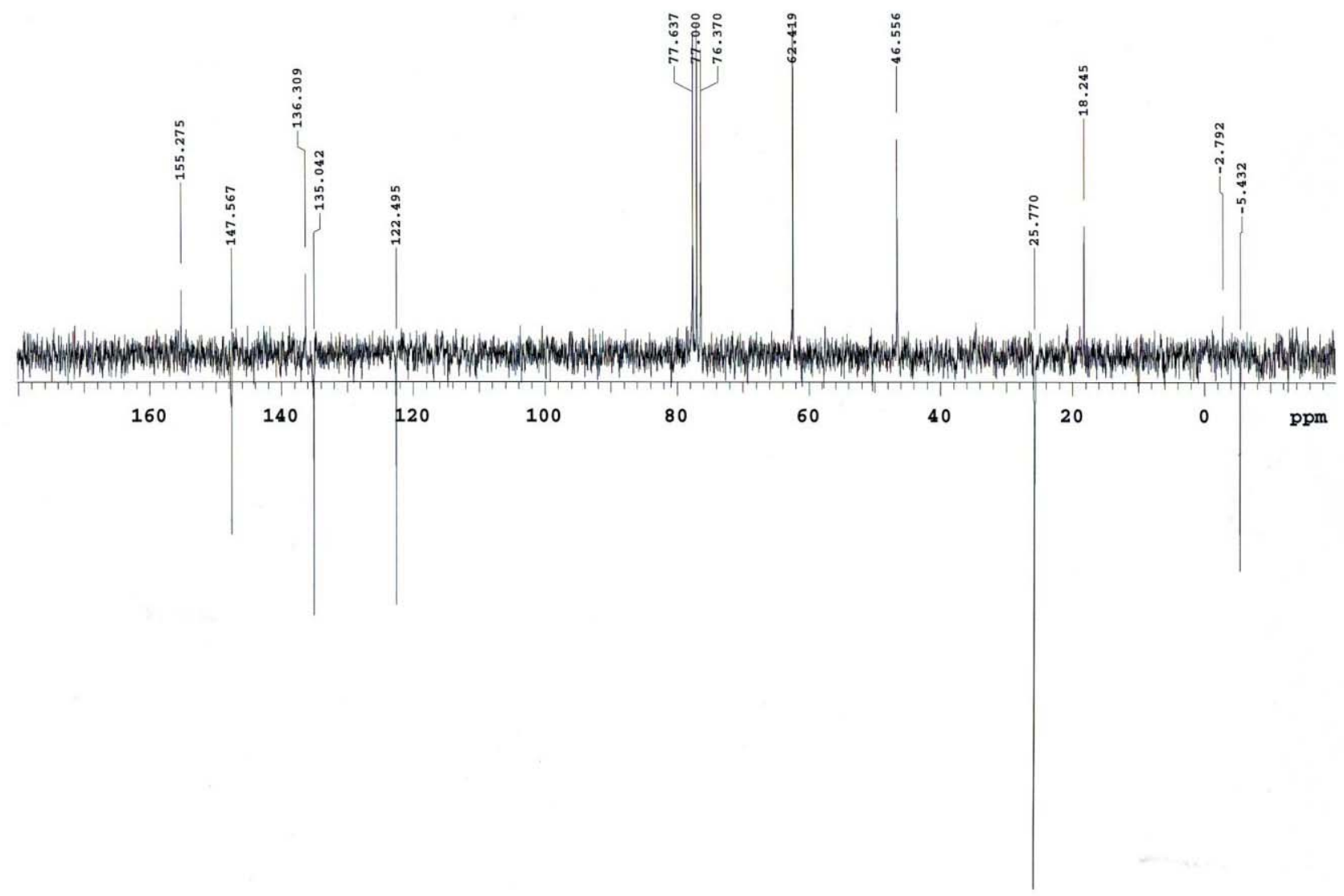


${ }^{1} \mathrm{H}$ NMR<smiles>C[AsH3]</smiles>

${ }^{13} \mathrm{C}$ NMR

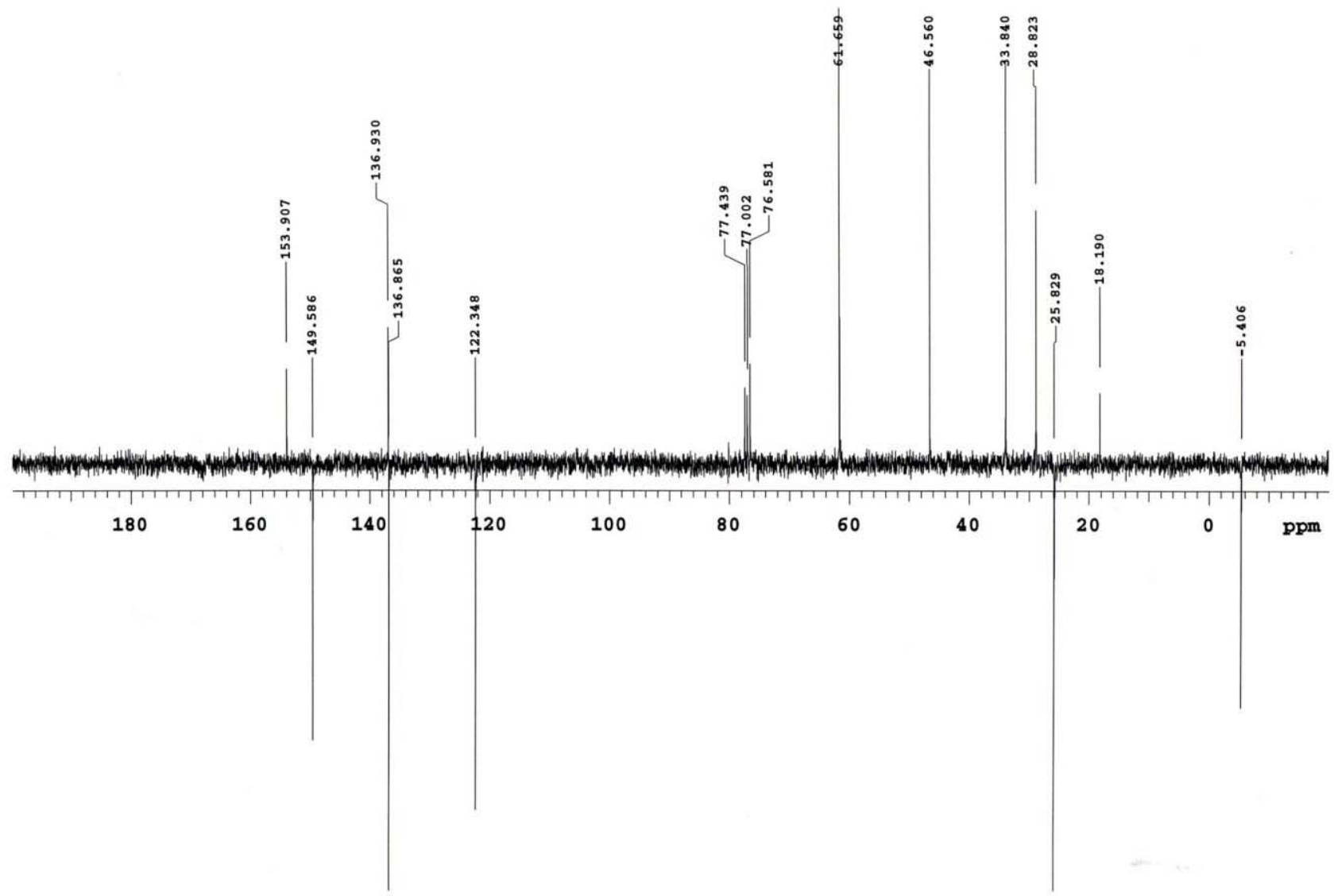


${ }^{1} \mathrm{H}$ NMR<smiles>CCCCOCc1ccc(C(=O)c2ccc(CO[SeH2])cn2)nc1</smiles>

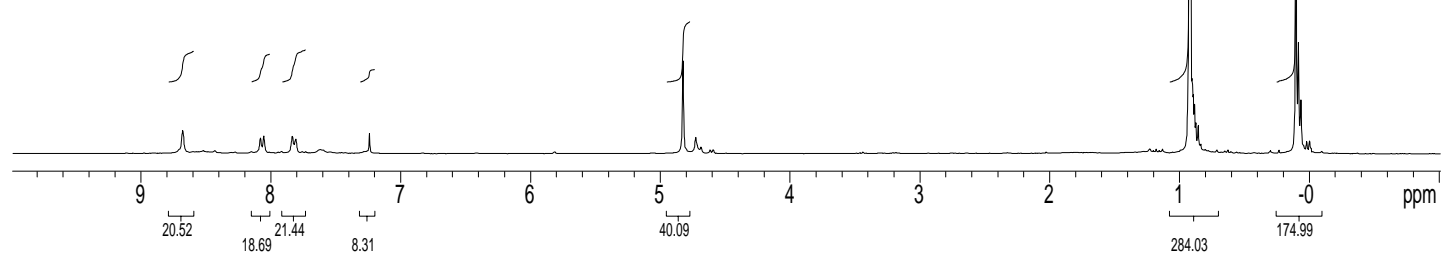

${ }^{13} \mathrm{C}$ NMR

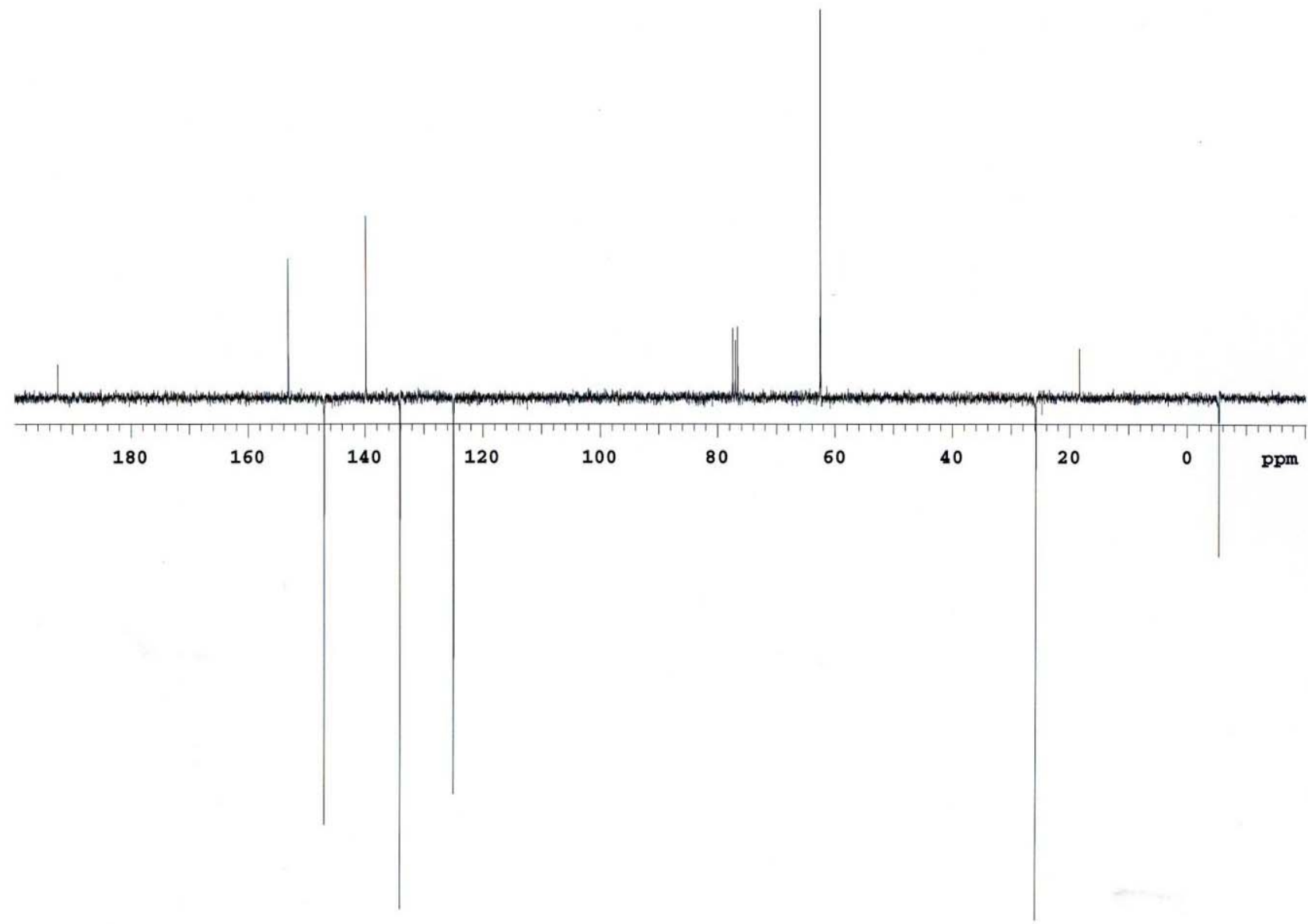


${ }^{1} \mathrm{H}$ NMR

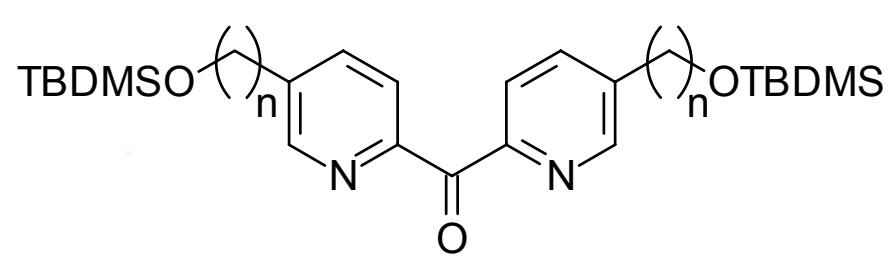

$18(n=3)$

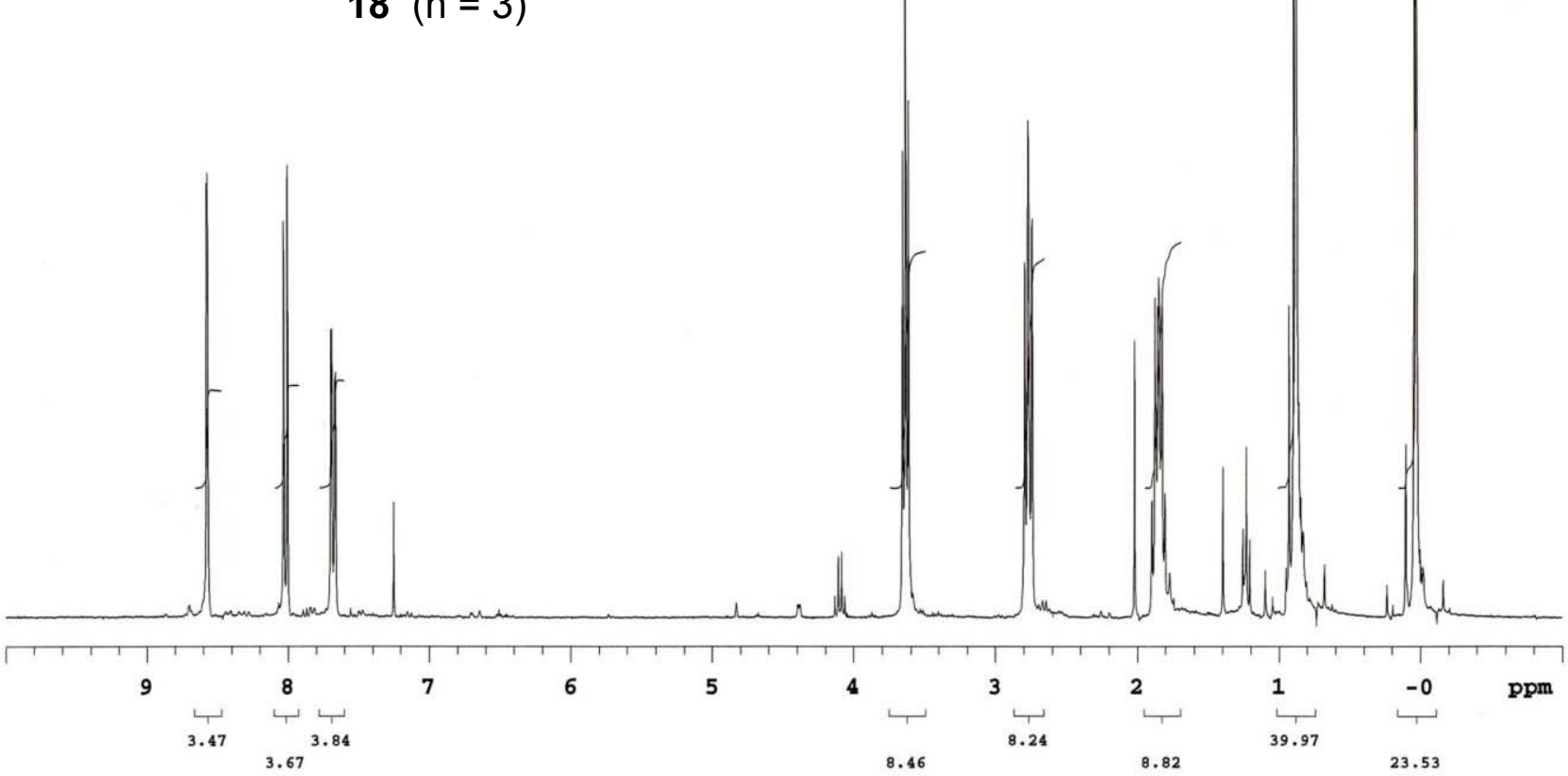

${ }^{13} \mathrm{C}$ NMR

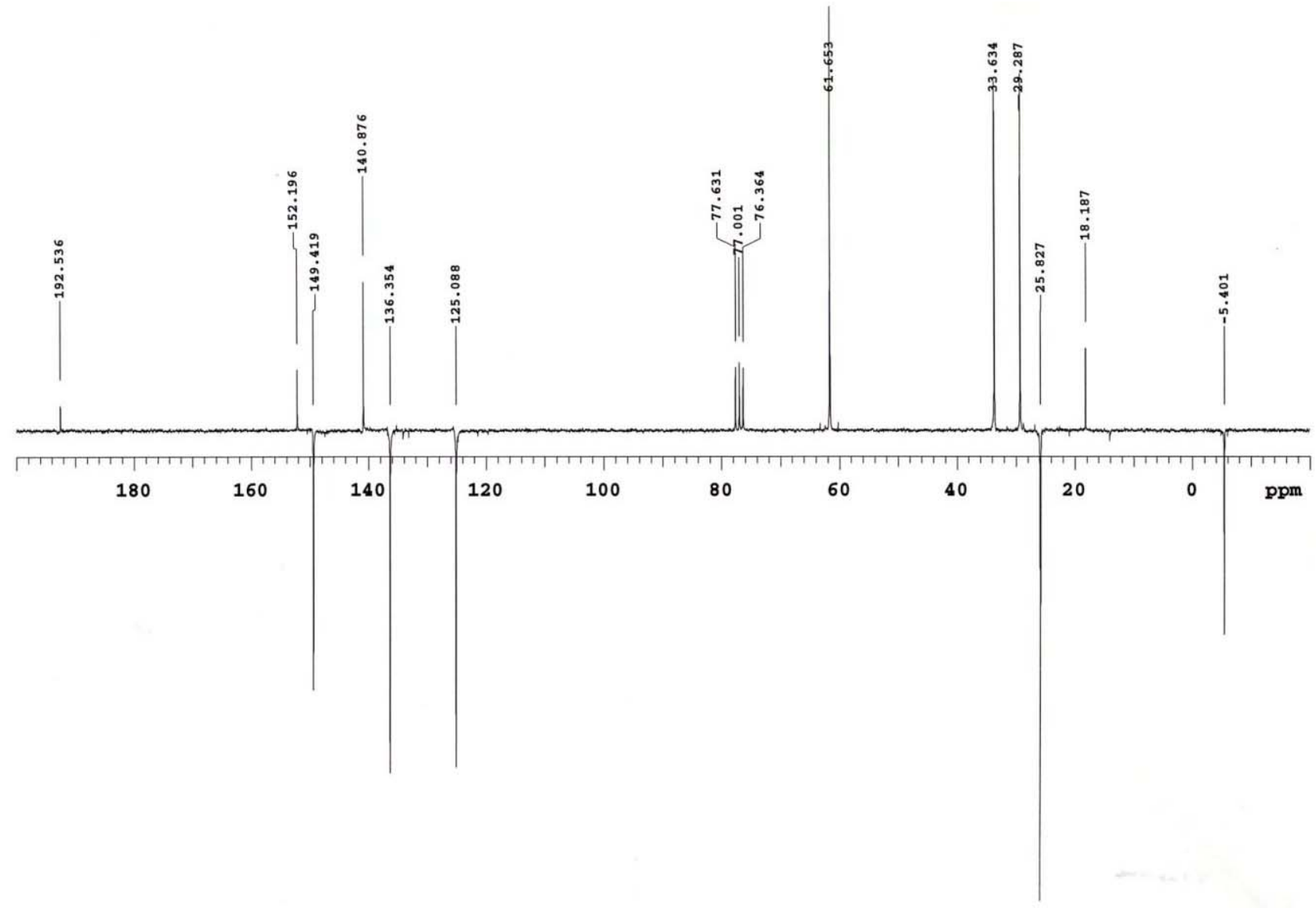


${ }^{1} \mathrm{H}$ NMR

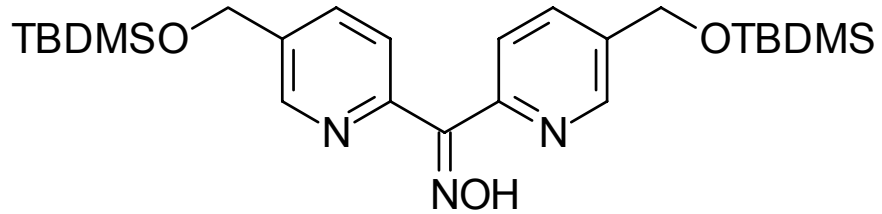

19

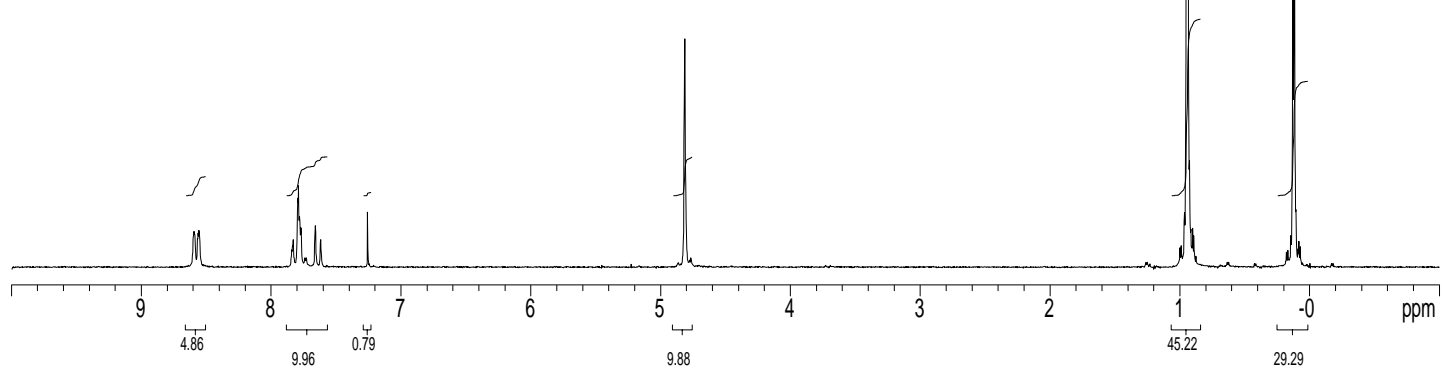

${ }^{13} \mathrm{C}$ NMR

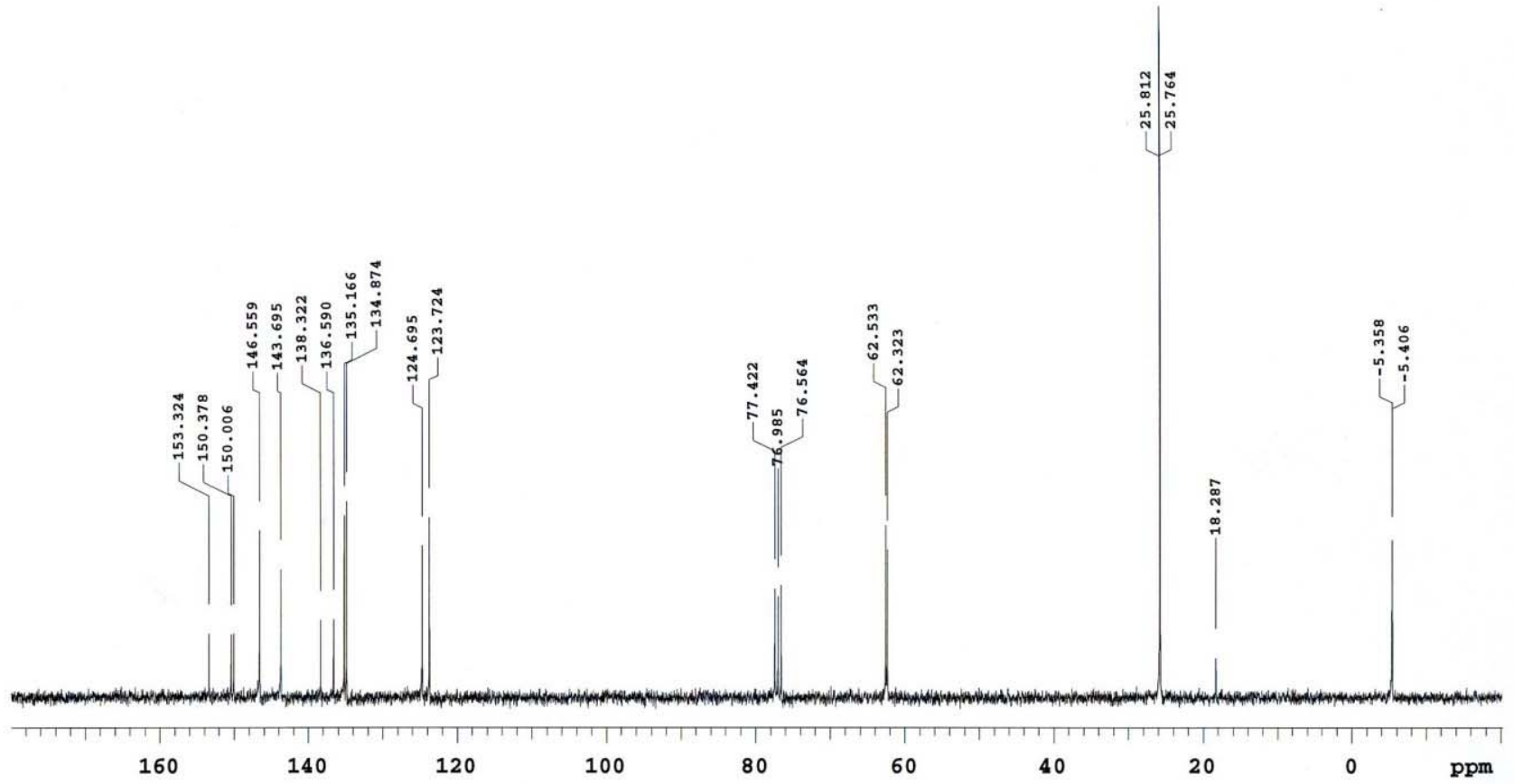


${ }^{1} \mathrm{H}$ NMR

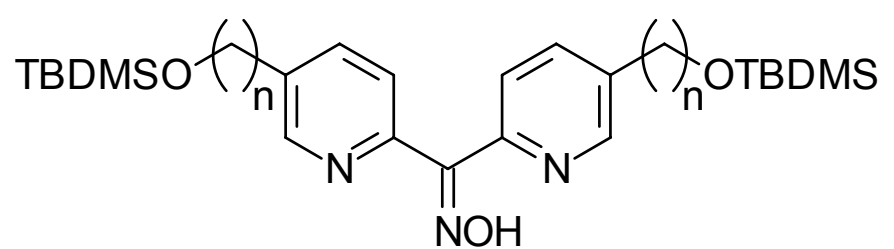

$$
20(n=3)
$$

${ }^{13} \mathrm{C}$ NMR

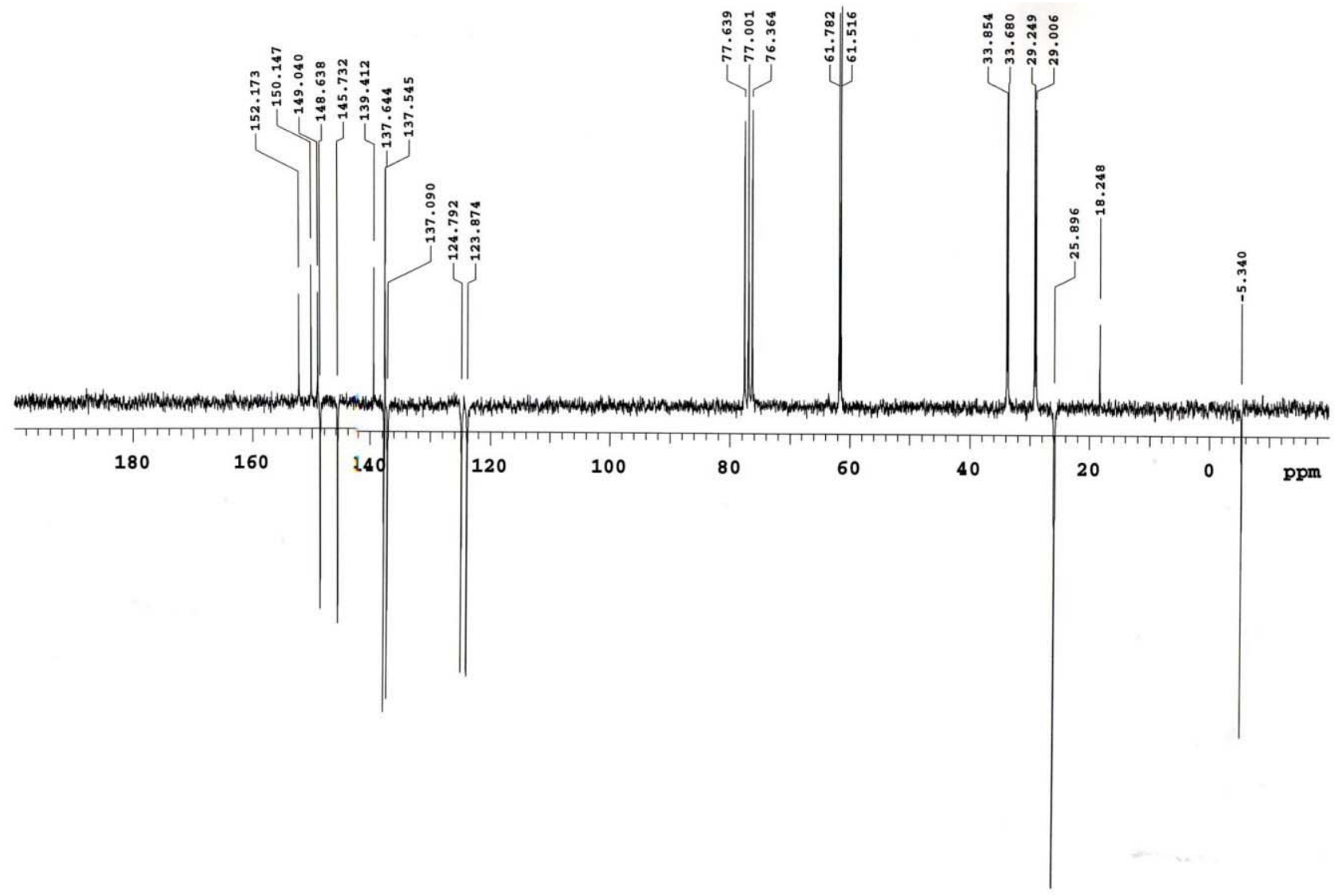


${ }^{1} \mathrm{H}$ NMR

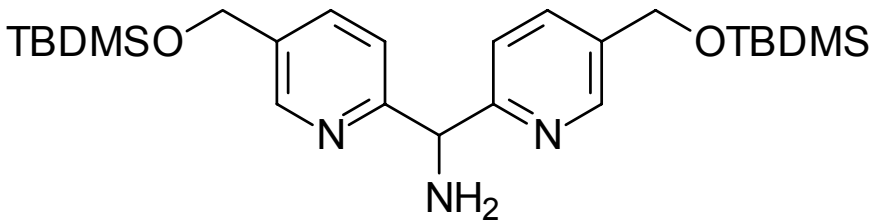

21

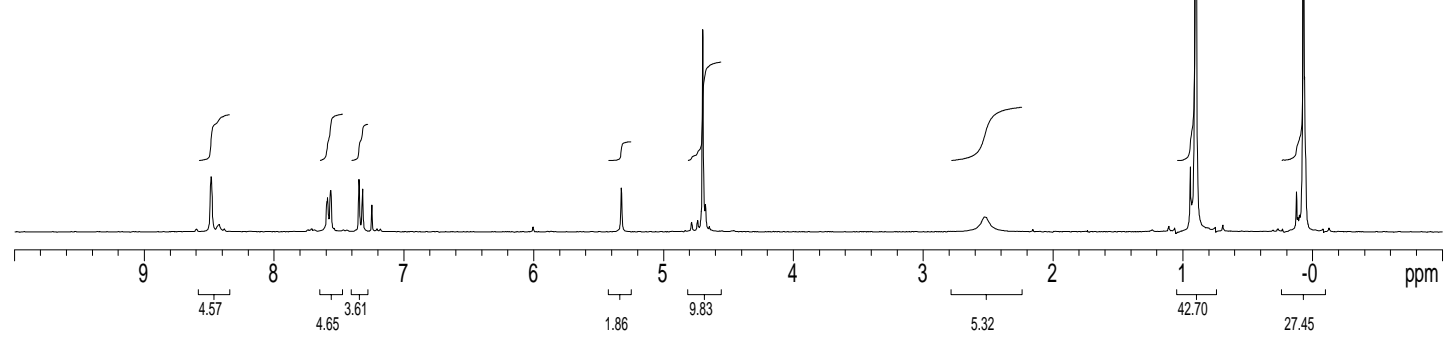

${ }^{13} \mathrm{C}$ NMR

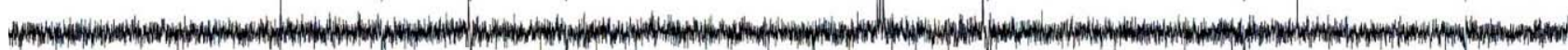

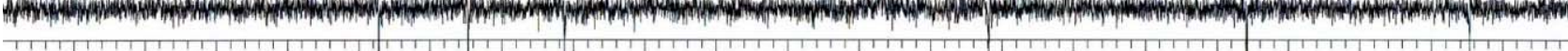
180 160 $140 \quad 120$

40

20 ppm 
${ }^{1} \mathrm{H}$ NMR

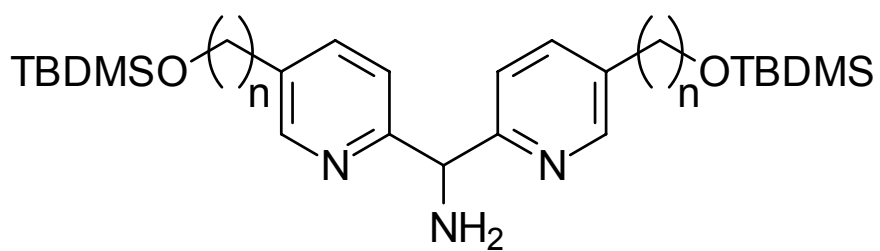

$22(\mathrm{n}=3)$

${ }^{13} \mathrm{C}$ NMR

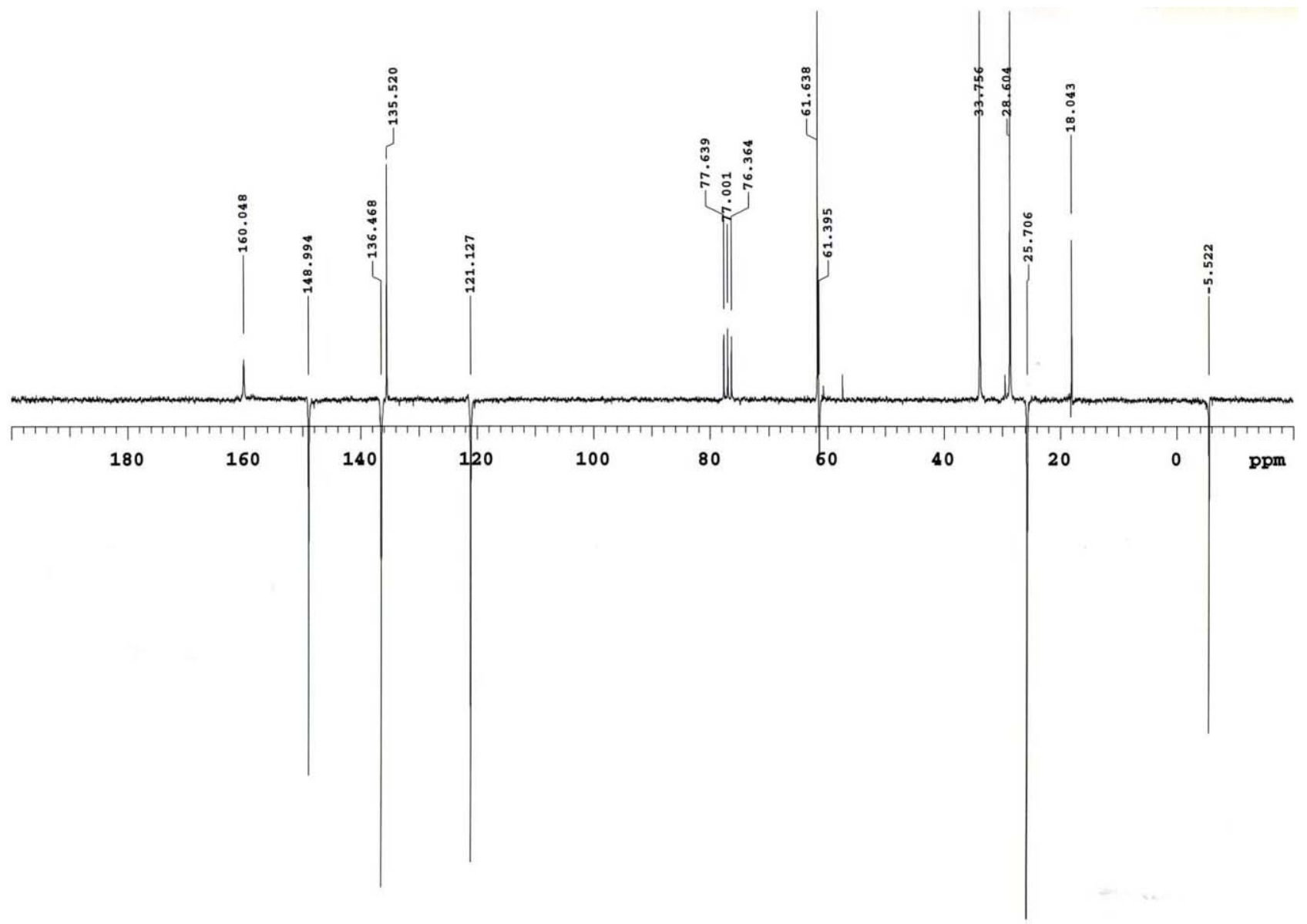


${ }^{1} \mathrm{H}$ NMR<smiles>CCCCOCc1ccc(C(NCc2ccc(COCCC)cn2)c2ccc(COC(C)C)cn2)nc1</smiles>

23

${ }^{13} \mathrm{C}$ NMR

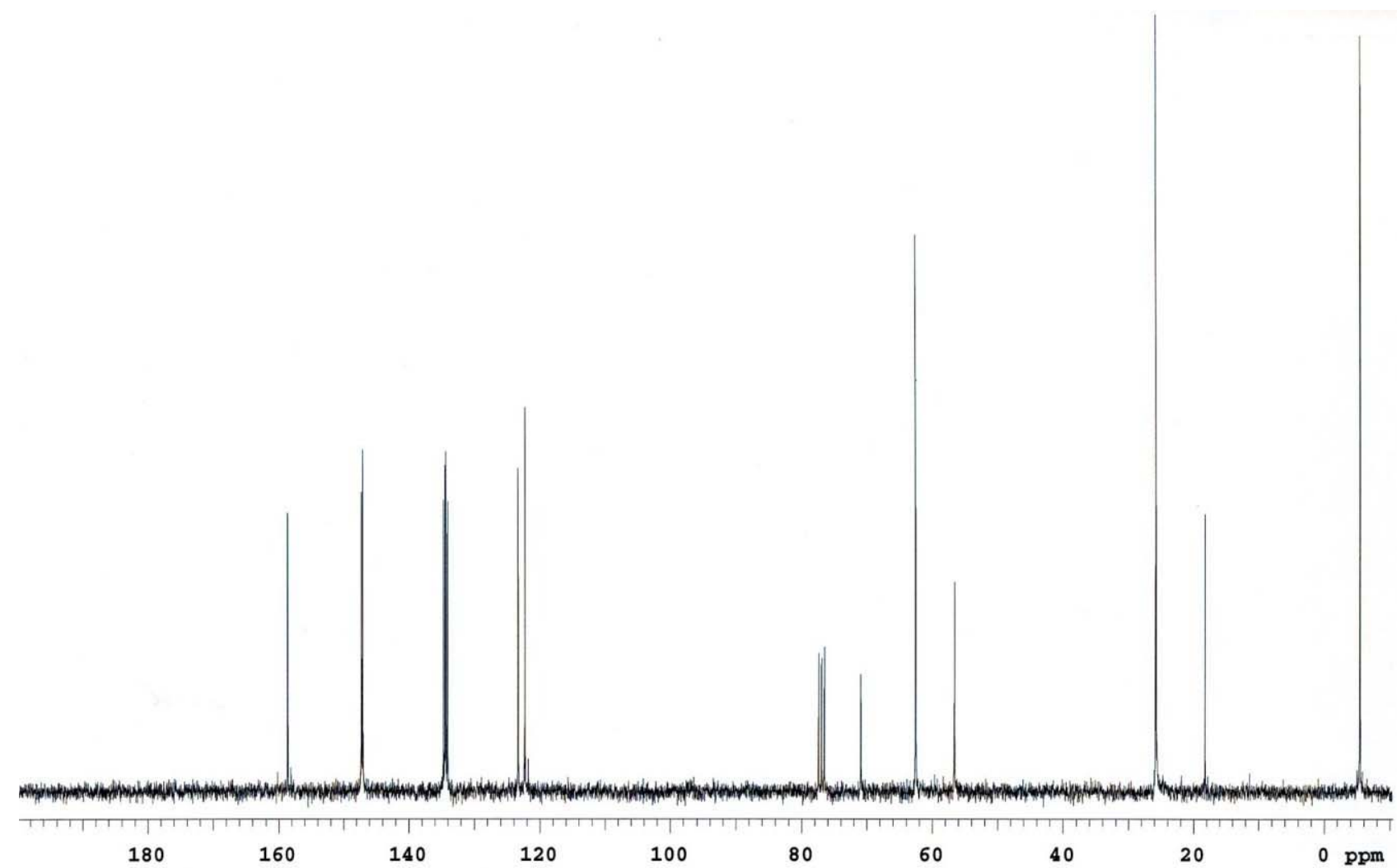


${ }^{1} \mathrm{H}$ NMR

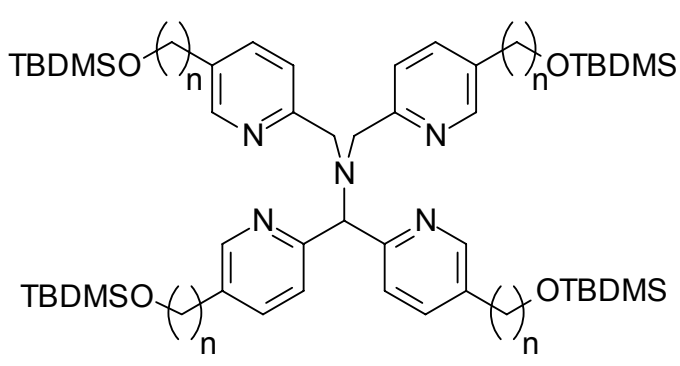

$24(n=3)$

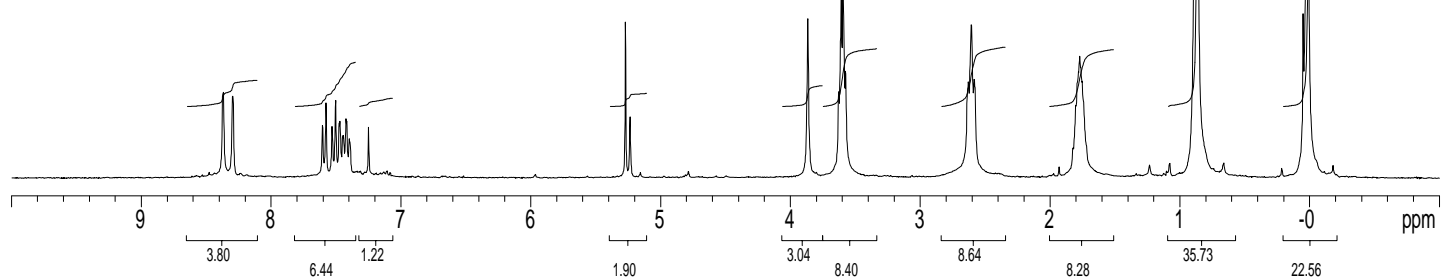

${ }^{13} \mathrm{C}$ NMR

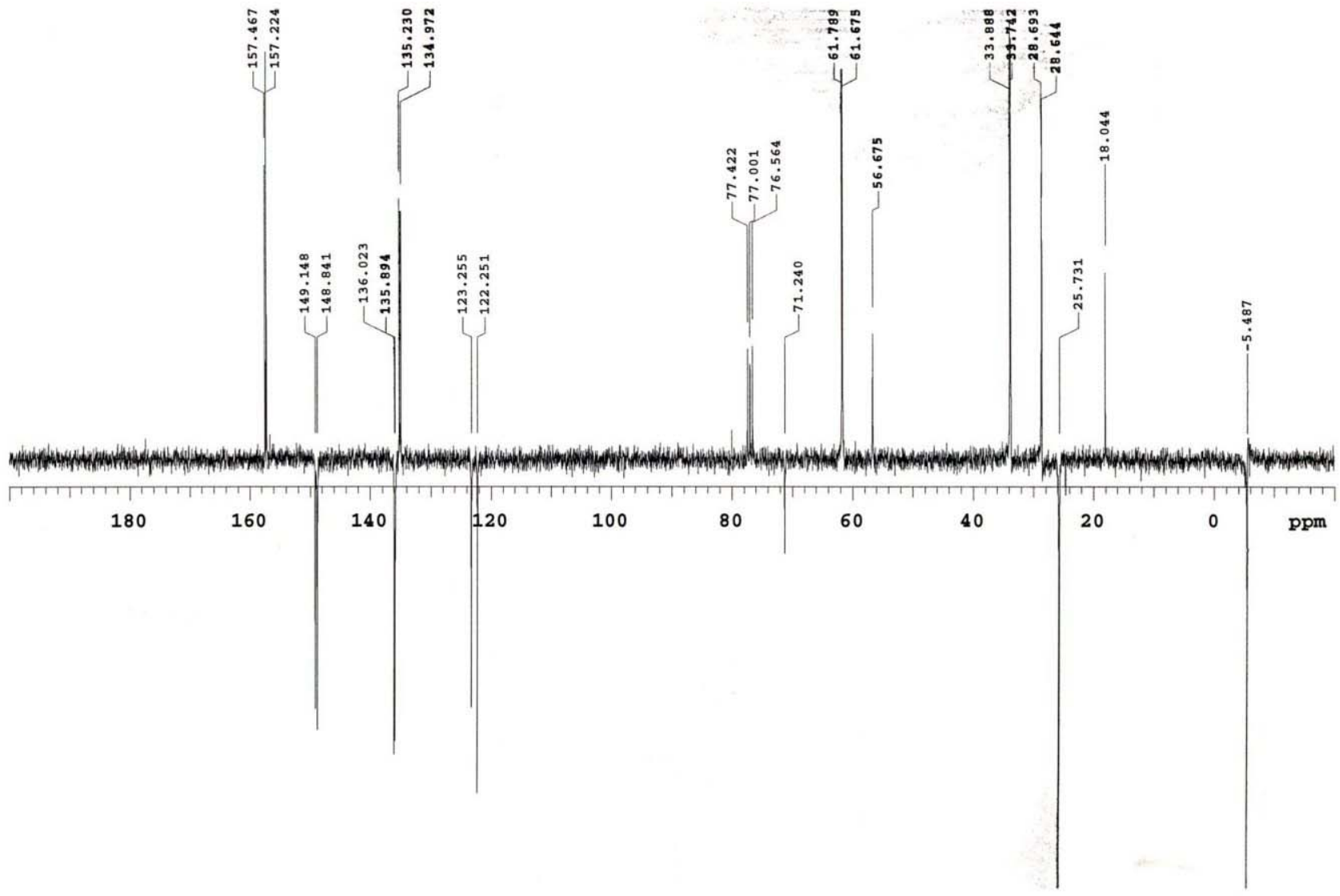


${ }^{1} \mathrm{H}$ NMR

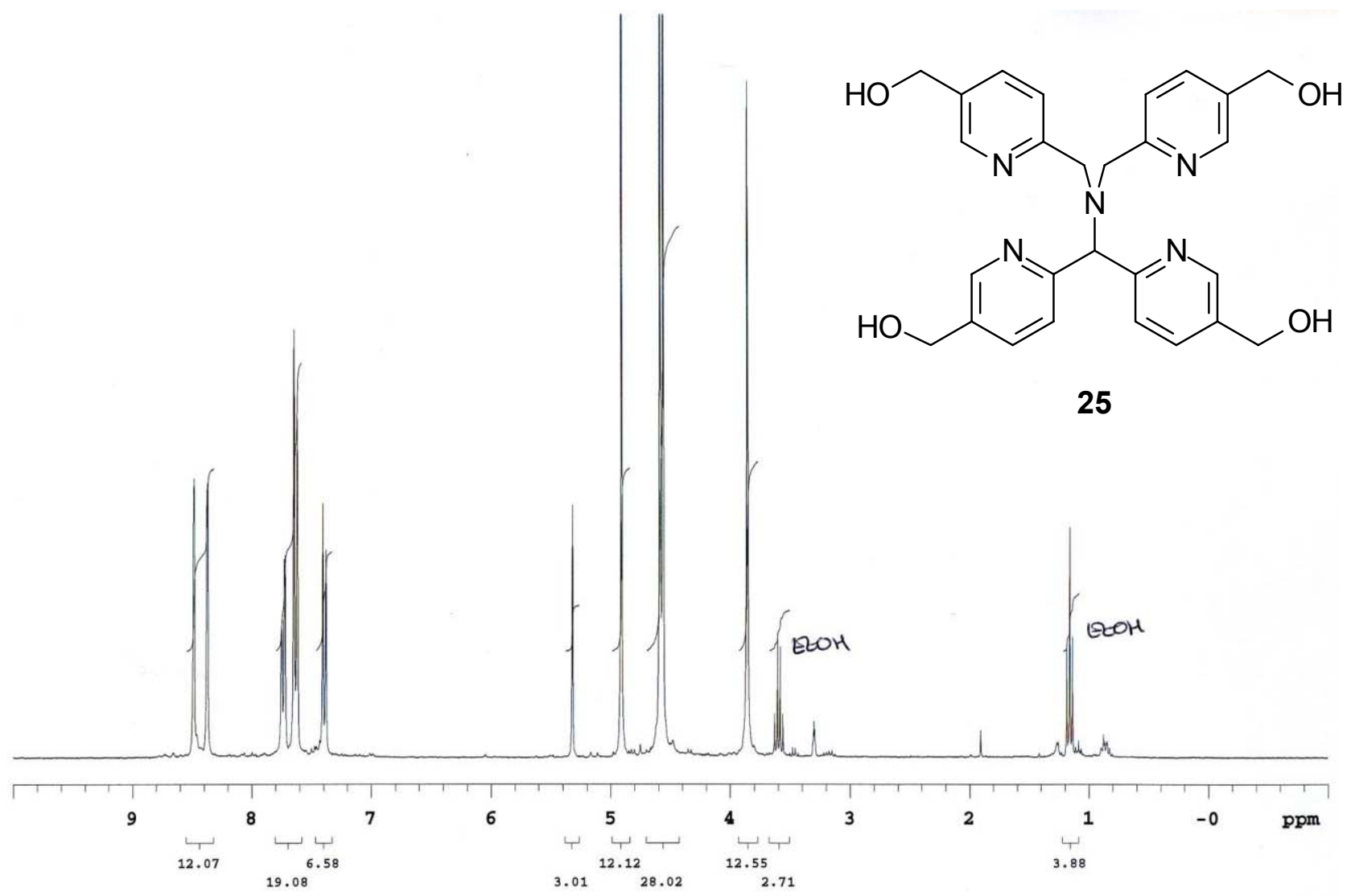

${ }^{13} \mathrm{C}$ NMR

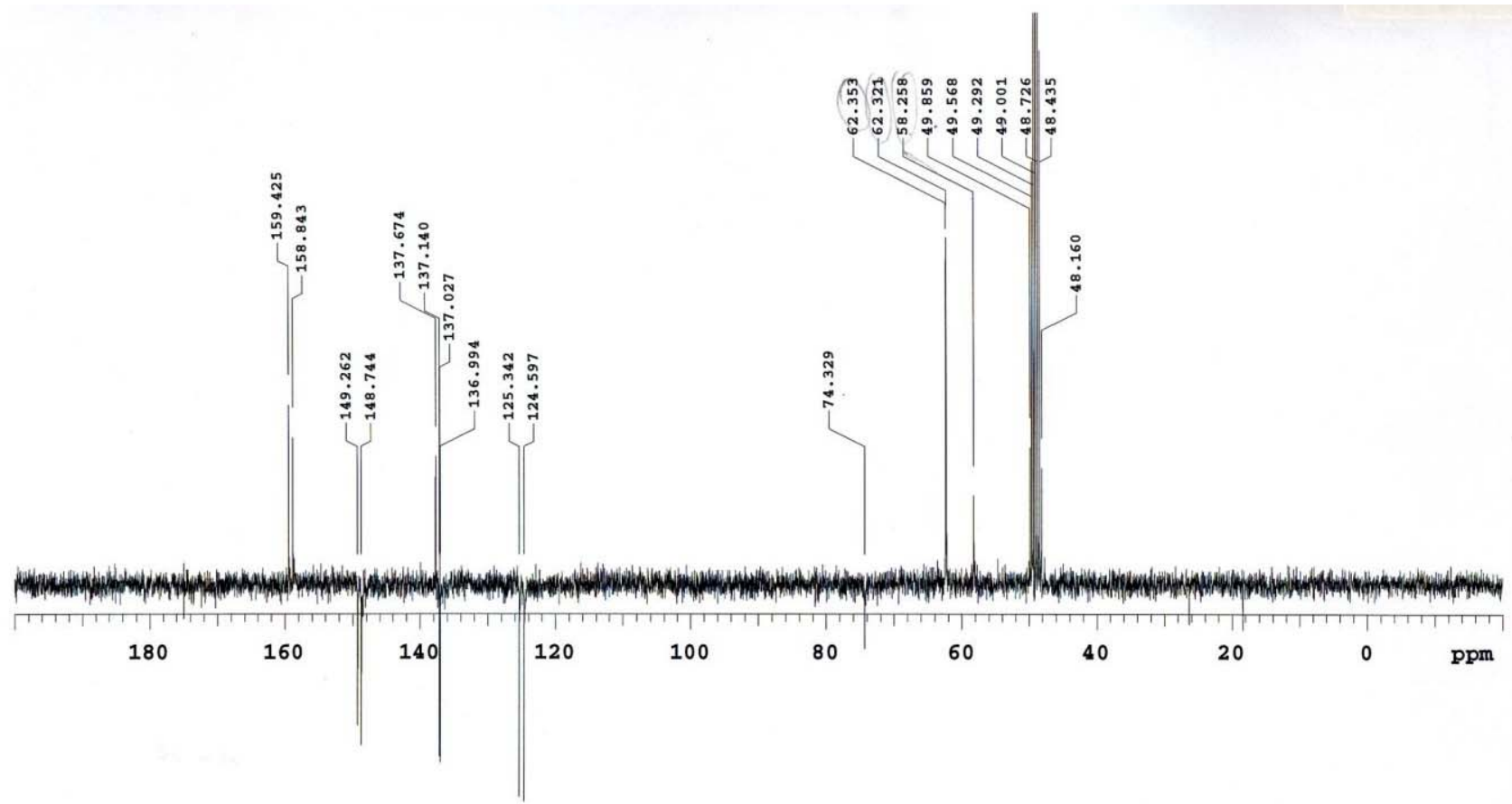


${ }^{1} \mathrm{H}$ NMR

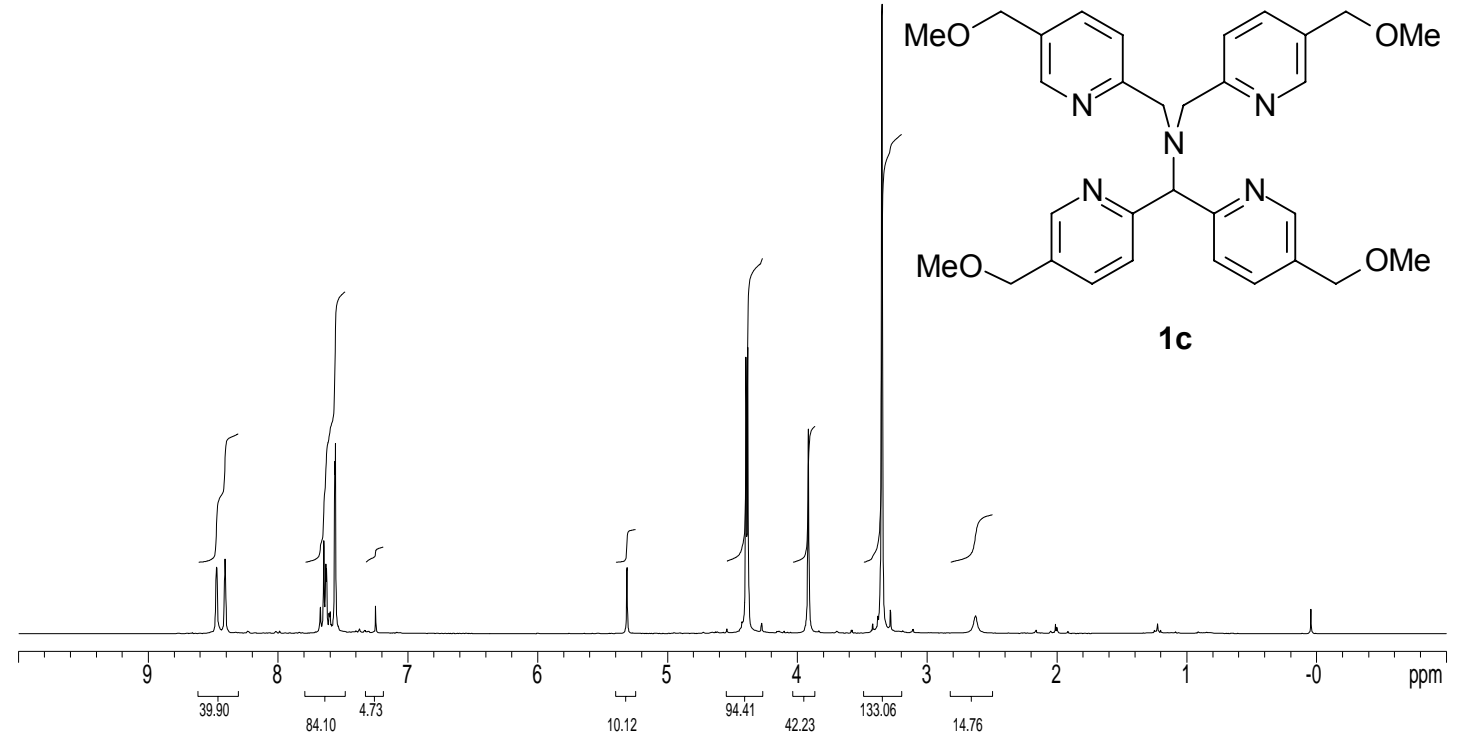

${ }^{13} \mathrm{C}$ NMR

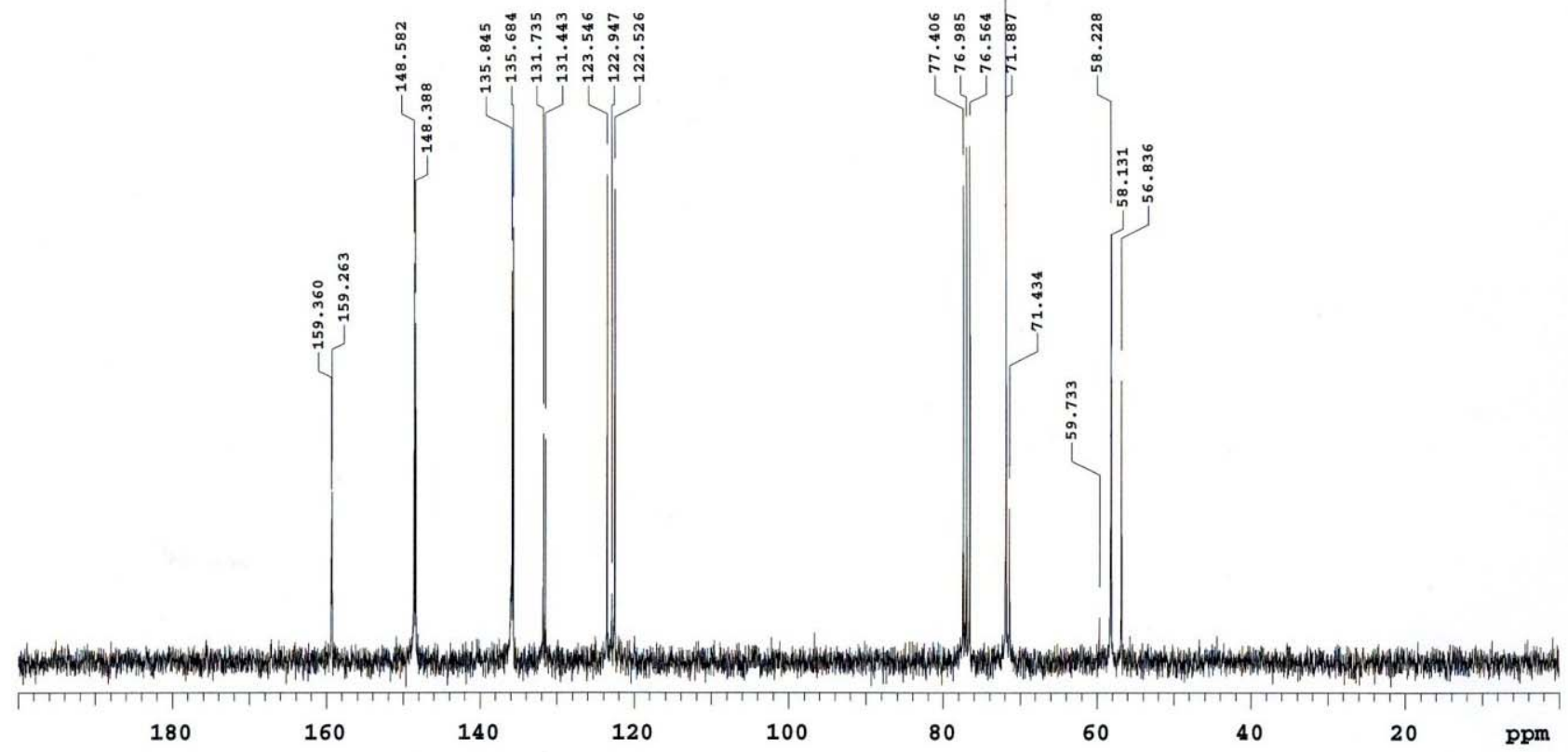


${ }^{1} \mathrm{H}$ NMR

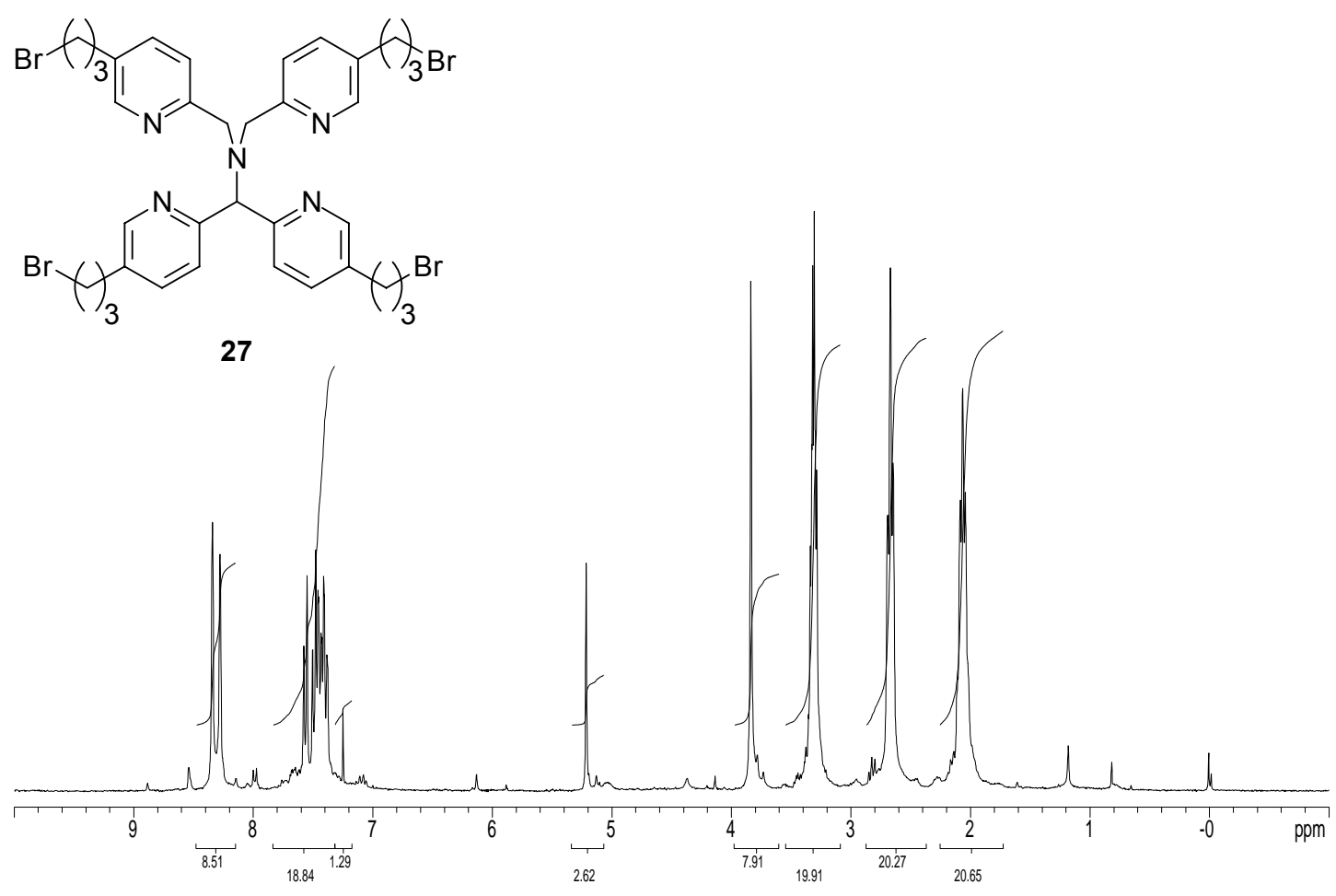

\section{${ }^{13} \mathrm{C}$ NMR}

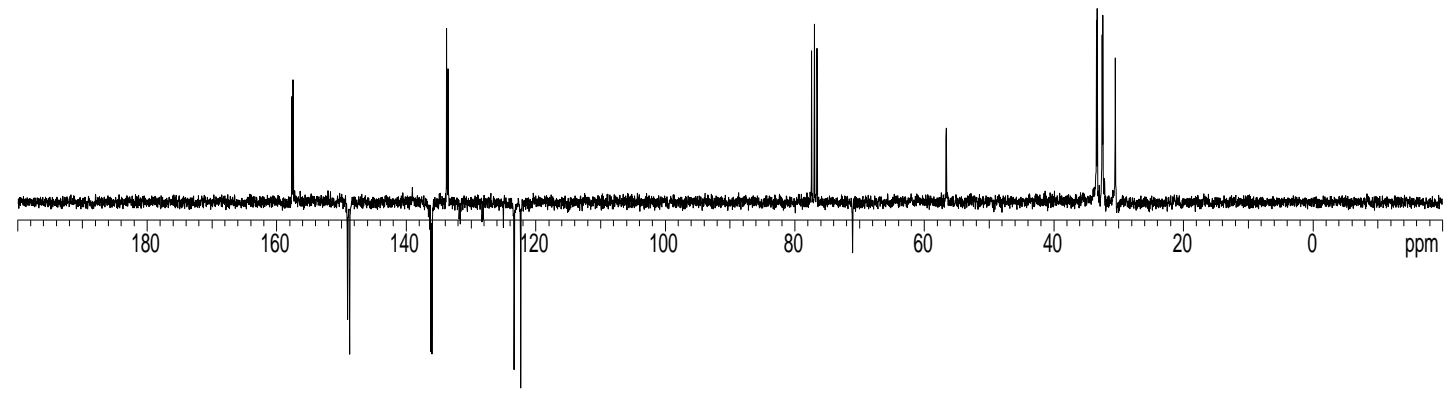


${ }^{1} \mathrm{H}$ NMR

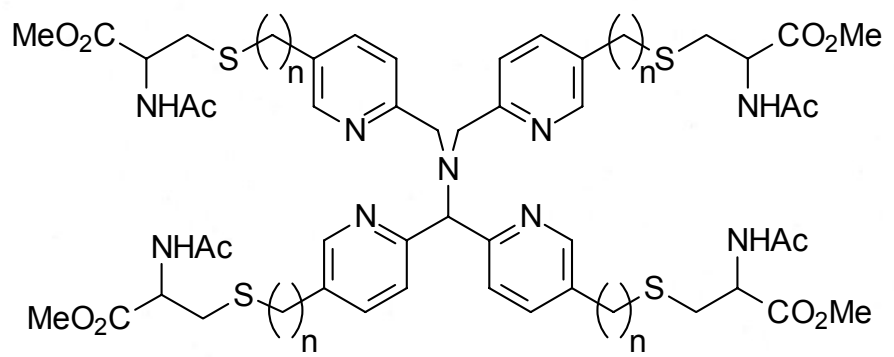

$$
\text { 1d }(n=3)
$$

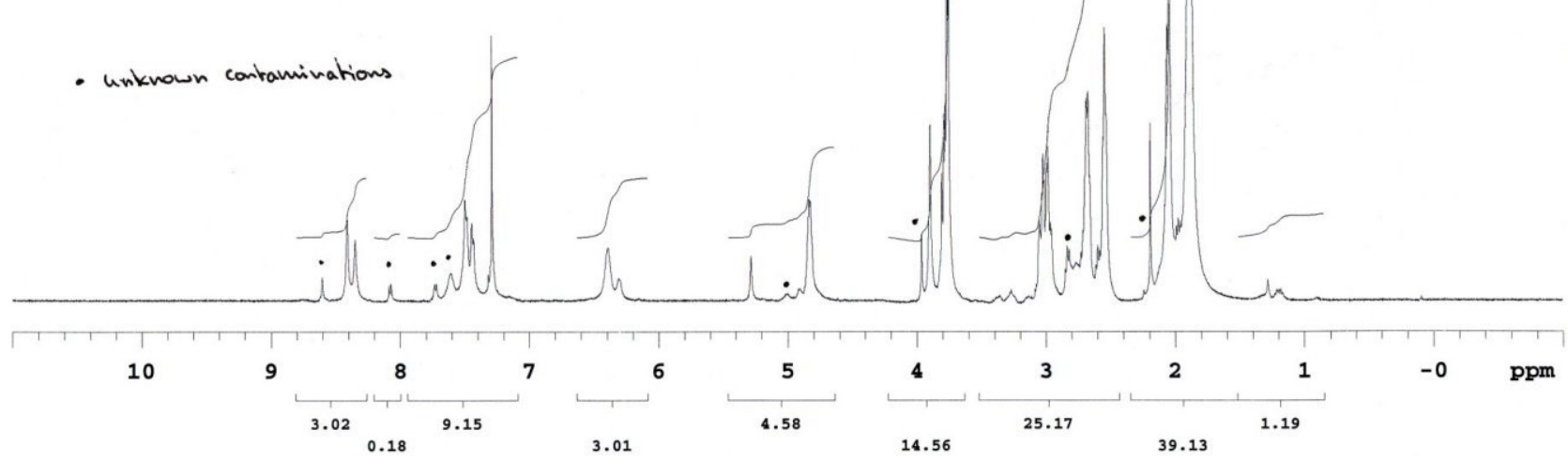

MS Analysis

\section{Columnless H2O/ACN 1/1, 0,3ml/min, m/z=1235}

$\mathrm{MH} 495 \mathrm{~b}$ (2) 7 (0.525) $\mathrm{Cm}(5: 12-46: 52)$

100

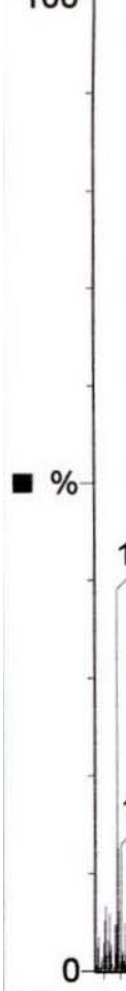

176.1

$[\mathrm{M}+2 \mathrm{H}]^{2+}$

637.8

375.1

180.1

273.1
1236.1

1: Scan ES+

$1.86 \mathrm{e} 5$

$[\mathrm{M}+\mathrm{H}]^{+}$

1258.0

- Nat-adduck

$70 \mathrm{~V}$

1259.1

1260.1

938.1

1095.0

\begin{tabular}{l|l|}
939.1 & 1117.0
\end{tabular}

\begin{tabular}{l|l|l|l|l|l|l}
998.1 & 1262.1
\end{tabular} 
MS Analysis of $\mathbf{1 e}$<smiles>[R]c1ccc(C=NCc2ccc([R])cn2)nc1</smiles><smiles>[R]c1ccc(C(C)c2ccc([R])cn2)nc1</smiles>

$1 e$

$$
\mathrm{R}=\left(\mathrm{CH}_{2}\right)_{3} \text { SPeptide }
$$

Peptide = Ac-Cys-Gly-Leu-His-Glu-Leu-Leu-Lys-Gly- $\mathrm{NH}_{2}$ mumn

\section{fr1/1 x10-5}

lie911 3 (2.009) Sm (SG, 1x3.00); Sb (99,40.00); Cm (1:4)

100

- 378.8

440.8

335.0

442.9

567.9

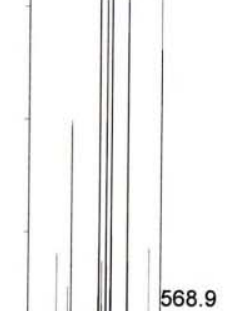

1143.0

\begin{tabular}{l|l}
568.9 & 1158.0
\end{tabular}

1158.9

$569.9 \quad 1010.0 \quad 1159.9$

1000

$3434.9 \quad 3645.8$ 
${ }^{1} \mathrm{H}$ NMR

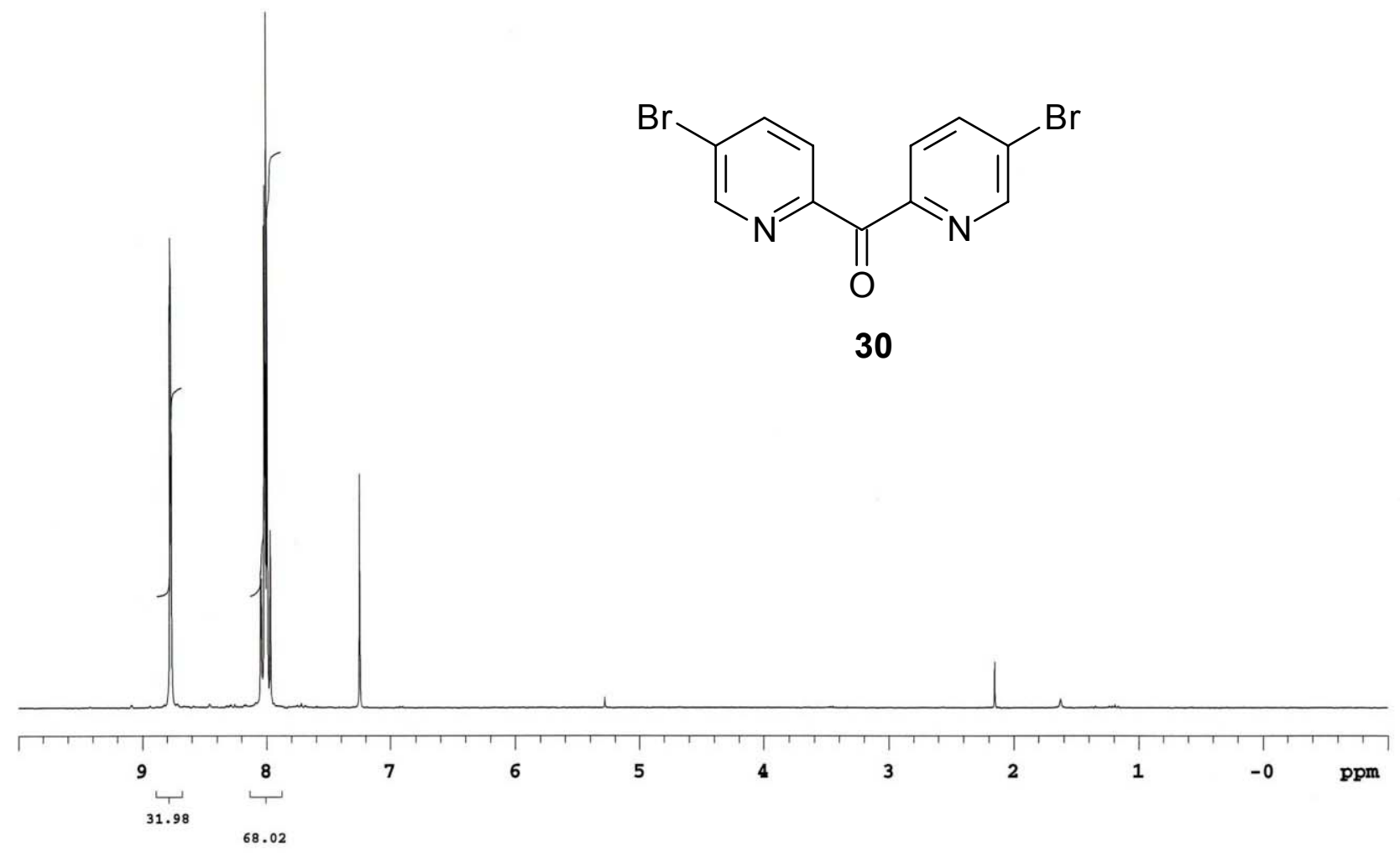

${ }^{13} \mathrm{C}$ NMR

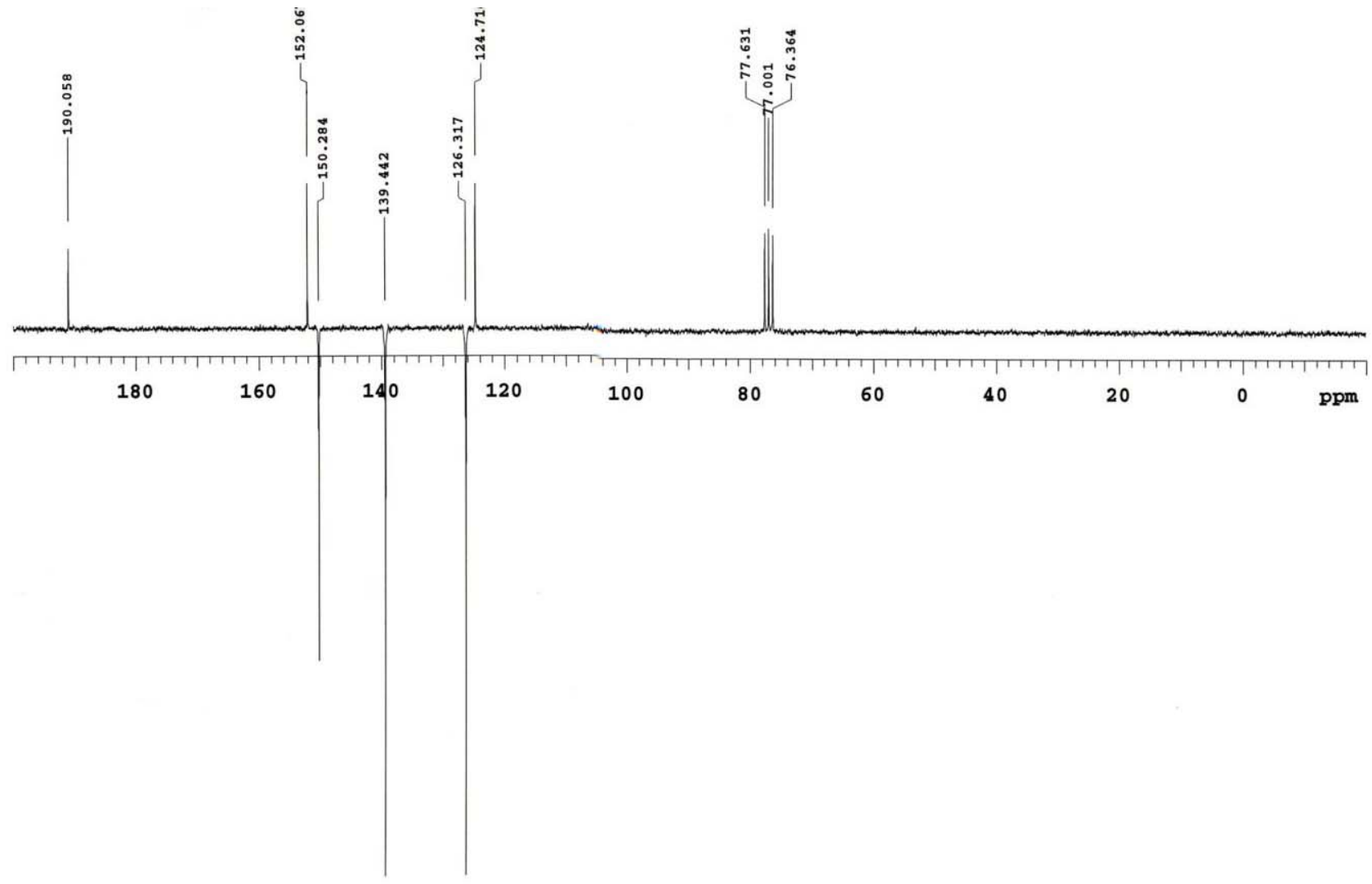


${ }^{1} \mathrm{H} \mathrm{NMR}\left(\mathrm{CDCl}_{3}\right)$

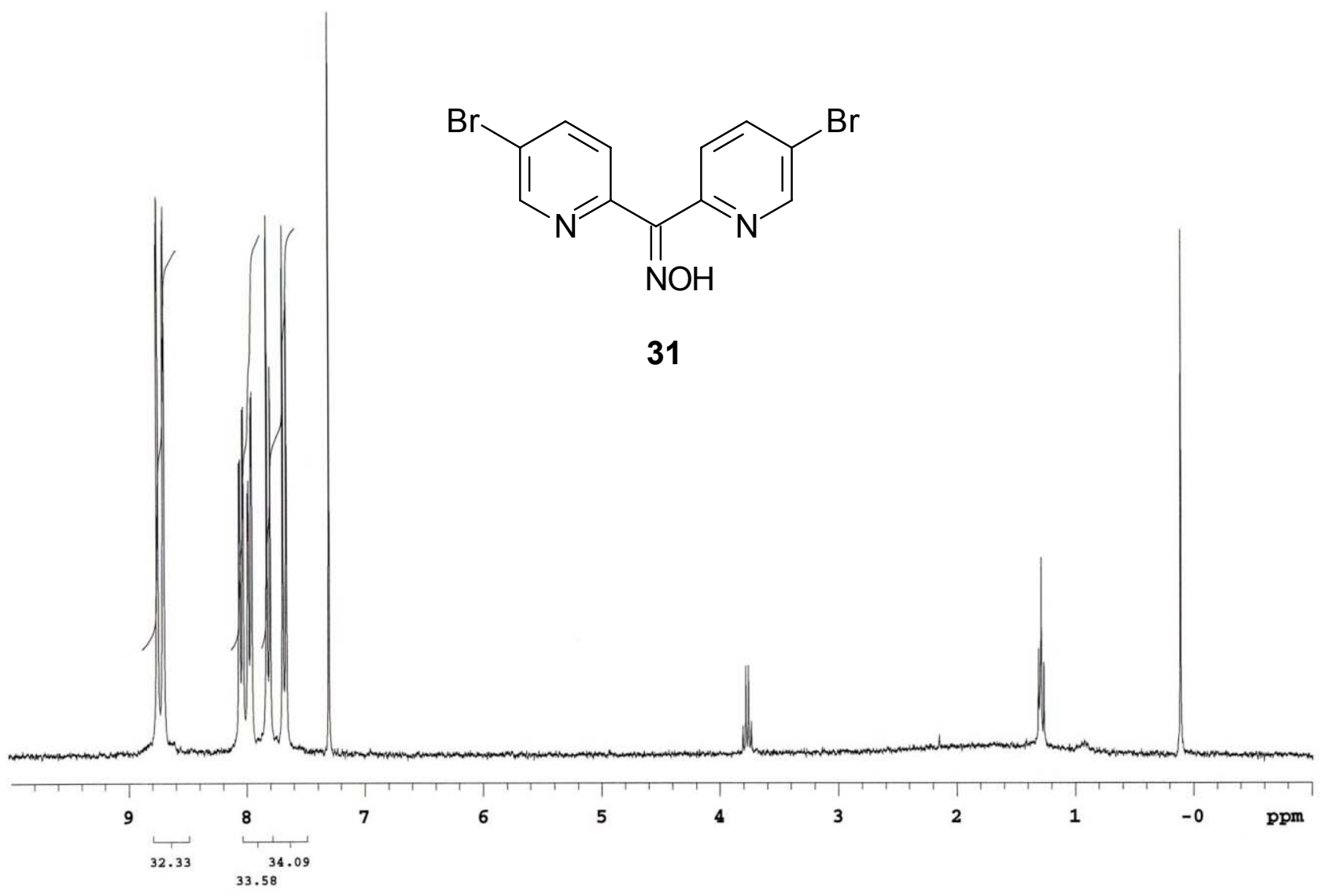

${ }^{1} \mathrm{H}$ NMR $\left(\mathrm{CD}_{3} \mathrm{OD}\right)$

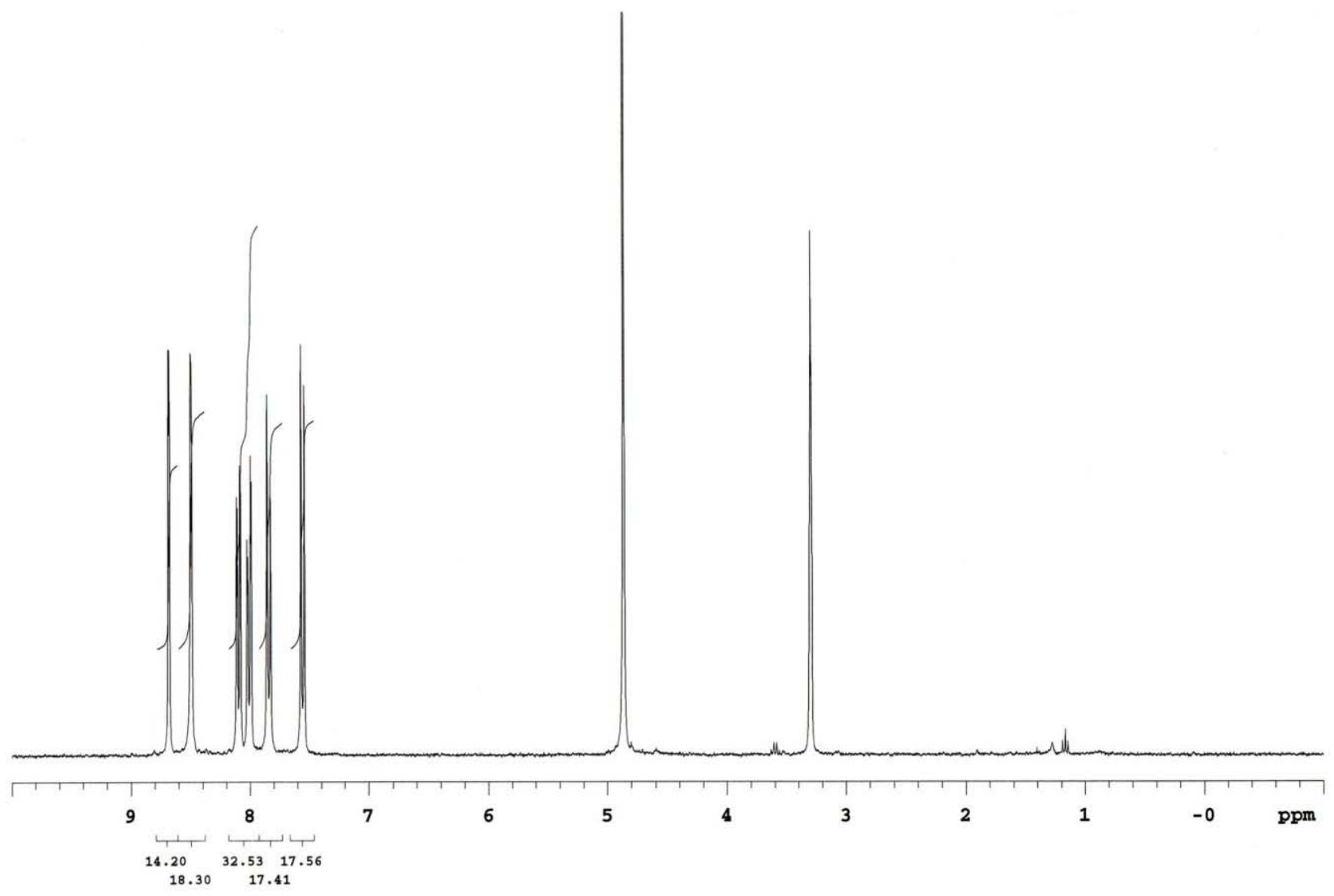


${ }^{13}$ C NMR

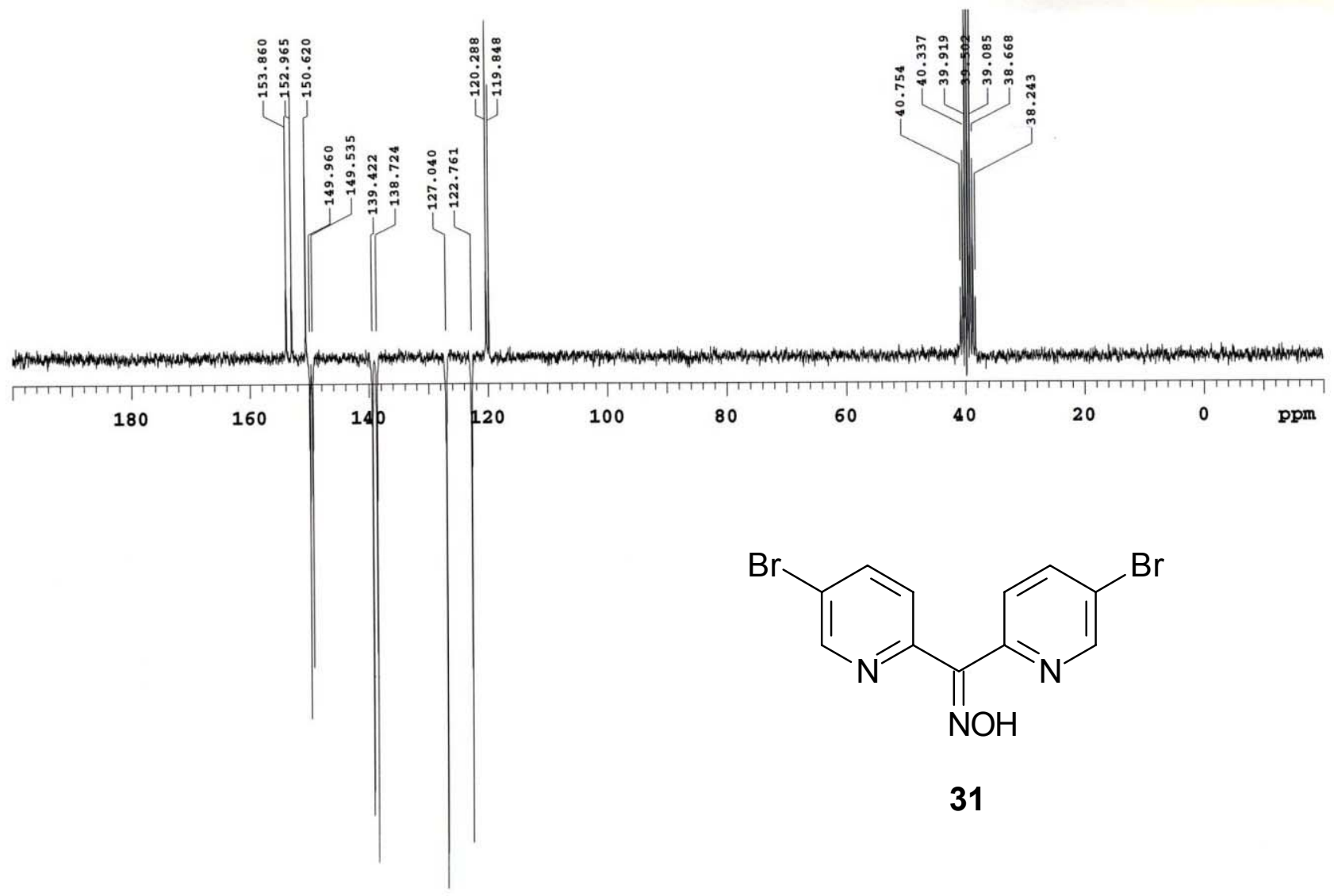


${ }^{1} \mathrm{H}$ NMR

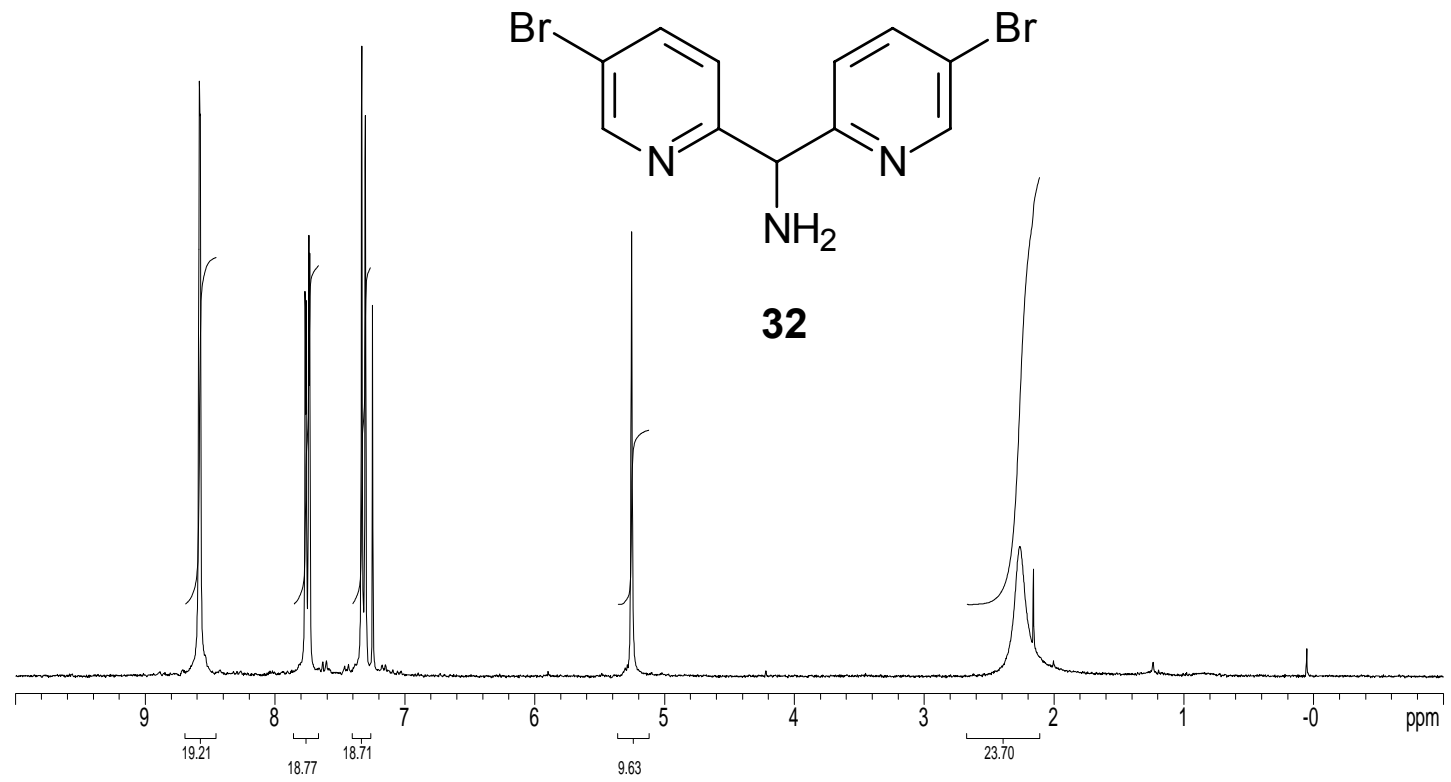

${ }^{13} \mathrm{C}$ NMR

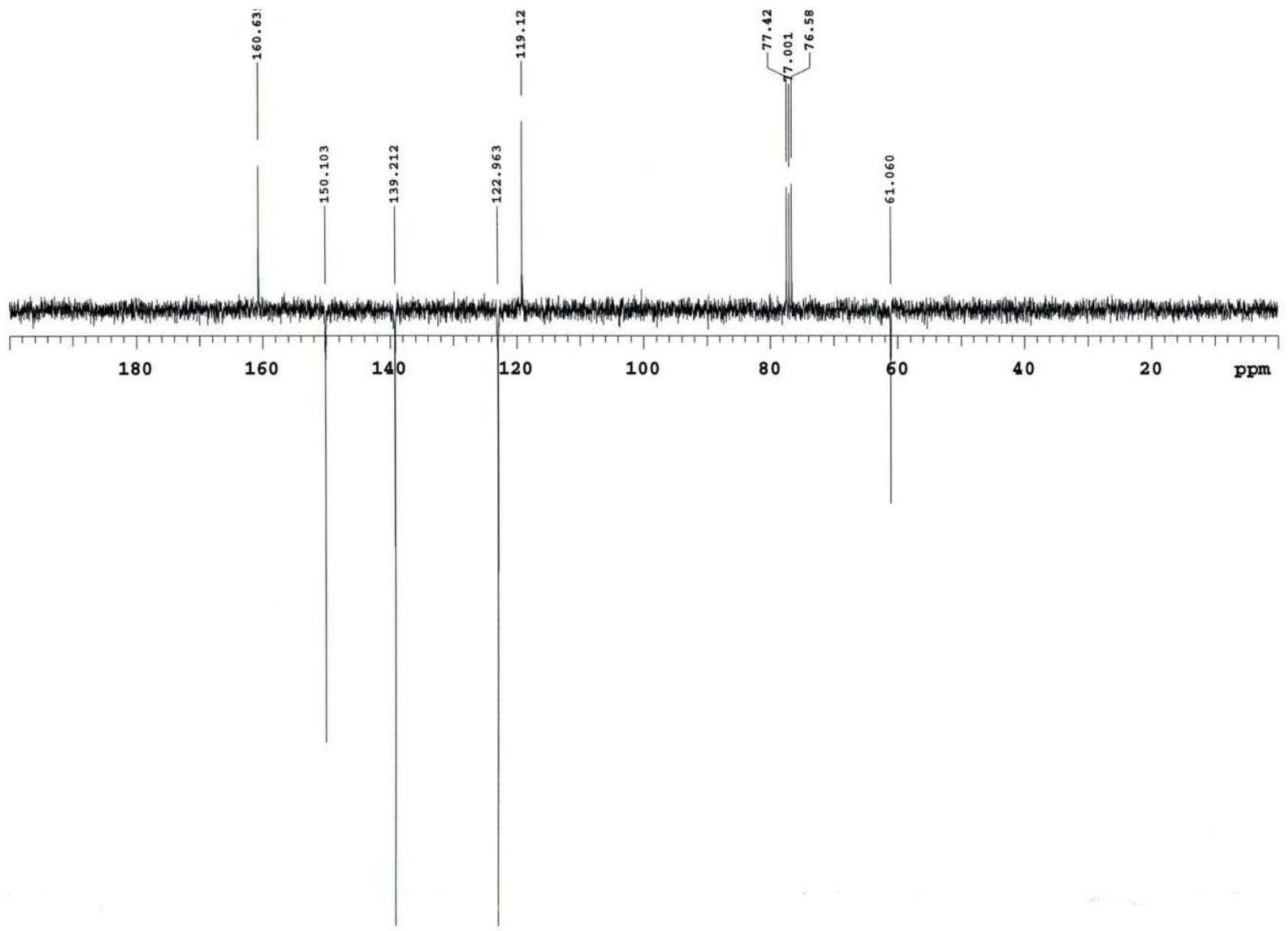


${ }^{1} \mathrm{H}$ NMR

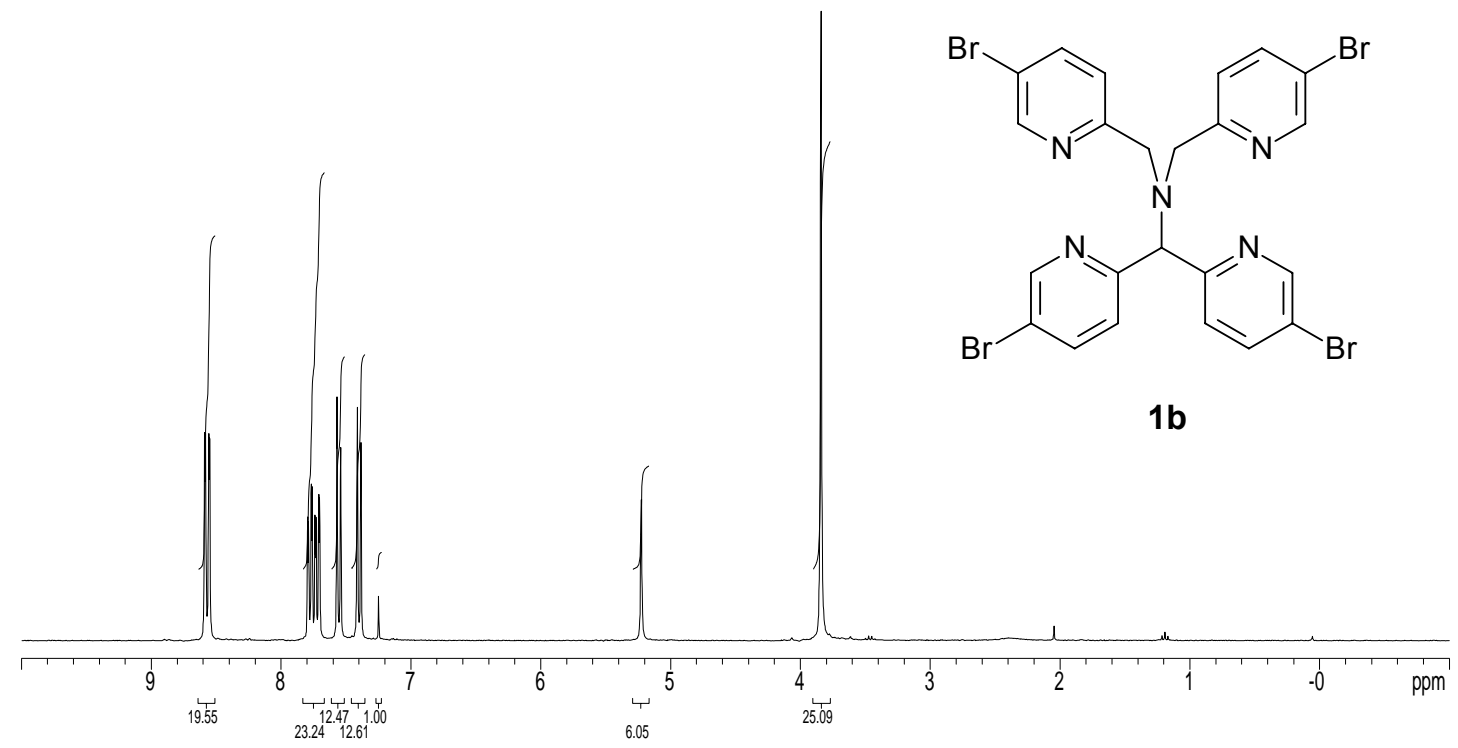

${ }^{13} \mathrm{C}$ NMR

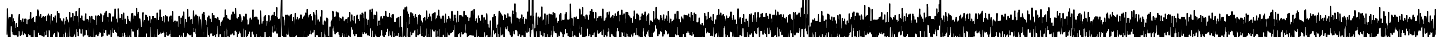


${ }^{1} \mathrm{H}$ NMR

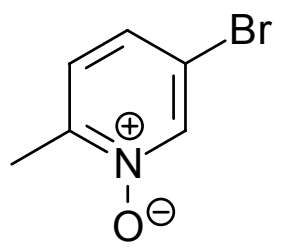

34

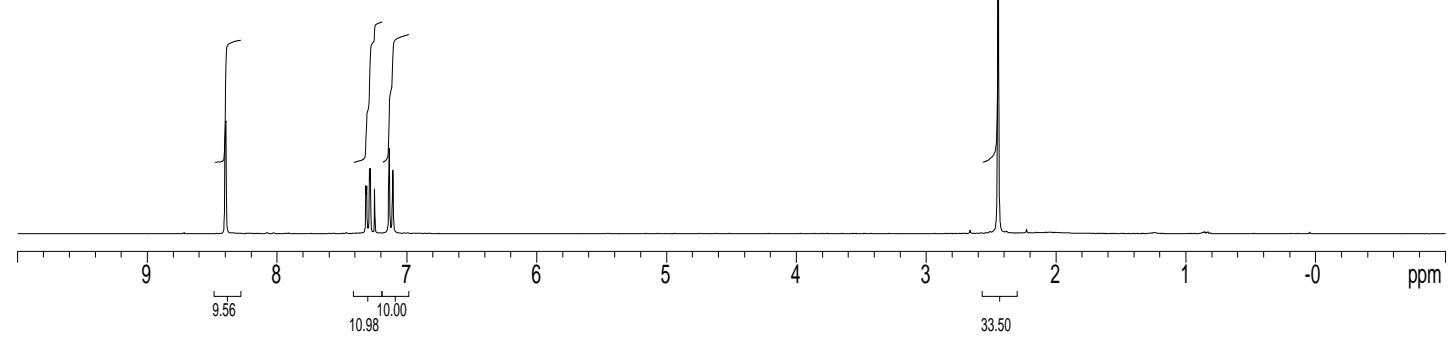

${ }^{13} \mathrm{C}$ NMR

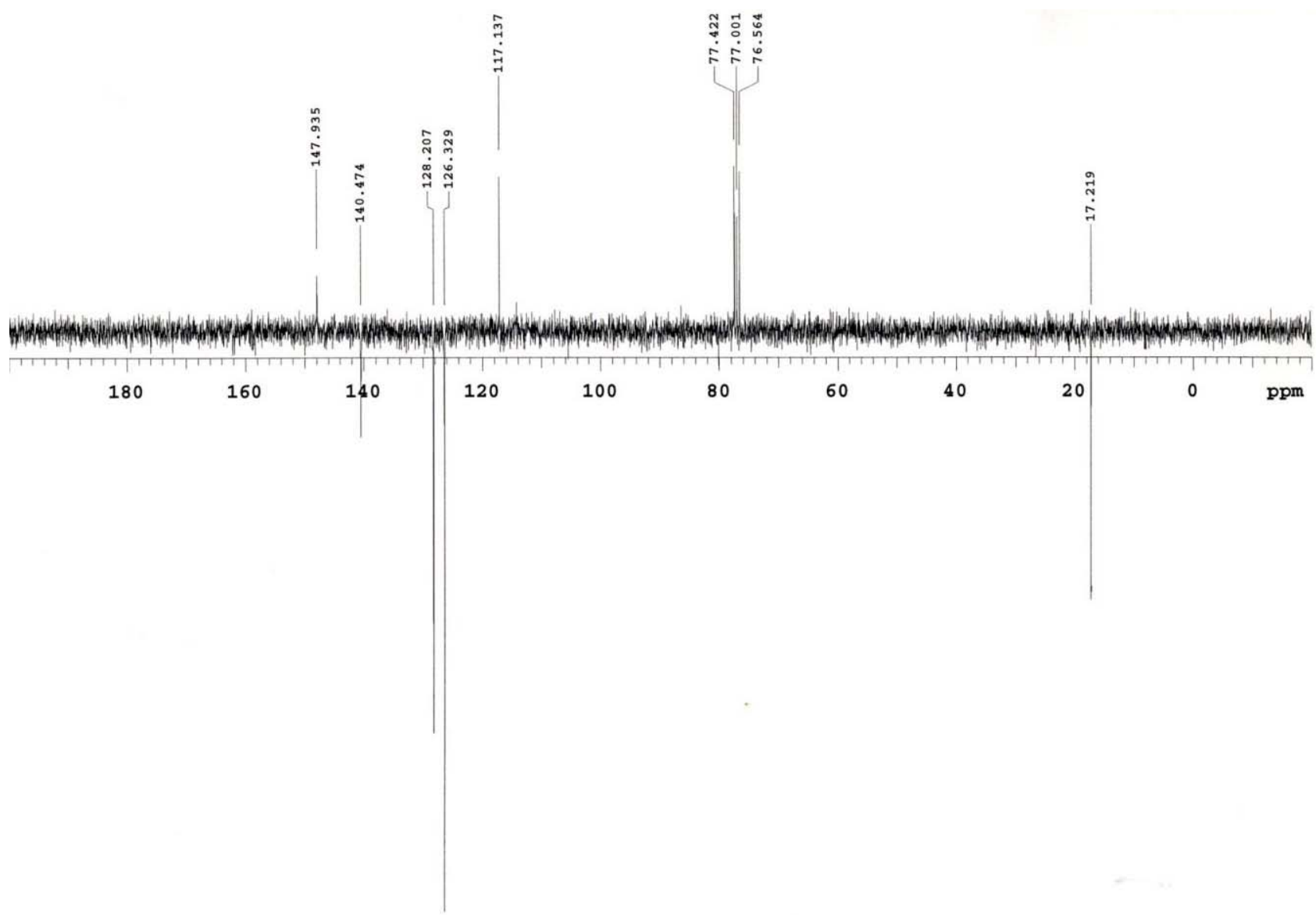


${ }^{1} \mathrm{H}$ NMR

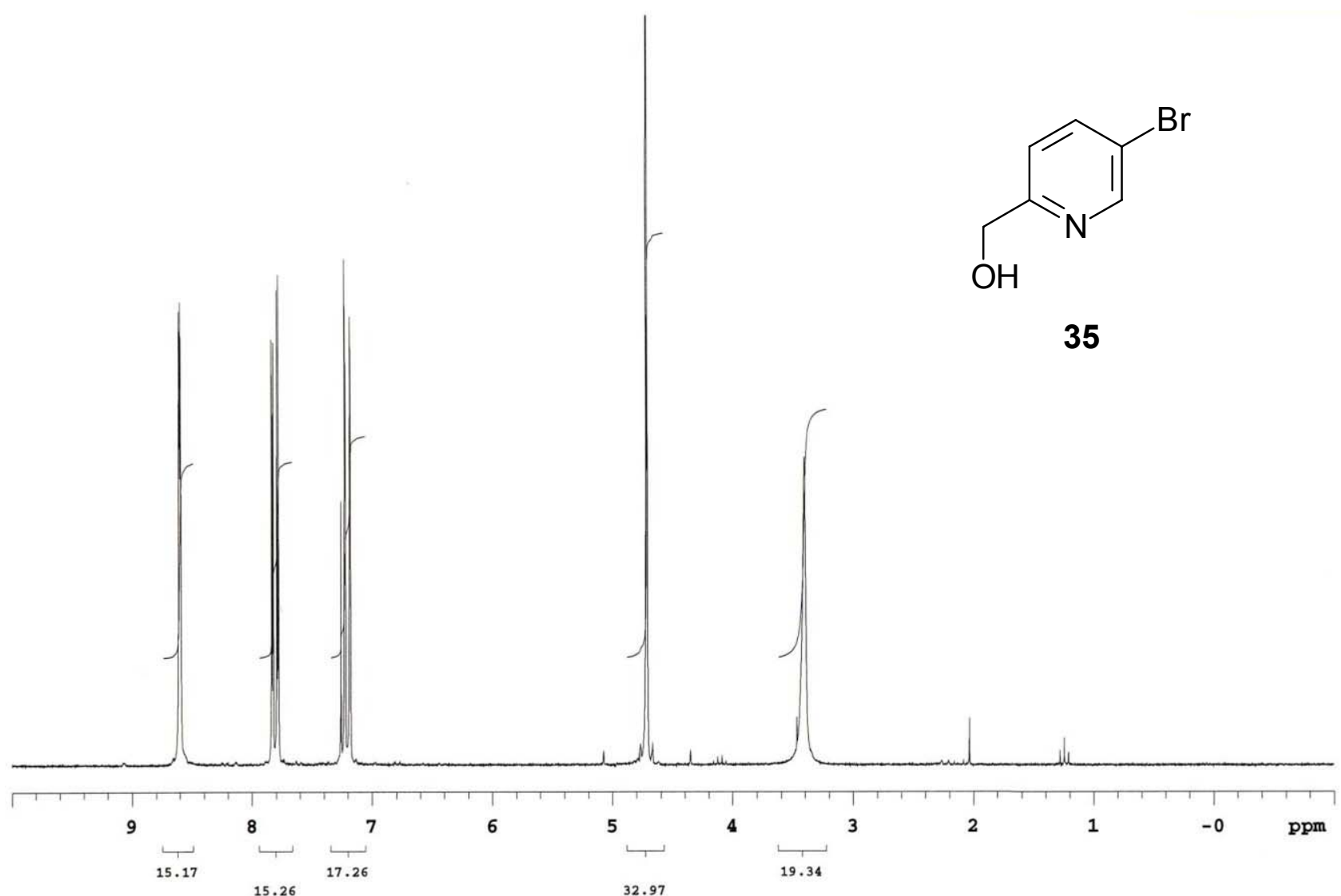

${ }^{13} \mathrm{C}$ NMR

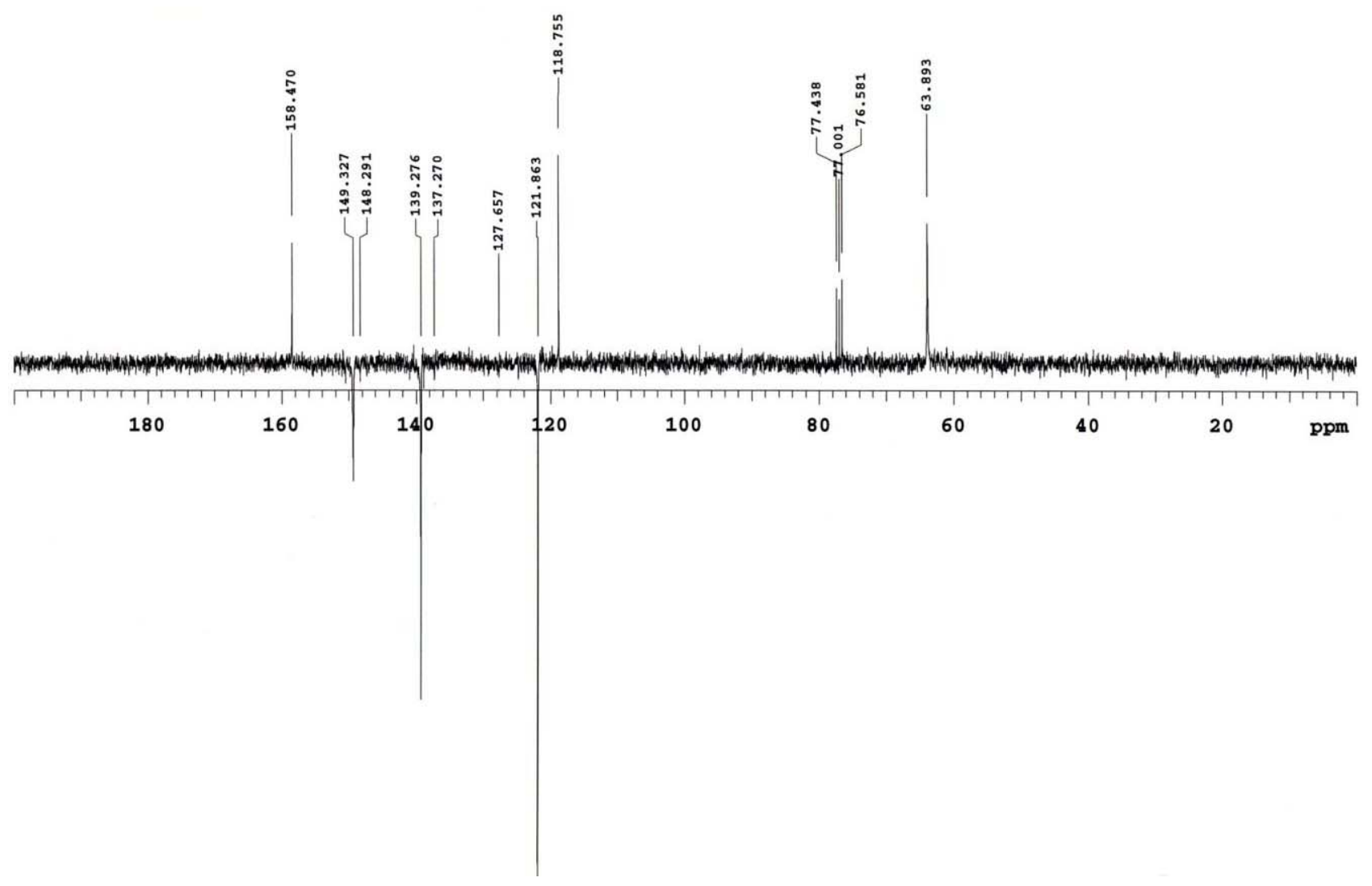


${ }^{1} \mathrm{H}$ NMR

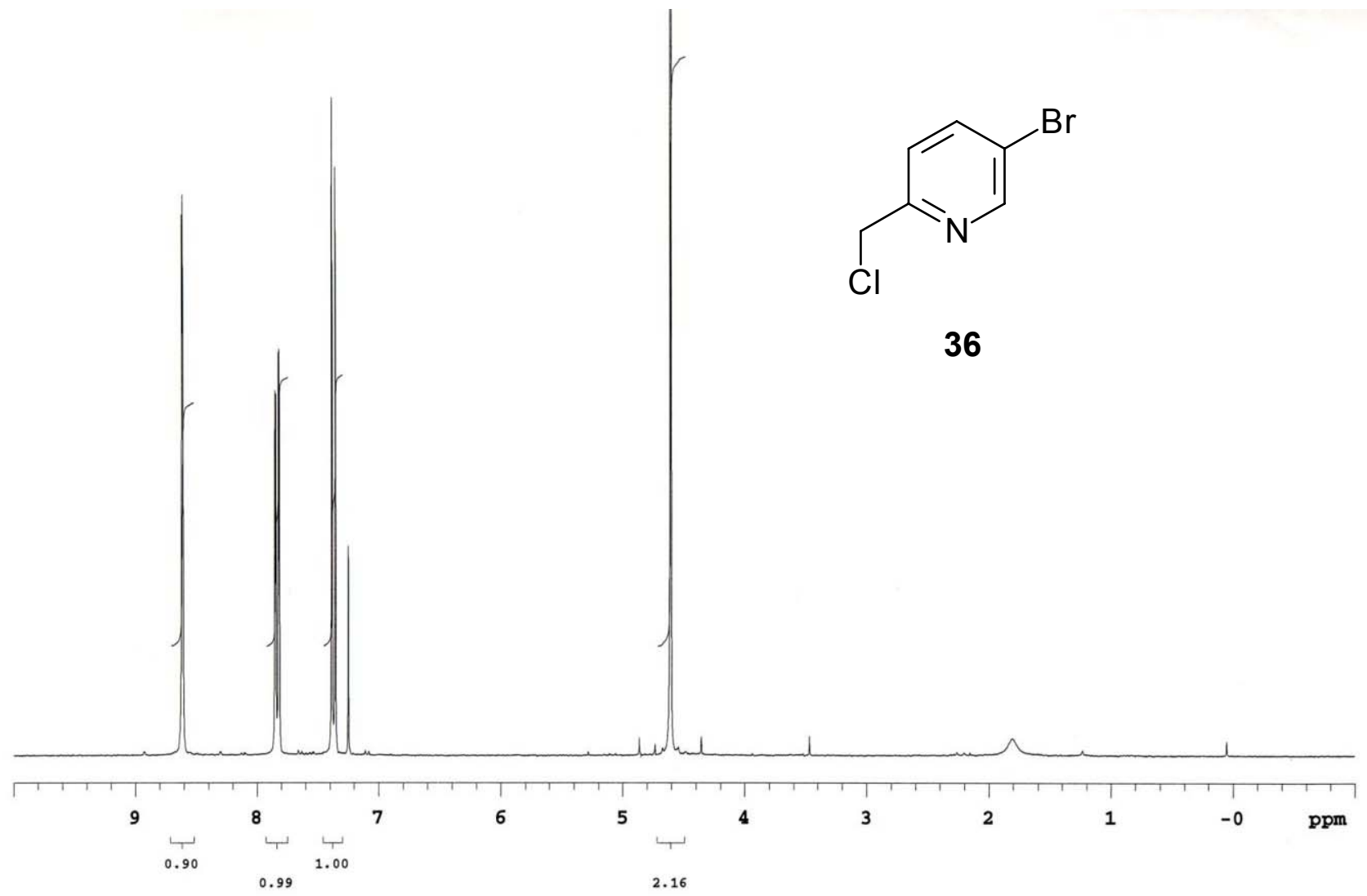

${ }^{13} \mathrm{C}$ NMR

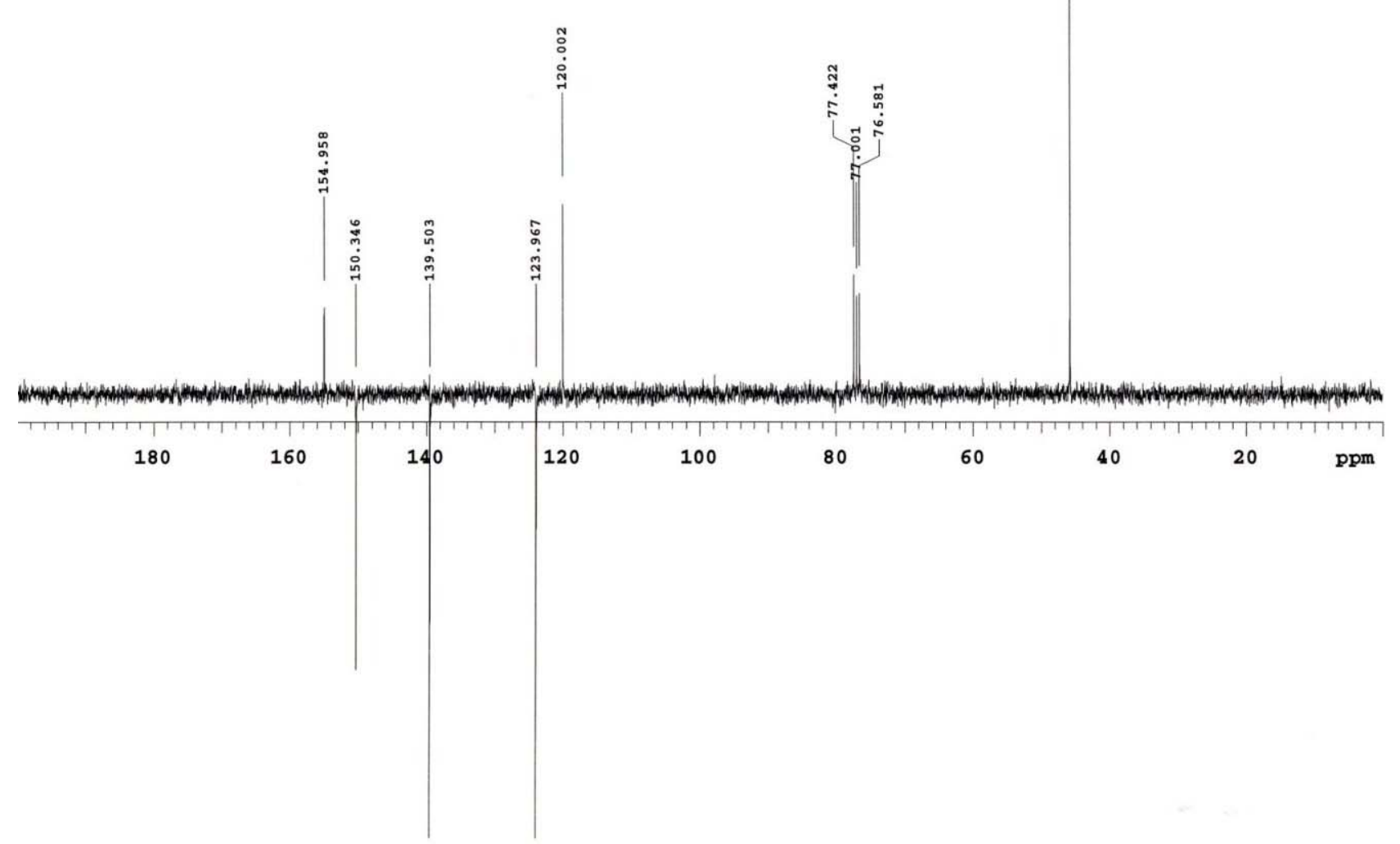


${ }^{1} \mathrm{H}$ NMR

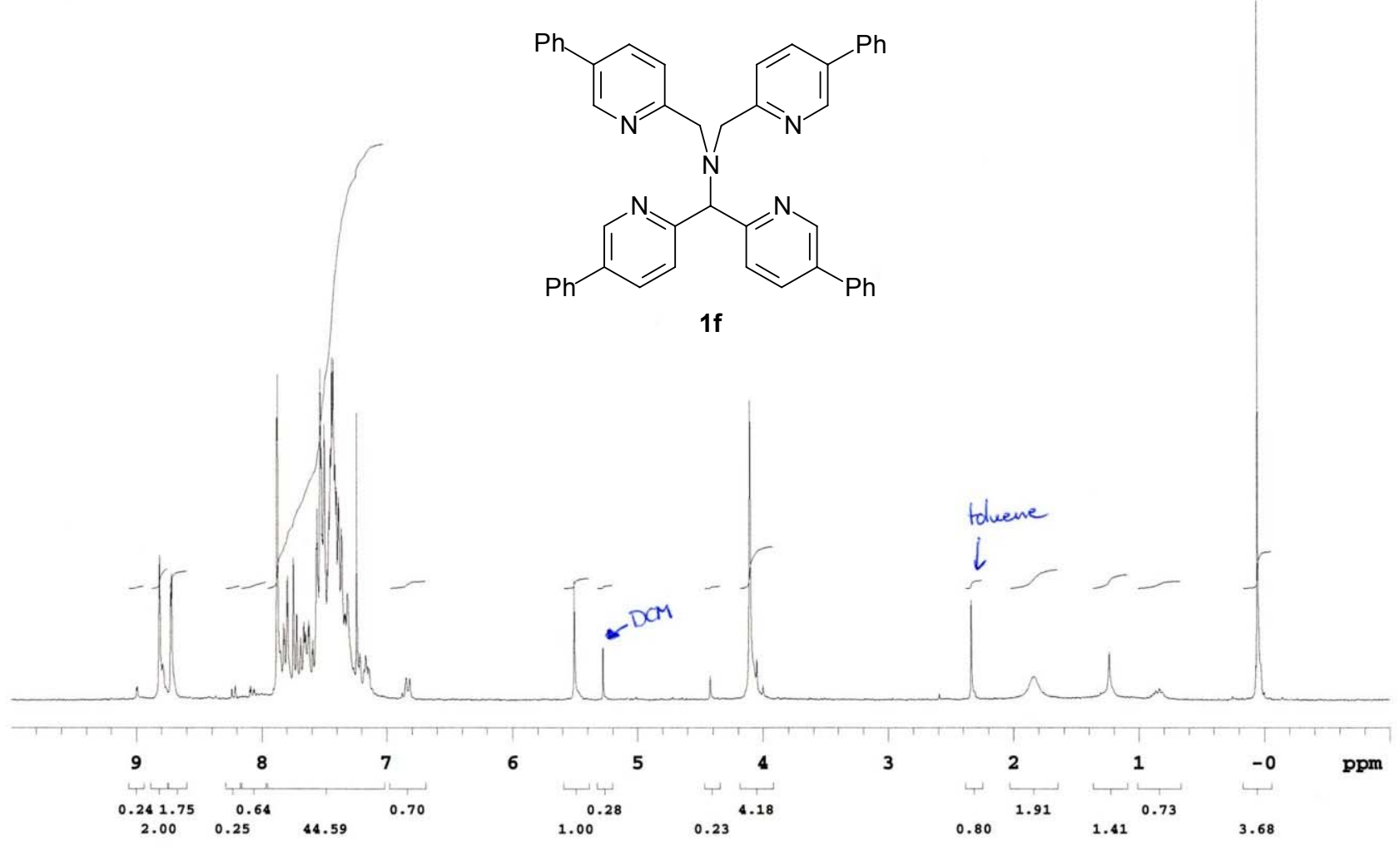

${ }^{13} \mathrm{C}$ NMR

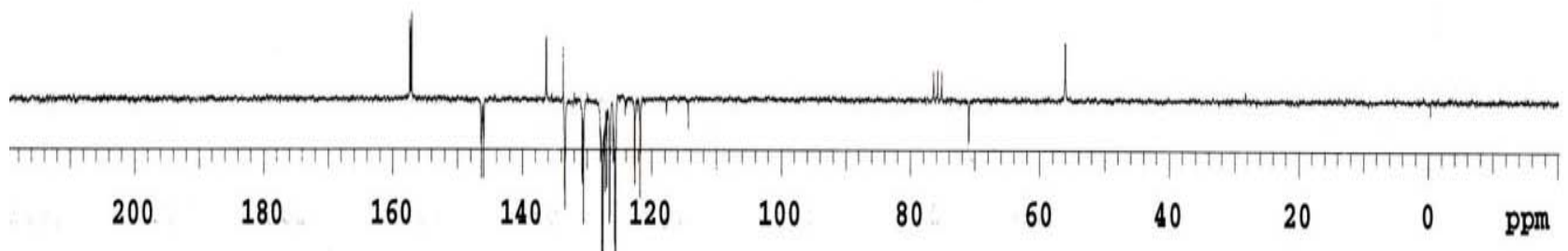


${ }^{1} \mathrm{H}$ NMR

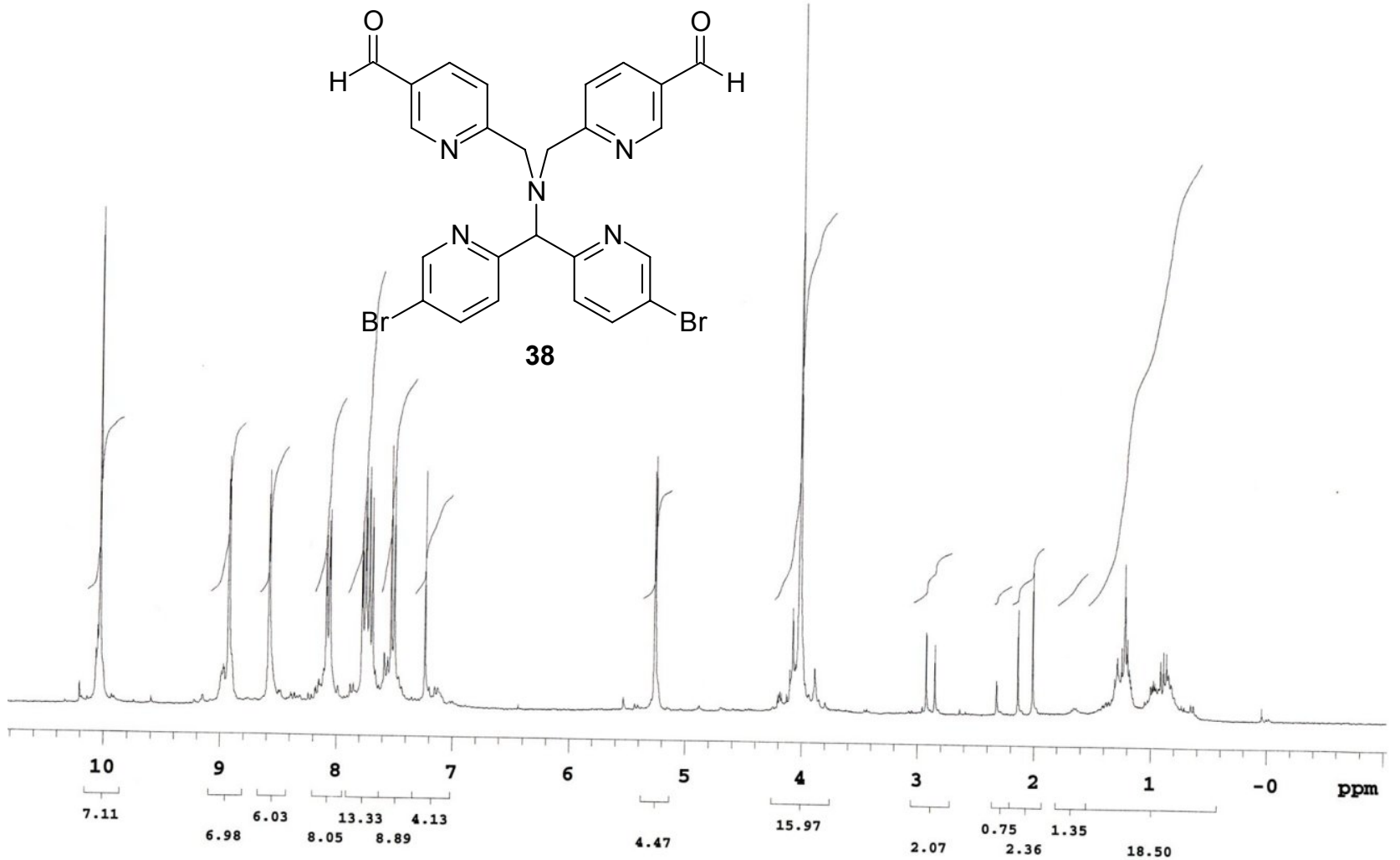

${ }^{13} \mathrm{C}$ NMR

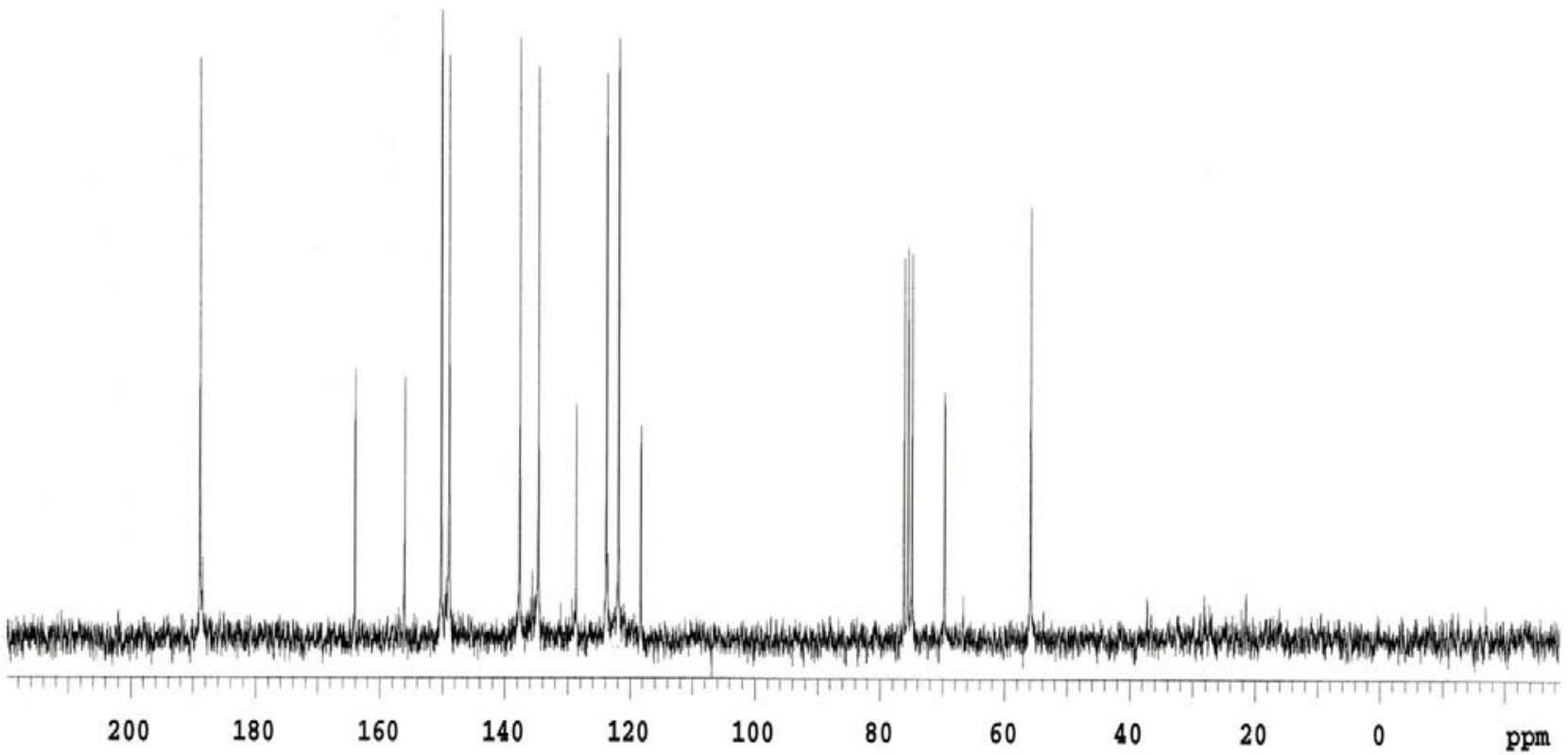


COSY NMR<smiles>O=Cc1ccc(CNCc2ccc(C=O)cn2)nc1</smiles><smiles>CC(c1ccc(Br)cn1)c1ccc(Br)cn1</smiles>

F2

(ppm)
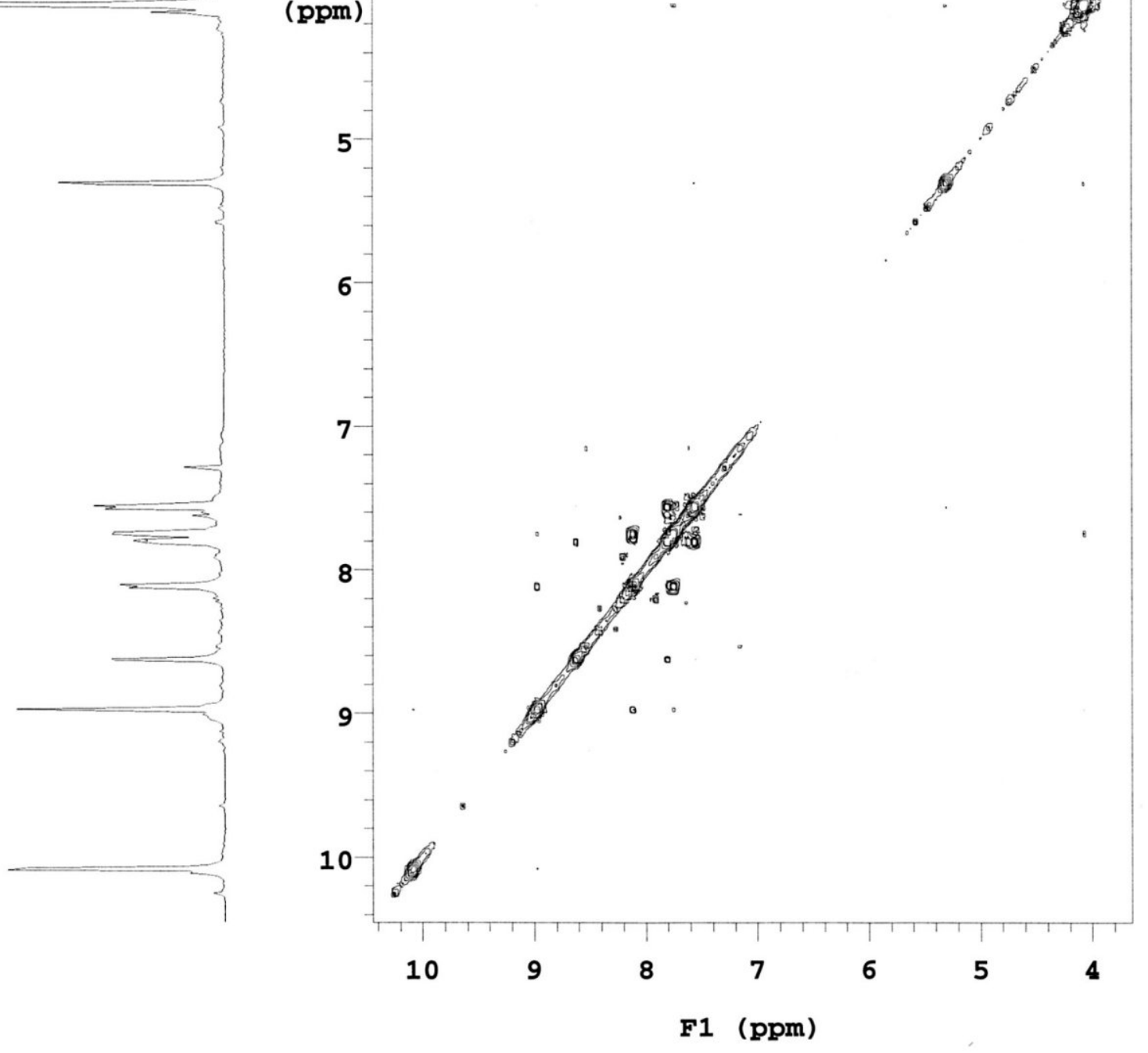
${ }^{1} \mathrm{H}$ NMR and MS Analysis of $\mathbf{2 b}$
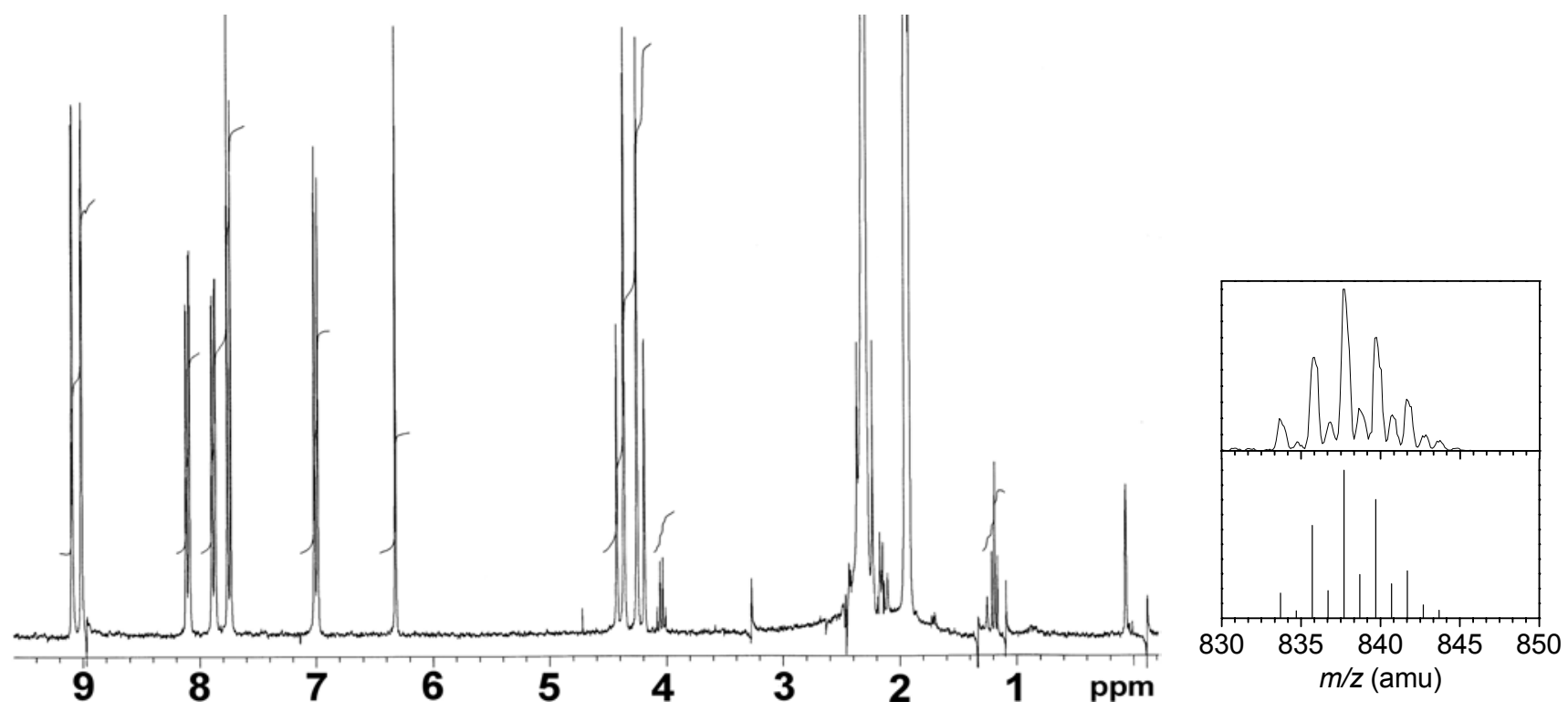

The ${ }^{1} \mathrm{H}$ NMR spectrum of $\mathbf{2 b}$ in $\mathrm{CD}_{3} \mathrm{CN}$ (left), and the observed and calculated isotope distribution patterns for $\left[\mathbf{2} \mathbf{b}-\left(\mathrm{ClO}_{4}\right)^{-}-(\mathrm{MeCN})\right]^{+}$(top and bottom right, respectively).

${ }^{1} \mathrm{H}$ NMR of $2 \mathrm{c}$

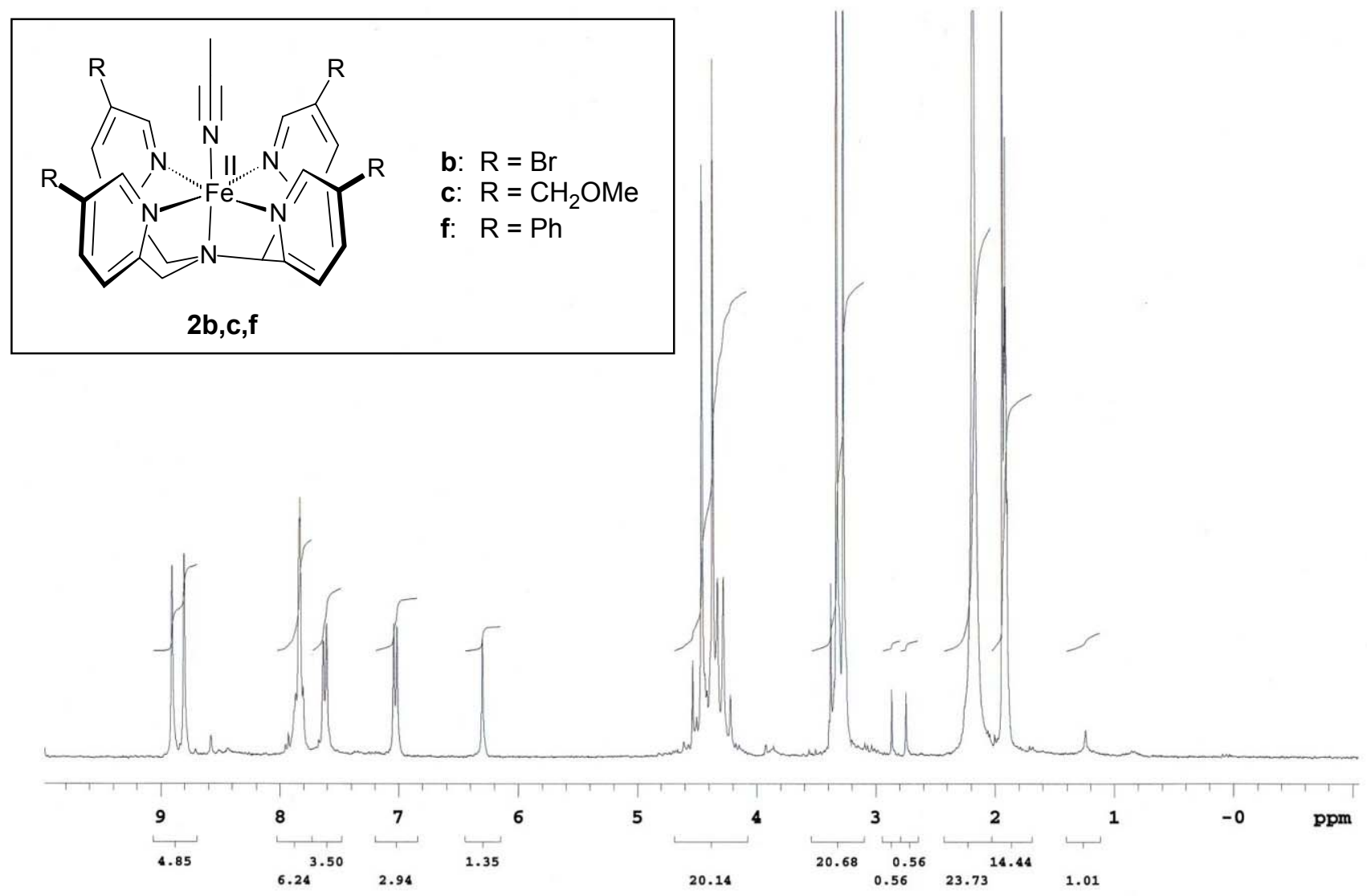


MS Analysis of $\mathbf{2 f}$

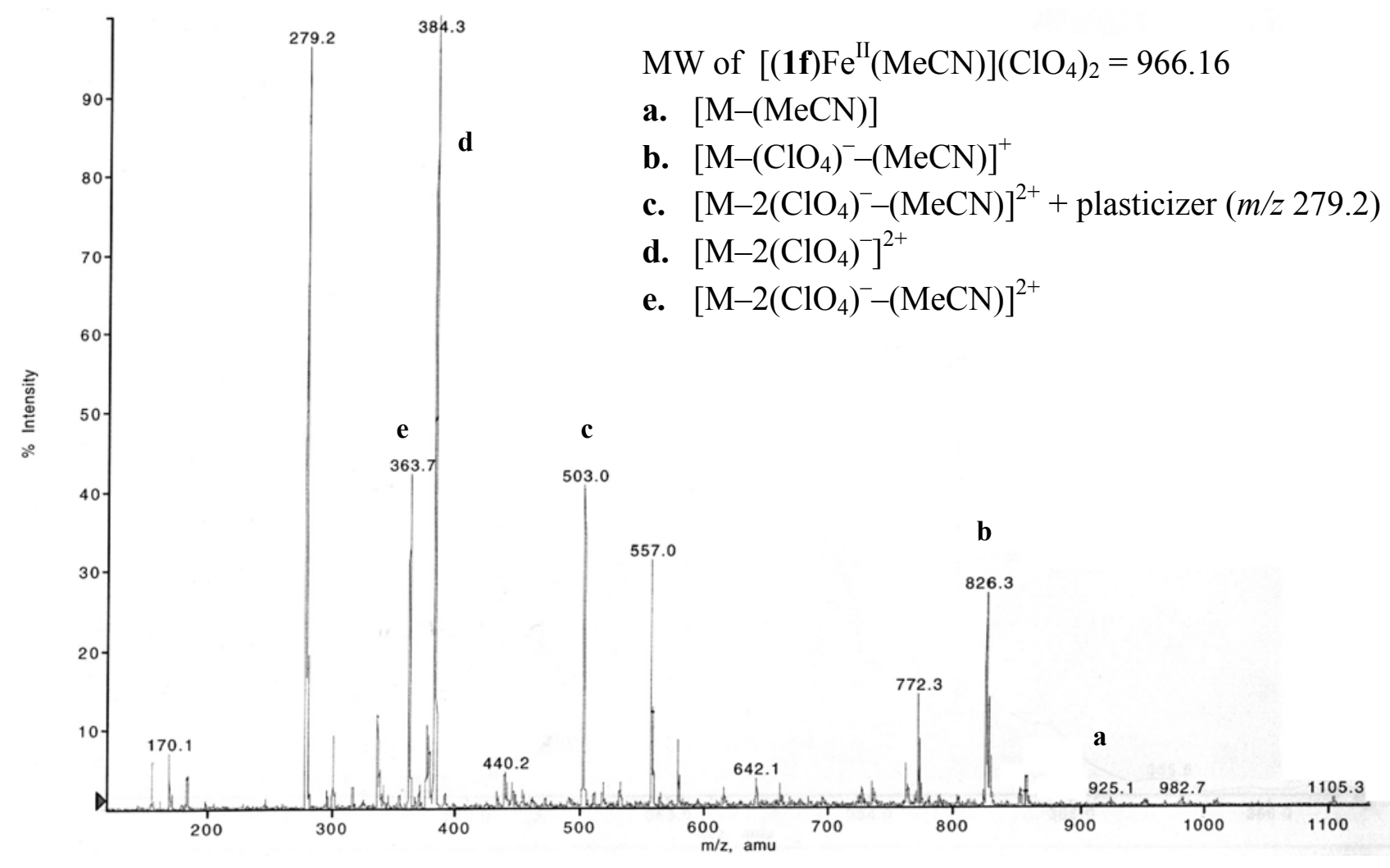

